\title{
The Development and Validation of a Finite Element Model of a Canine Rib For Use With a Bone Remodeling Algorithm.
}

\author{
A Thesis Presented to \\ the Faculty of the College of Engineering \\ California Polytechnic State University \\ San Luis Obispo \\ In Partial Fulfillment of the Requirements \\ for the Degree of \\ Master of Science in Engineering
}

By

Scott James Sylliaasen

December 2010 
(C) 2010

Scott James Sylliaasen

ALL RIGHTS RESERVED 
TITLE:

AUTHOR:

DATE SUBMITTED:

COMMITTEE CHAIR:

COMMITTEE MEMBER:

COMMITTEE MEMBER:
The Development and Validation of a Finite Element Model of a Canine Rib For Use With a Bone Remodeling Algorithm.

Scott James Sylliaasen

December, 2010

Dr. Scott Hazelwood, Associate Professor, Biomedical \& General Engineering

Dr. Peter Schuster, Associate Professor, Mechanical Engineering

Dr. Robert Crockett, Director, General Engineering 


\begin{abstract}
The Development and Validation of a Finite Element Model of a Canine Rib For Use With a Bone Remodeling Algorithm.
\end{abstract}

By Scott James Sylliaasen

Studies are currently being performed to determine the effects of bisphosphonate treatments on the structure and density of bone tissue. One of the pathways for gaining a better understanding of the effects of this and other treatments involves creating a computer simulation. Theory suggests that bone tissue structure and density are directly related to the manner in which the tissue is loaded. Remodeling is the process in which bone tissue is resorbed in areas of low stress distributions, and generated in areas of high stress distributions. Previous studies have utilized numerical methods and finite element methods to predict bone structure as a result of stress distributions within the tissues. The Finite Element method was chosen for this study. This study was done on a canine (beagle) rib. The goal of this study was to develop an FEA model of the rib that would be used in conjunction with a bone remodeling algorithm, to model the behavior of the bone tissue. Appropriate boundary conditions, loads, and loading cycles were determined from literature, and applied. Respiration was assumed as the dominating activity; therefore the muscles involved in respiration were the primary source of the rib loading. The model also included an integrated UMAT sub-routine, which utilized data from the FEA model to iterate bone tissue densities and structures. The model closely predicted the porosities of the bone tissue, when compared to actual tissue samples, as well as what literature describes. 


\section{Acknowledgements}

I would like to thank Dr. Scott Hazelwood of California Polytechnic State University, San Luis

Obispo for the opportunity to work on this project. His patience, guidance, and expertise were greatly appreciated throughout the entire span of this project.

Additionally I would like to thank my family, and fiancé for their continuous support. 


\section{Table of Contents}

List of Tables ................................................................................................................. ix

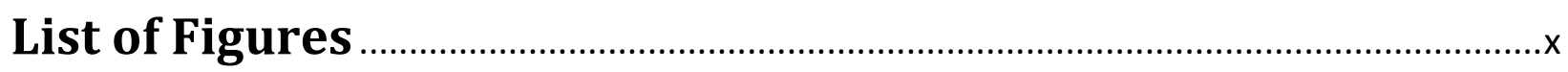

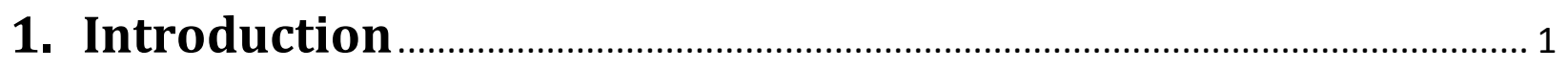

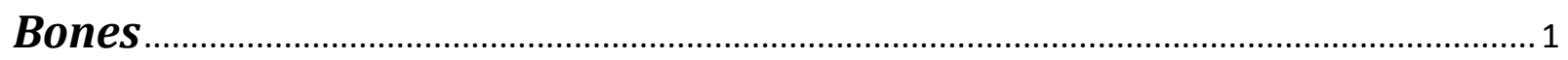

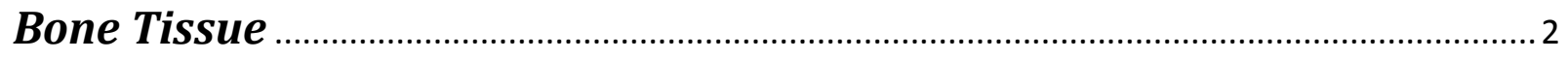

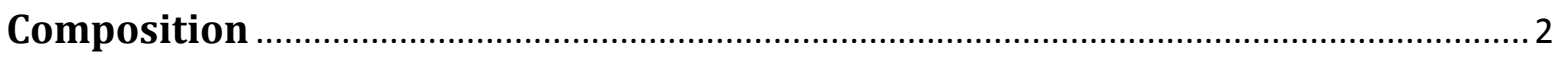

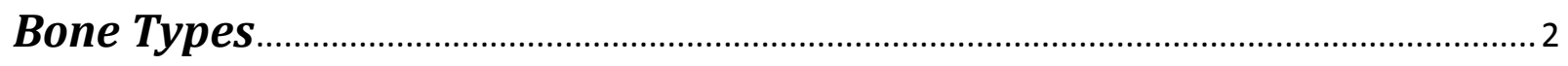

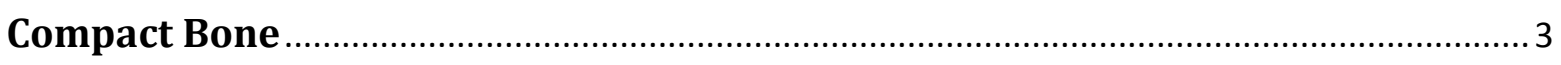

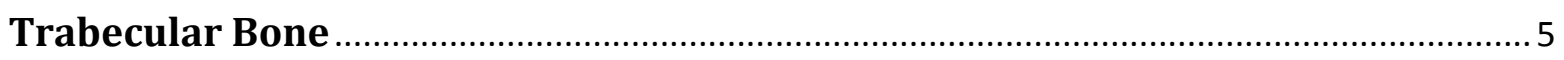

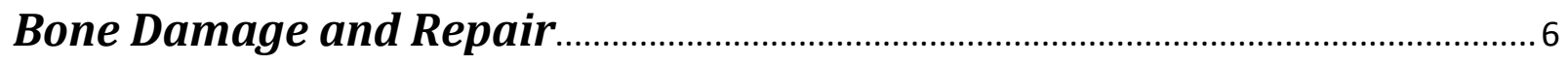

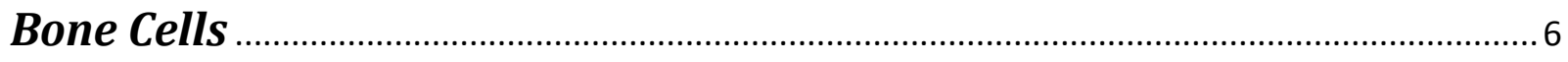

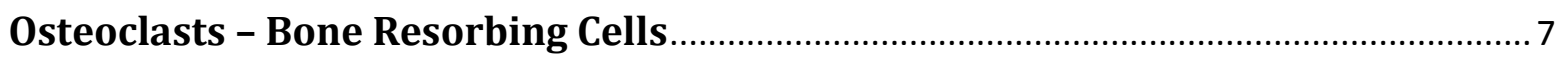

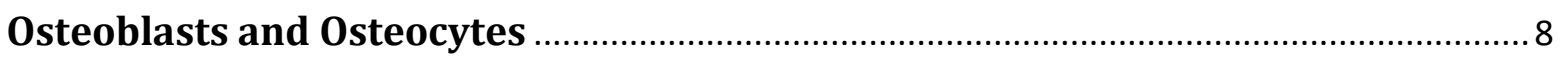

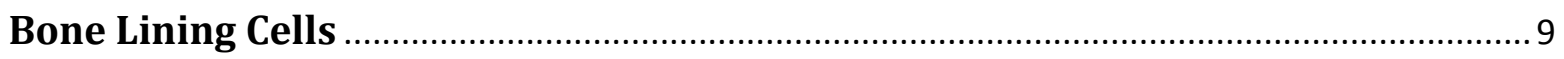

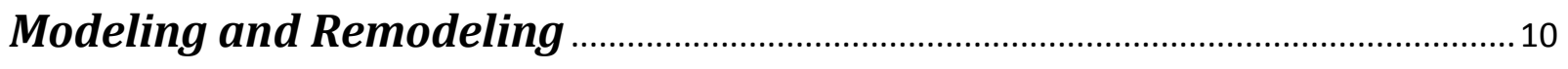

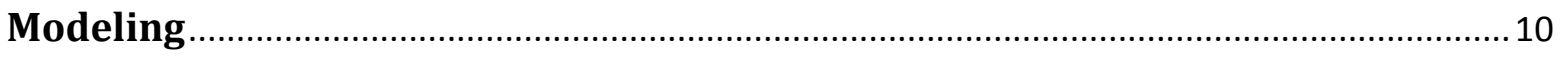

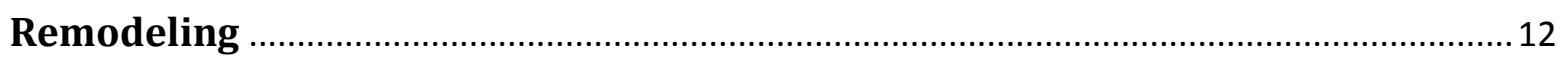

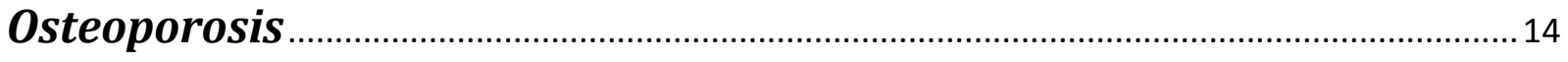

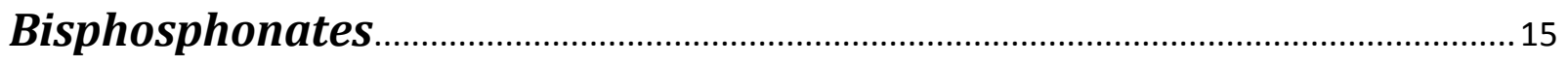

Finite Element Modeling - Bone Remodeling Simulations …….......................16

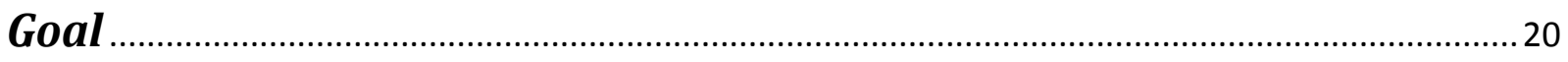

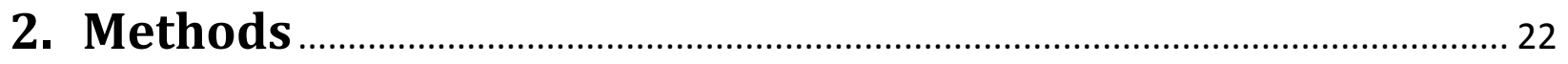

Overall Model Generation/Execution Procedure …………………………….....22

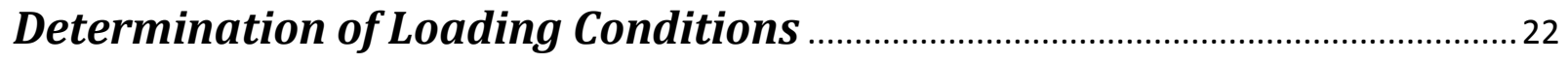

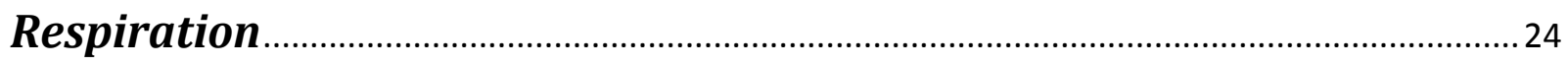

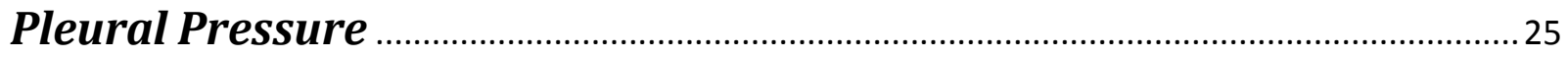




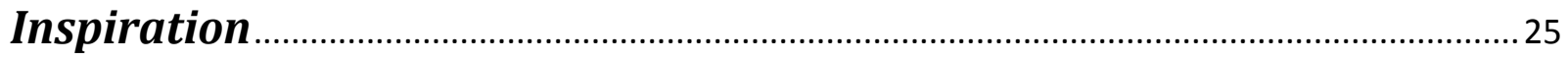

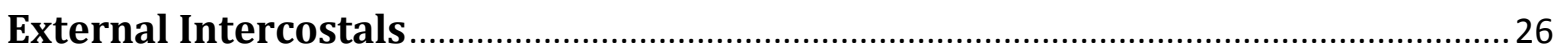

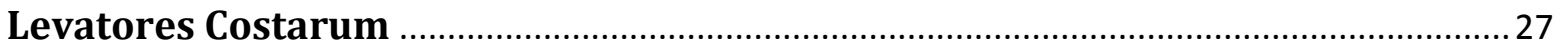

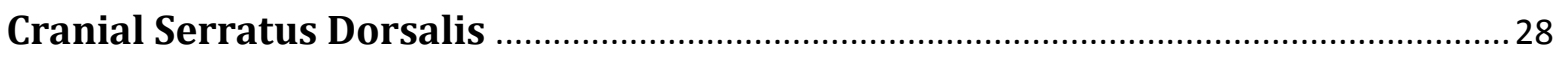

Expiration

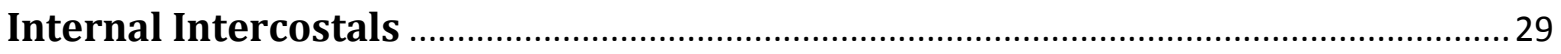

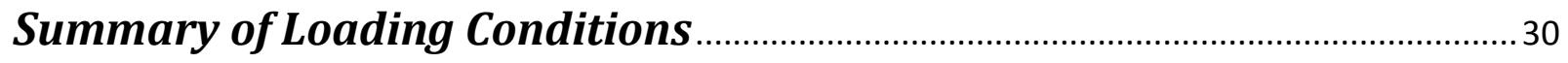

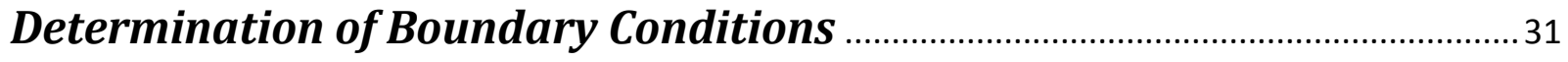

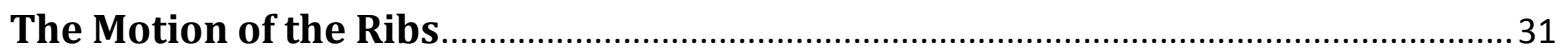

Application of Loading/Boundary Conditions to FEA Model ............................ 32

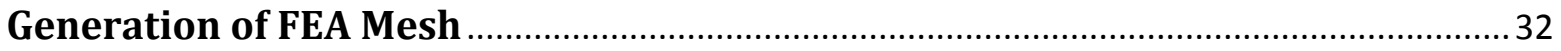

Application of Loading/Boundary Conditions to FEA Mode .........................................33

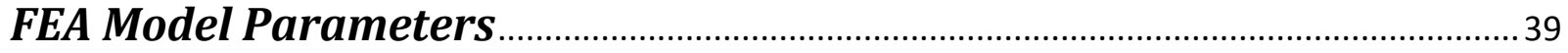

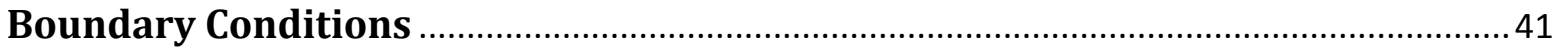

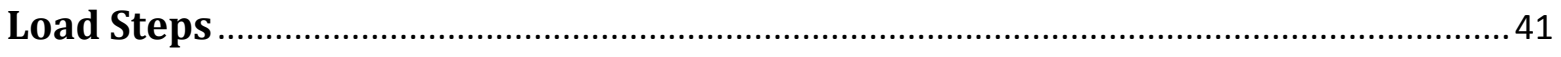

Modification of UMAT Subroutine Parameters to Simulate Bone Adaptation for the Dog Rib.................................................................................. 41

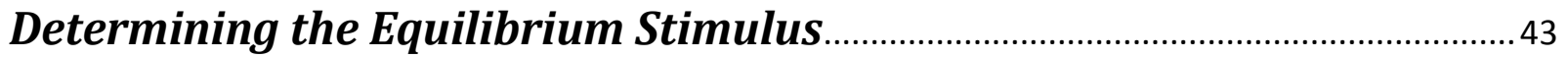
45

Validation of model by comparing to CT scan results .......................................46

Obtaining Density/Porosity from Mimics …………………………………………..... 47

Obtaining Porosity Values from Abaqus ……………………………………………..... 50

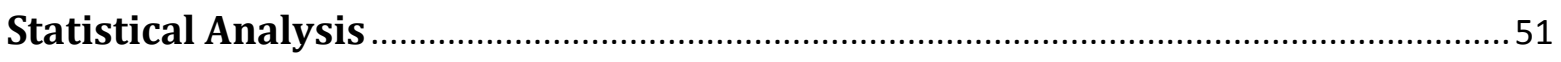

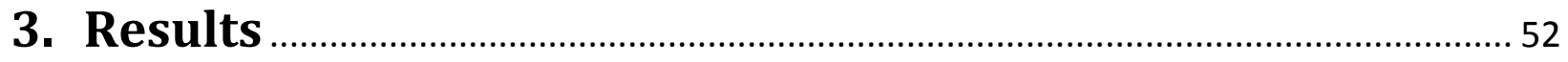

Visual Comparison of Model and Tissue Sample ..................................................52

Quantitative Comparison of Model and Tissue Sample .....................................54

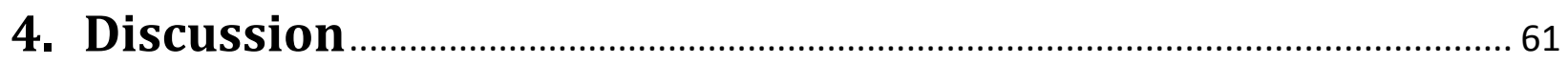

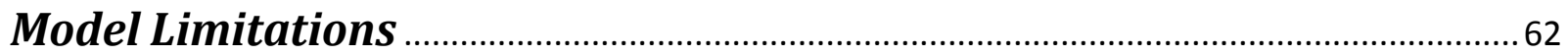


Loading/Boundary Conditions

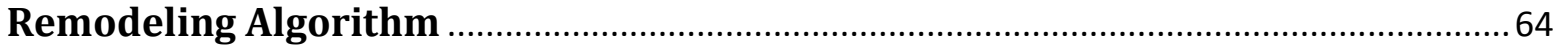

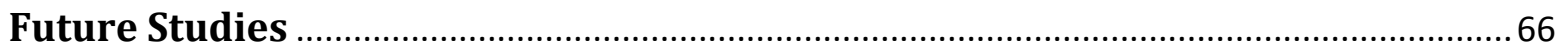

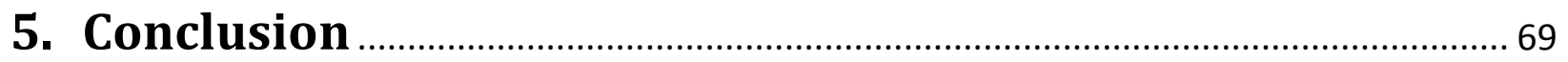

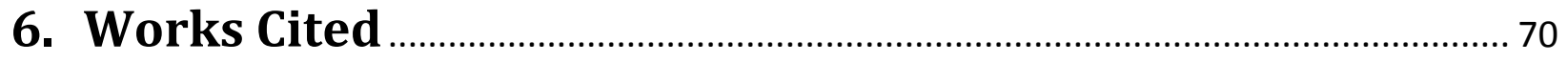

APPENDIX A - UMAT SUBROUTINE …..................................................... 73 


\section{List of Tables}

Table 1 - Loading Conditions of 10th Rib During Inspiration and Expiration............................. 30

Table 2- Range of Remodeling Parameters Investigated ................................................. 45

Table 3 - Regions where Model Predicted Tissue Densities Exceptionally Well (\% Diff < 20\%).... 55

Table 4 - Summary of Quadrant Based Porosity Comparisons of Bone Tissue Porosities

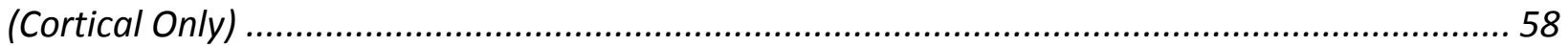




\section{List of Figures}

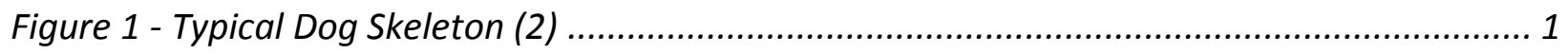

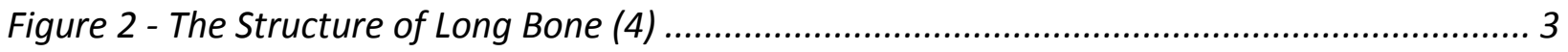

Figure 3 - Close up of osteonal bone in cross-section. (4) ............................................... 4

Figure 4 - Trabecular bone structure in the distal end of a human femur. (4) ........................... 5

Figure 5 - Multinuclear osteoclast (upper right) resorbing bone (lower left). CZ labels clear zones where the cell is sealed to the bone surface; RB labels the ruffled border where enzymes are released to break down bone; B labels the calcified bone matrix. (4)

Figure 6 - Osteoblast forming bone. The dark area at the bottom is mineralized bone. Lighter material is osteoid produced by the rough endoplasmic reticulum of the cell. A portion of a process of the cell protrudes into the lighter osteoid material. (4) ......................................... 8

Figure 7 - Network of Canniculi (Fine Dark Lines) (4) ....................................................... 9

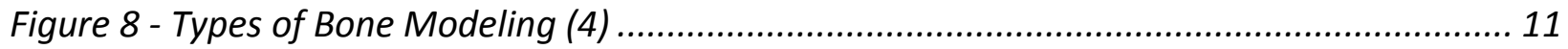

Figure 9 - Osteoclasts (on the right) form the cutting cone of the BMU while osteoblasts (on the left) form new bone in the space created by the osteoclasts. BMU is traveling to

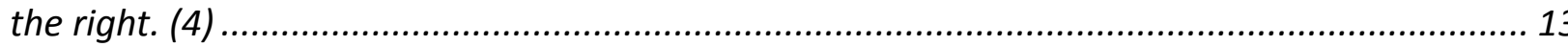

Figure 10 - Huiskes, et al. and Carter et al. Remodeling Algorithm Flow Charts........................ 19 Figure 11 - Thoracic Cavity, levatores costarum, rectus thoracis, cranial serratus dorsalis, and

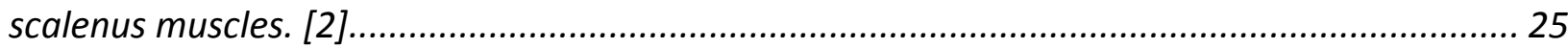

Figure 12 - Insertion Points for Serratus Dorsalis Cranialis and Levatores Costarum and

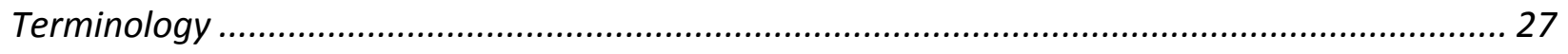

Figure 13 - Summary of Inspiration Forces ..................................................................... 28 


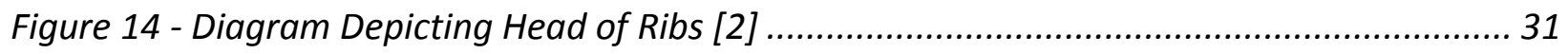

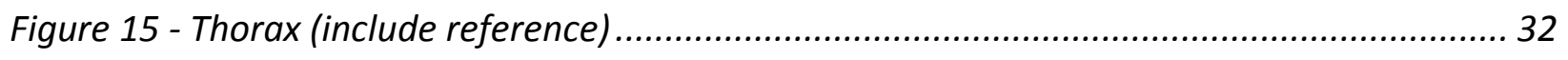

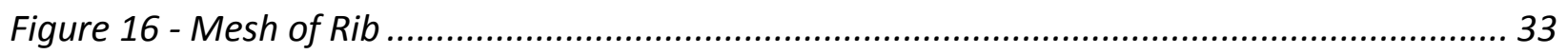

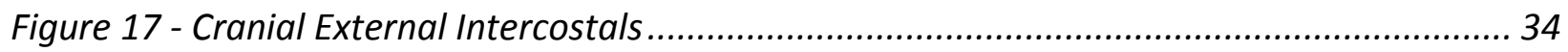

Figure 18 - Caudal External Intercostals ....................................................................... 34

Figure 19 - Caudal Internal Intercostals (Loading Not Shown) ............................................. 35

Figure 20 - Cranial Internal Intercostals (Loading Not Shown) ............................................ 35

Figure 21 - Cranial Serratus Dorsalis......................................................................... 36

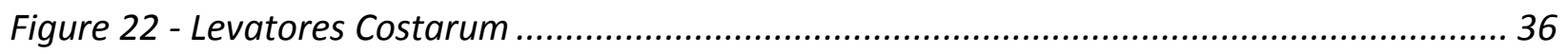

Figure 23 - Pleural Pressure (Applied to Medial Surfaces of Rib, Varies Based on Inspiration or

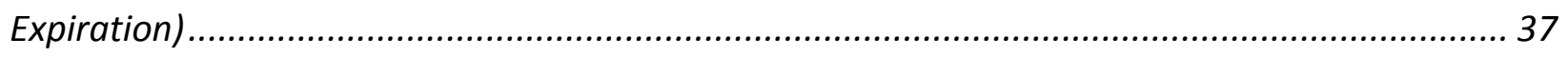

Figure 24 - Dorsal Boundary Conditions (No Displacement or Translation Allowed. Rotation

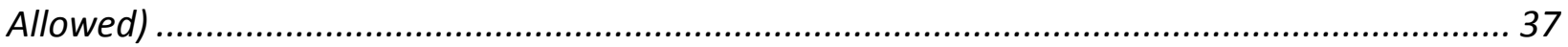

Figure 25 - Ventral Boundary Conditions (No Displacement or Translation Allowed. Rotation

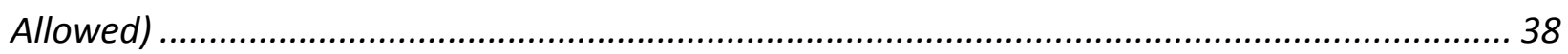

Figure 26 - Lateral Boundary Conditions (No Displacement Allowed. Rotation and Translation

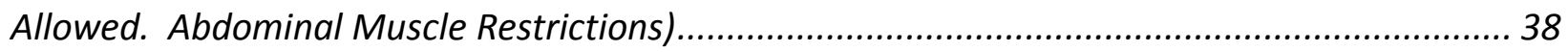

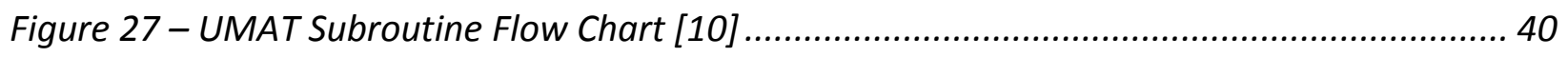

Figure 28 - Locations of Cross Sections for Comparison of Predicted Porosities to Actual.......... 45

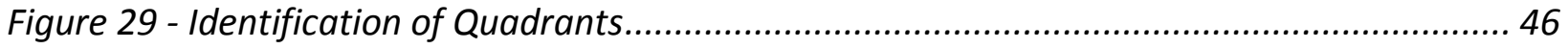

Figure 30 - Mimics Interface, Grayscale Values Listed as "Mean". Three locations where grayscale measured highlighted in Yellow, Red and Purple.............................................. 48 
Figure 31 - Cross Sectional Porosity Analysis of FEA Model..

Figure 32 - Longitudinal Cross Section of Abaqus Model (SDV1 = Porosity \%) .......................... 51

Figure 33 - Horizontal Cross Section (Mimics Left, Abaqus Right, SDV1 = Porosity \%)................ 52

Figure 34 - Horizontal Cross Section (Mimics Left, Abaqus Right, SDV1 = Porosity \%)................ 53

Figure 35 - Comparison of Predicted and Actual Porosities Based on Location on Rib .............. 55

Figure 36 - \% Differences for Porosity Values by Quadrant ................................................. 56 


\section{Introduction}

\section{Bones}

The average canine body consists of 321 bones (Figure 1) [1]. The main functions of bone are to provide structural support, structure for motion, protection of vital organs, mineral storage, and hematopoiesis (the formation of red blood cells) [3]. Bone is a living, dynamic tissue that is constantly adapting to its mechanical environment, undergoing structural changes in order to optimize strength while minimizing weight. Bones are generally classified in four separate categories depending on their shape and location [2]: long bones, short bones, flat bones, and irregular bones. As the name suggests, irregular bones are bones whose shapes and configurations do not fall into any of the other categories. Long bones are found in the limbs, short bones are found in the ankle and wrist, while flat and irregular bones are characteristic of the skull and spine.

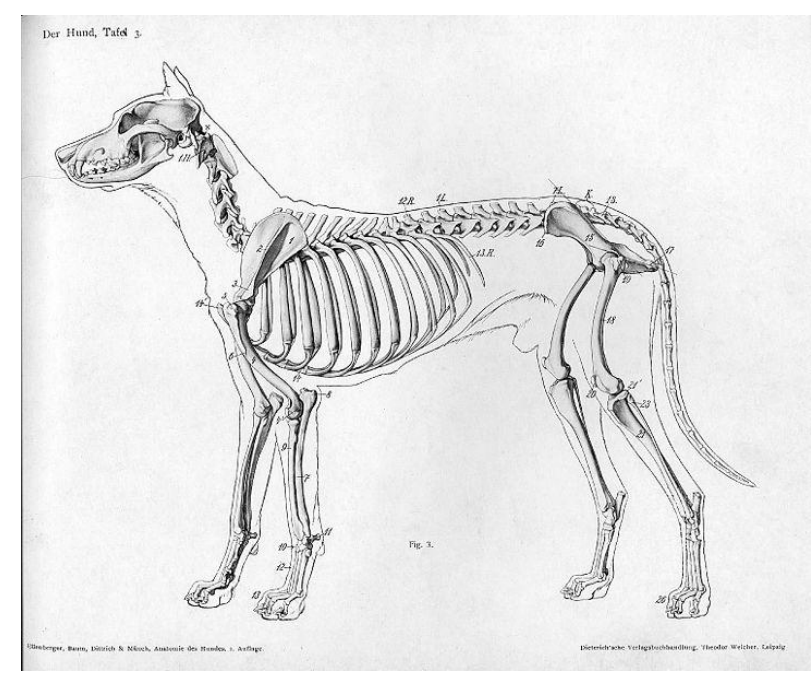

Figure 1 - Typical Dog Skeleton [2] 


\section{Bone Tissue}

\section{Composition}

Bone is composed of hydroxyapatite mineral (70\%), collagen, mostly type-1 (18\%), noncollagenous proteins and proteoglycans (2\%), and water (10\%) [2]. Collagen is a structural protein, also found in tendons, ligaments, and skin, which gives bone its tensile strength and flexibility. In addition, collagen also provides sites for the nucleation of bone mineral crystals, composed primarily of hydroxyapatite, $\mathrm{Ca}_{10}\left(\mathrm{PO}_{4}\right)_{6} \mathrm{OH}_{2}$, which gives bone its characteristic rigidity and compressive strength [4].

\section{Bone Types}

There are two main bone types, called cortical (compact) and trabecular (cancellous) bone. Trabecular bone has a high porosity, 75\% - 95\%, whereas compact bone has a much lower porosity, 5\% - 10\% [4]. The composition and structure of each individual bone making up the human body is based on its specific function, and what physiological and mechanical environment it exists in. Trabecular bone is found in vertebrae, flat bones and the ends of long bones, and compact bone is found in the shafts of long bones and around vertebrae. Figure 2 below illustrates the structure of long bone, with an outer shell of compact bone surrounding an interior of trabecular bone. The center of the bone contains bone marrow, which is responsible for the production of red blood cells and bone cells, as well as some immune system cells. 


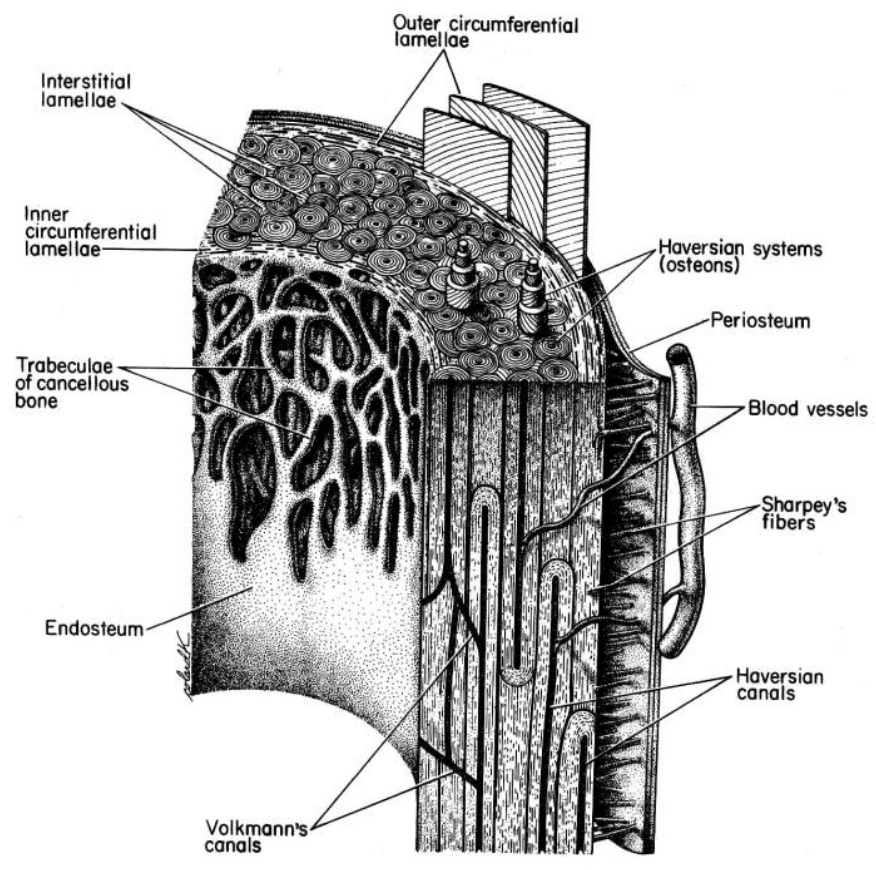

Figure 2 - The Structure of Long Bone [4]

\section{Compact Bone}

Due to its lower porosity which results in higher density, compact bone is the heavier of the two types of bone. Compact bone tissue is formed in layers approximately $5 \mu \mathrm{m}$ thick called lamellae which are arranged differently in different parts of bone. Near the outer and inner surface of bone, they are arranged circumferentially, while the compact bone that exists in between these two layers is generally characterized as osteonal bone. Osteonal bone, shown in Figure 2, and in more detail in Figure 3, consists of cylindrical structures formed by concentric lamellae, approximately $200 \mu \mathrm{m}$ in diameter, $1 \mathrm{~cm}$ long, and aligned with the long axis of the bone [4]. 


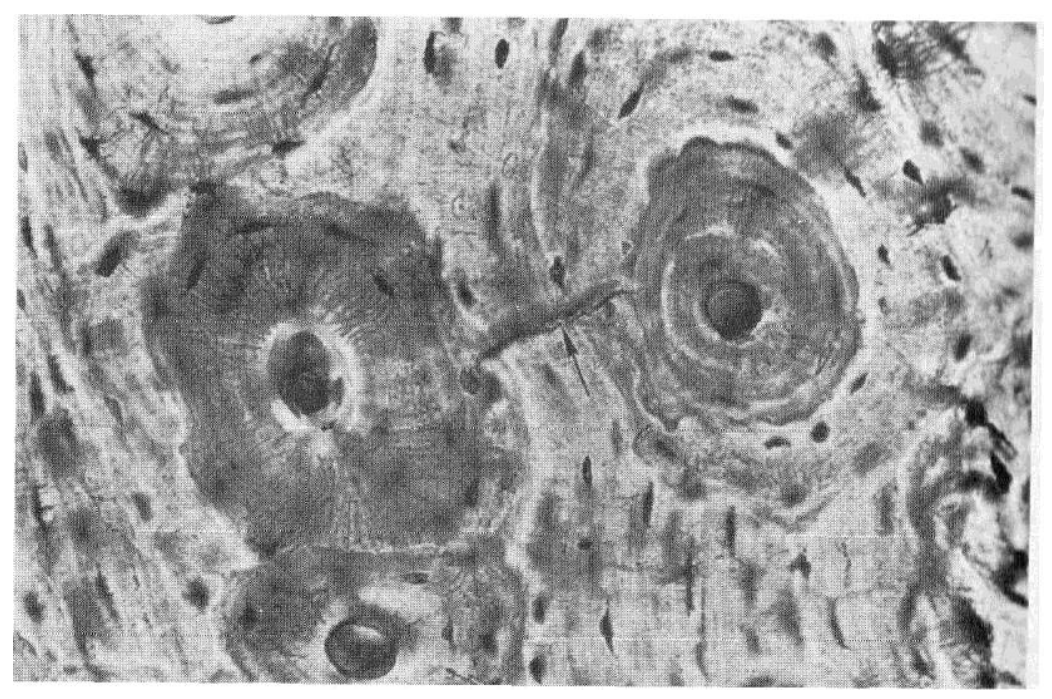

Figure 3 - Close up of osteonal bone in cross-section. [4]

At the center of each osteonal structure lies a Haversian canal approximately $50 \mu \mathrm{m}$ in diameter, and within each canal exists blood vessels and nerves [4]. The function of the Haversian canals is to provide nutrients and remove wastes from the surrounding bone. Volkmann's canals run transversely between Haversian canals, connecting them to each other and to the outside surfaces of the bone.

The longitudinal alignment of the osteons and the orientation of the lamellae give compact bone high stiffness and strength along the long axis of the bone, as well as good fatigue resistance. The lamellar structure of compact bone gives the bone the ability to keep fatigue cracks small and run in harmless directions, thus improving fatigue resistance [4]. The structure essentially dissipates crack energy around the edge of the osteons, keeping the crack small, rather than allowing the crack to propagate entirely through the bone. The lamellar and osteonal structure of compact bone allows it to achieve an elastic modulus between 14.8 and 
17.4 GPa, an ultimate strength between 133 and $195 \mathrm{GPa}$, and a fracture toughness of 2.2-6.3 $\mathrm{MPa}-\mathrm{m}^{1 / 2}[2,4]$

\section{Trabecular Bone}

Trabecular bone, also known as spongy or cancellous bone, has a much more porous structure than compact bone. Interconnecting struts that are $200 \mu \mathrm{m}$ thick, called trabeculae, form the structure of trabecular bone [4] (See Figure 4). The arrangement of these struts varies from highly organized to highly random. This complex, interconnecting structure gives bone the ability to dissipate and spread energy from impacts, acting as a sort of shock absorber. In general, trabecular bone is characterized with an elastic modulus of $272 \pm 195 \mathrm{MPa}$ and an ultimate strength of $2.54 \pm 0.62 \mathrm{MPa}$ [4].

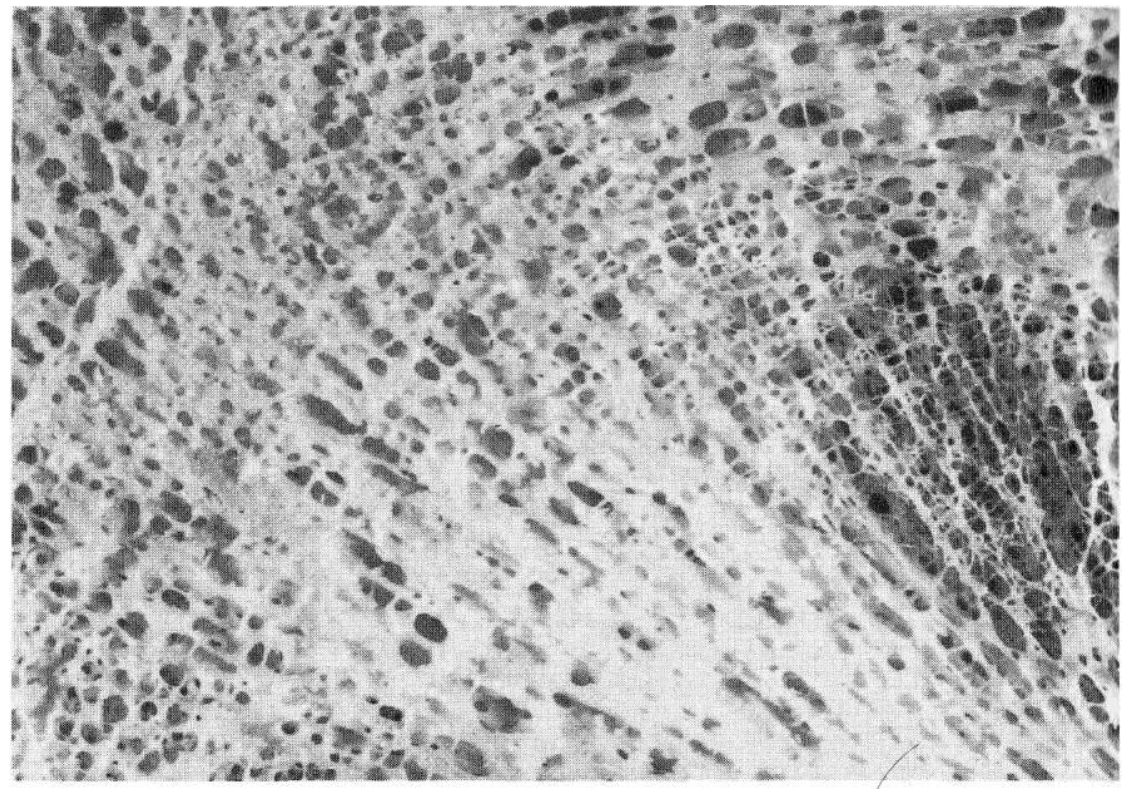

Figure 4 - Trabecular bone structure in the distal end of a human femur. [4] 


\section{Bone Damage and Repair}

Bones in the body are subjected to two types of loading conditions which can lead to failure, creep and fatigue. In creep, a load is applied continuously, such as the continual loading of the vertebrae. Fatigue involves cyclic loading, such as the cyclic loading of the femur during walking. The continual and cyclic loading of bones can lead to the creation and propagation of damage, in the form of microcracks. If microcracks continue to grow, they can eventually lead to failure of the bone, in the form of a fracture. Fortunately, our body's remodeling mechanisms, described in the following sections, repair these microcracks and prevent them from growing and leading to failure.

\section{Bone Cells}

Earlier, it was mentioned that bone is a dynamic tissue, whose structure is constantly being modified to adapt to its biochemical and mechanical environment, in order to optimize strength with respect to weight. These processes are carried out by bone cells of two categories; bone cells that remove/resorb bone, and bone cells that form bone. The cooperation of these two cell types makes it possible for the skeletal system to undergo important structural changes and repairs. 


\section{Osteoclasts - Bone Resorbing Cells}

Osteoclasts are multinuclear cells which resorb bone tissue. They are closely related to macrophages, which are responsible for removing harmful impurities from the tissues of the body. Bone resorption occurs along the ruffled border of the cell and occurs at a rate of tens of micrometers per day, utilizing a combination of acids and enzymes, to demineralize the adjacent bone, and break down the remaining collagen [4]. Figure 5 below shows a portion of an osteoclast resorbing bone.

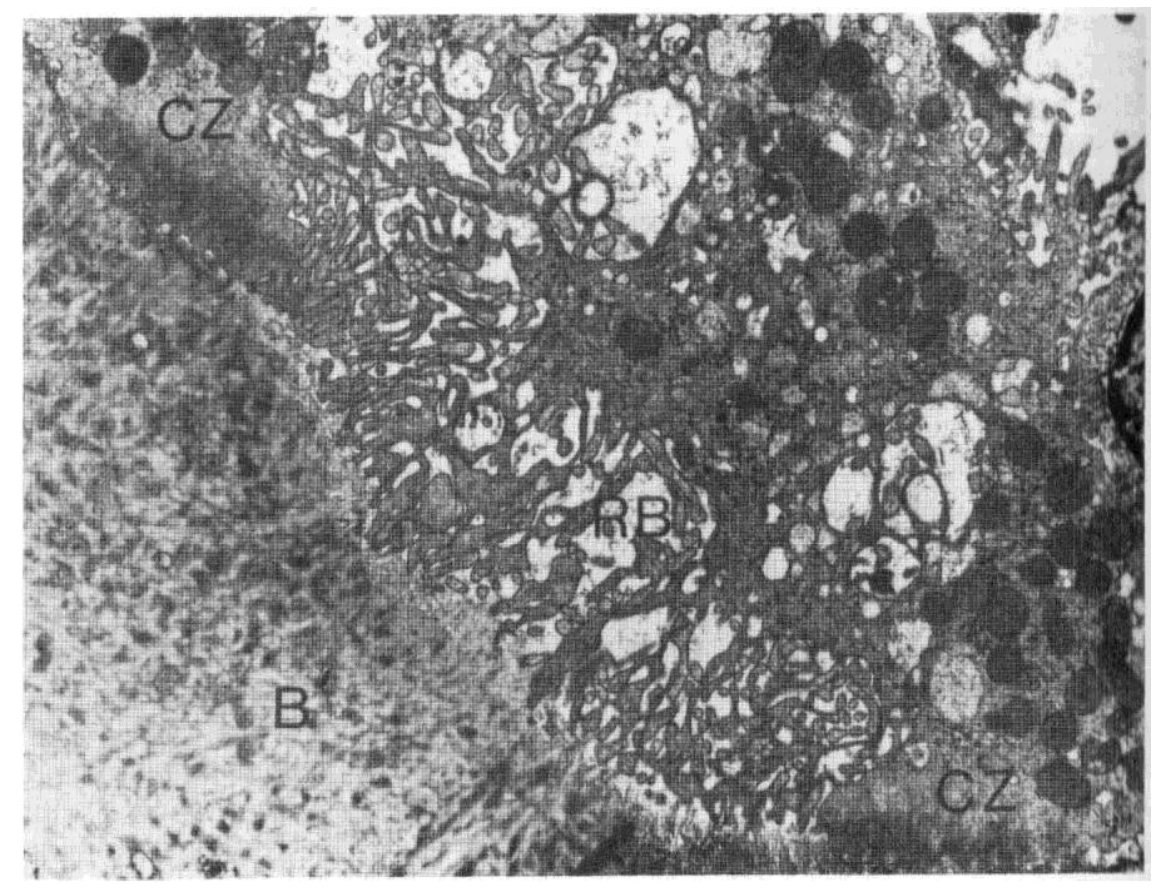

Figure 5 - Multinuclear osteoclast (upper right) resorbing bone (lower left). CZ labels clear zones where the cell is sealed to the bone surface; RB labels the ruffled border where enzymes are released to break down bone; B labels the calcified bone matrix. [4] 


\section{Osteoblasts and Osteocytes}

Unlike osteoclasts, osteoblasts are mononuclear cells that aid in forming new bone tissue (Figure 6). Osteoblasts produce osteoid, which is the organic portion of the bone matrix, consisting of collagen, noncollagenous proteins, proteoglycans, and water [4]. Much of the organic components of osteoid are produced in the osteoblast's rough endoplasmic reticulum [4]. As more and more osteoid is produced, the osteoblasts become engulfed in bone tissue, and become osteocytes. Osteocytes are embedded in a complex network of tunnels called canaliculi which create a vast communication and transportation network between osteocytes

(Figure 7). This complex network has lead researchers to believe that osteocytes are important in the transportation of minerals and nutrients in and out of bone, and possibly in the sensing of mechanical stress [4].

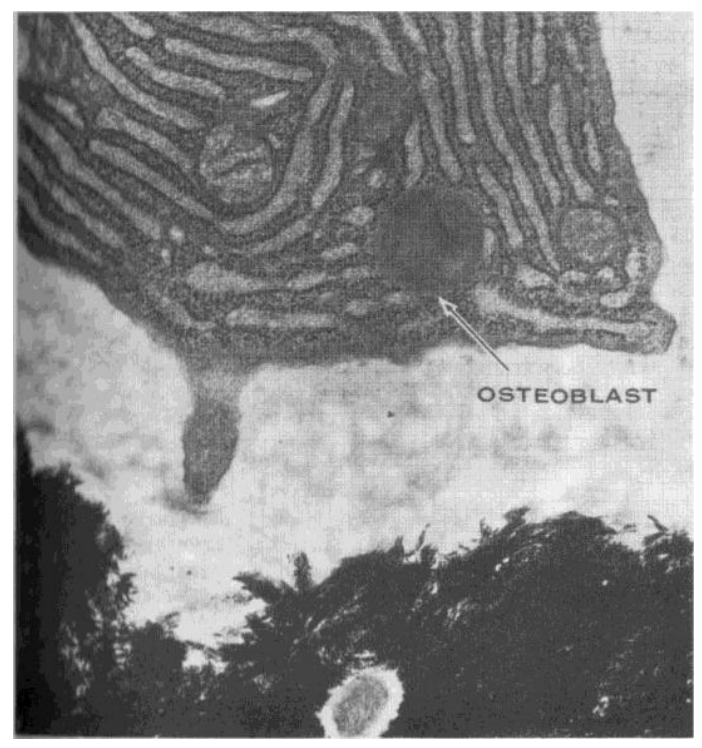

Figure 6 - Osteoblast forming bone. The dark area at the bottom is mineralized bone. Lighter material is osteoid produced by the rough endoplasmic reticulum of the cell. A portion of a process of the cell protrudes into the lighter osteoid material. [4] 


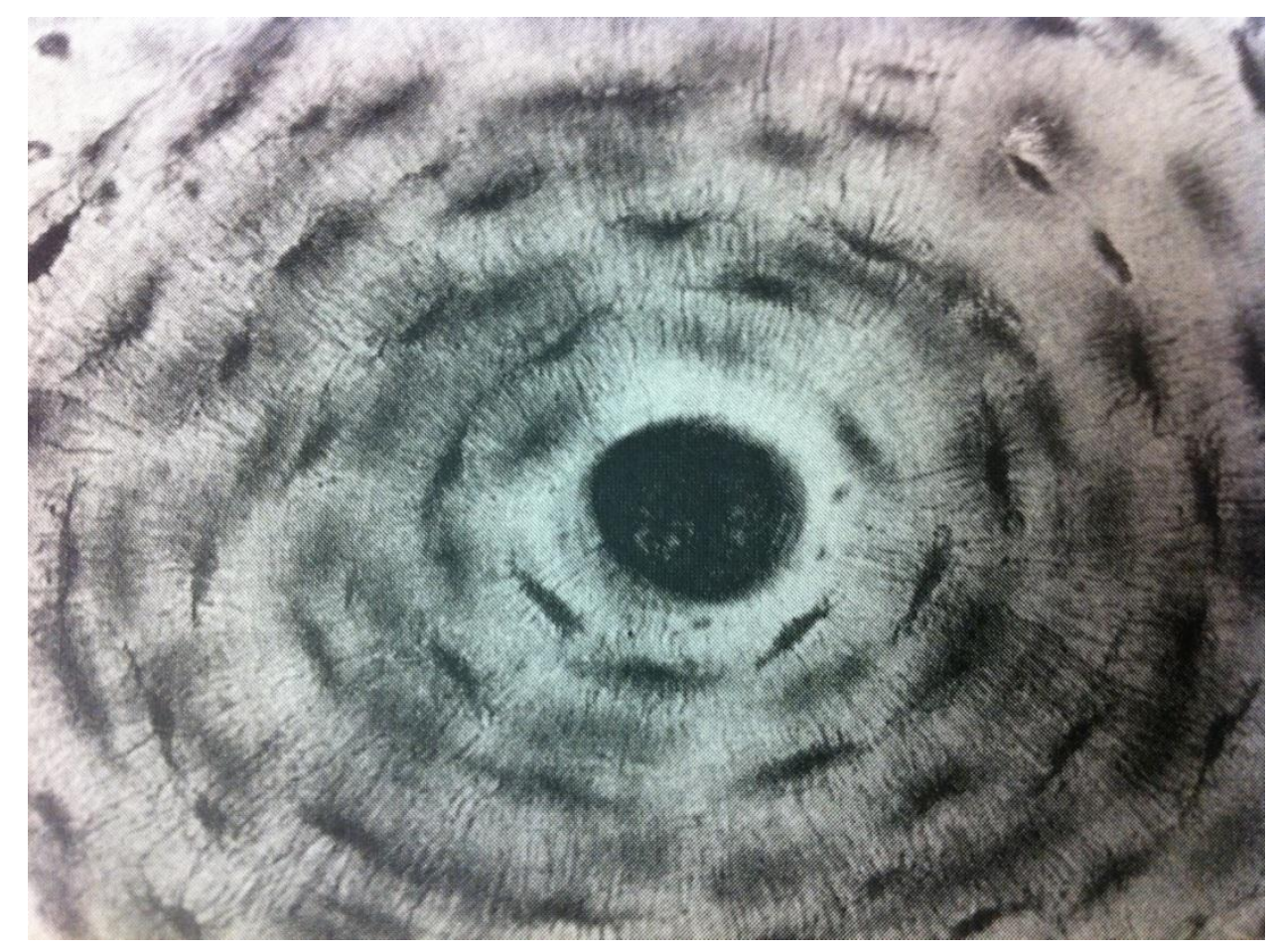

Figure 7 - Network of Canniculi (Fine Dark Lines) [4]

\section{Bone Lining Cells}

Bone lining cells are former osteoblasts that were not engulfed in osteoid and lie inactive on the external surface of the bone tissue. Bone lining cells communicate with osteocytes via the communication network described in the previous section. Because of their connection to the extensive network of canals, as well as their possession of chemical receptors, they are believed to be responsible for mineral and nutrient transfer in and out of the bone, as well as sensing mechanical strain [4]. 


\section{Modeling and Remodeling}

The structure of skeletal tissue is modified via two methods: modeling and remodeling. Modeling involves the independent actions of osteoclasts and osteoblasts to shape bones into the desired geometries. Remodeling utilizes the combined actions of osteoclasts and osteoblasts in groups called basic multicellular units (BMU's) to maintain and modify the structural integrity of the bone tissue, by simultaneously removing and replacing bone tissue, without changing the bone's overall shape.

Modeling occurs rapidly during growth, and is greatly reduced once skeletal maturity is reached. Remodeling occurs throughout life, but the rate at which remodeling takes place is reduced when growth stops.

\section{Modeling}

Modeling is a process which takes place during growth which essentially sculpts bones into specific shapes. The shape of each bone is modified by osteoclasts removing bone in one area while osteoblasts form bone in another. The rate and locations of these activities are greatly influenced by the stresses the bones are subjected to. Thus, every individual has a skeleton that is essentially tailored to their specific loading conditions.

Examples of bone modeling include: metaphyseal modeling to reduce bone diameter, diaphyseal modeling to modify bone diameter and alter curvature, and flat bone modeling to accommodate for brain growth in the skull. Metaphyseal modeling involves the creation of the 
diaphysis by the continual removal of bone tissue from the periosteal surface of the metaphysis to reduce the shaft to the proper diameter (Figure 8a).

Diaphyseal modeling to modify bone diameter involves the addition of bone to the exterior surface of long bone shafts, while bone is removed from the interior of the shafts (Figure $8 b$ ). The curvature of the diaphysis is modified by removing and forming bone on the sides of the bone, causing the cross section of the bone to drift in relation to the ends of the bone (Figure 8c) [4]. Another example of modeling involves the sculpting of the flat bones in the skull. As the brain grows, the flat bones of the skull must increase in size as well as change shape to accommodate.

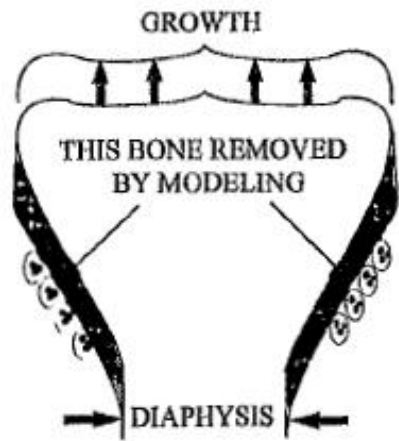

METAPHYSEAL CUT BACK

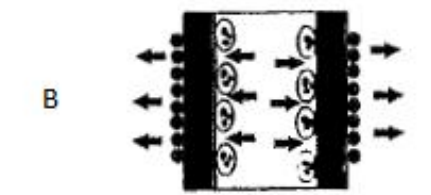

DIAPHYSEAL ENLARGEMENT

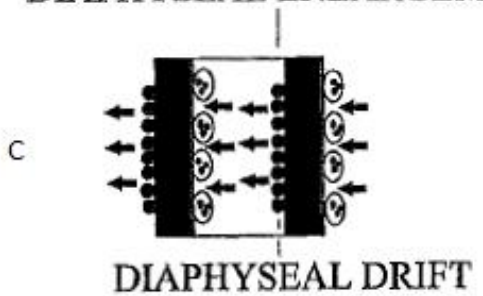

Figure 8 - Types of Bone Modeling [4] 


\section{Remodeling}

Remodeling involves the cooperation of osteoclasts and osteoblasts in BMUs to repair bone, by removing old or damaged tissue and replacing it with newly formed tissue. The repair of microscopic damage prevents the accumulation of fatigue damage, essentially reducing the likeliness of fracture or other fatigue damage. It is also hypothesized that the action of remodeling "fine tunes" the bone tissue to optimize mechanical efficiency, by reducing weight and optimizing strength [4]. Remodeling also aids in calcium homeostasis, helping bones act as a calcium reservoir for the body; removing calcium from the reservoir via osteoclasts, and adding calcium to the reservoir via osteoblasts.

As stated before, remodeling occurs via the cooperation of osteoclasts and osteoblasts in BMUs. BMUs are first activated by chemical or mechanical signals, which cause osteoclasts to form. After the activation and formation of the osteoclasts, the BMU enters the resorption phase. Osteoclasts begin removing bone tissue, forming a ditch (on the bone surface), or a tunnel (in compact bone). Following the initiation of resorption, the osteoblasts begin differentiating from mesenchymal cells (a specific type of stem cell) and begin the formation stage, in which the resorbed tissue is replaced. The entire ARF (activation, resorption, formation) lifecycle of BMUs takes about 4 months, with resorption taking about 3 weeks in humans, and formation/refilling taking about 3 months [4]. The exact ARF lifecycle in canines has not been specifically established in prior research.

Bone remodeling encompasses osteonal remodeling, trabecular remodeling, and endosteal and periosteal remodeling. Osteonal remodeling involves the tunneling of a BMU 
which forms a secondary osteon. The BMUs become so isolated in the cortical tissue that in order to maintain vascular supply, they must not entirely fill in the resorbed area, leaving behind a Haversian canal when the process is finished. In human adults, osteonal BMUs replace about $5 \%$ of compact bone per year [4].

BMUs are composed of about 10 osteoclasts, which form a cutting cone at the tip of the BMU, removing bone, followed by several hundred osteoblasts, which replace the resorbed bone with new bone tissue [4]. BMUs tunnel at a rate of approximately $40 \mu \mathrm{m}$ a day. In cortical bone the tunneling BMUs leave behind small cylindrical cavities, which are characteristic of the osteonal structure ditches on the surface of trabecular bone, and tunnels through compact bone.

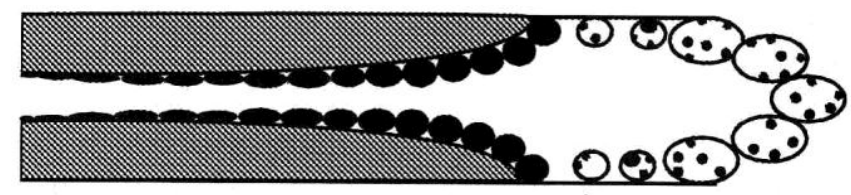

Figure 9 - Osteoclasts (on the right) form the cutting cone of the BMU while osteoblasts (on the left) form new bone in the space created by the osteoclasts. BMU is traveling to the right. [4]

Trabecular remodeling also involves BMUs, but, the BMUs travel along the surfaces of the trabeculae, digging and refilling trenches [4]. The bone turnover rate for adult humans is about $25 \%$ per year, but varies widely depending on the location in the skeleton [4]. Researchers have observed that long bones expand radially with age, which has led to speculation that remodeling occurs on the endosteal and periosteal surfaces of bones [4]. In order for the diameters to grow, bone formation must exceed resorption on the periosteal surface, but the lack of data on this issue has left it uncertain. 


\section{Osteoporosis}

Osteoporosis is defined as the reduction in bone mass and deterioration of its microstructure, accompanied by an increased susceptibility to fracture [3]. Essentially, the porosity of the bone tissue increases, leading to reduced fracture toughness. Over one million osteoporotic fractures occur each year in the United States, occurring most often in the spine, hip, and wrist [3]. Osteoporotic fractures are more common in women than in men, due to hormonal differences between each sex, and in part due to the fact that women live longer than men.

Osteoporosis is caused by malfunctioning remodeling actions of the bone tissue an unbalance between the amount of bone removed by osteoclasts and the bone replaced by osteoblasts, leading to the net removal of bone tissue [5]. This reduction in bone tissue density reduces the mechanical strength of the bone and increases the susceptibility to fracture.

Current treatment options for subjects with osteoporosis include the use of nutritional supplements, such as calcium and vitamin D, to provide the body with sufficient nutrients and minerals to maintain bone tissue [5]. Resistance training is additionally used to increase the loading to bone tissue to stimulate remodeling and improve fracture resistance. In the past 10 years, bisphosphonate drugs have become the most widely used drugs in the treatment of postmenopausal osteoporosis [5]. 


\section{Bisphosphonates}

The utilization of bisphosphonates (BPs) in the treatment of osteoporosis has shown remarkable promise. They have been shown to halve vertebral fracture risk, and reduce nonvertebral fracture risk by $20-30 \%$ [5]. Bisphosphonate drugs work by inhibiting osteoclasts, effectively reducing bone turnover. The tradeoff of using BP drugs is that by inhibiting the action of osteoclasts, they inhibit the actions of BMUs and the process of remodeling. This results in the accumulation of microdamage, which may increase fracture risk.

Reductions in bone toughness as well as reduction in bone turnover rates have been consistently documented following bisphosphonate treatment, especially in the vertebrae of animals. Dogs receiving high doses of BPs showed increased microdamage and reduced mechanical strength of bone tissue [5]. Beagles exposed to bisphosphonate treatments equal to or lesser than the doses used to treat postmenopausal women, showed no significant reduction in vertebral bone toughness, while beagles exposed to higher doses experienced significant reductions in vertebral bone toughness [6]. Although extensive studies have been performed in the vertebrae of beagles validating the theory that the use of bisphosphonates reduces bone toughness, studies involving the rib are conflicting, with one study showing no effect on rib toughness and another showing a significant reduction $[7,8]$.

A more recent study determined that although rib cortical bone experiences significant reductions in turnover following bisphosphonate treatment, only animals treated with doses above what are normally used to treat osteoporosis experienced a significant reduction in bone toughness [6]. 


\section{Finite Element Modeling - Bone Remodeling Simulations}

Finite element models of bone allow researchers to predict the effects of various treatments on the mechanical properties of the bone tissue itself. Finite element modeling involves the division of a specific volume of the structure into elements, each having its own geometry and mechanical properties [4]. Complex algorithms can be applied to the model to simulate the processes of modeling, remodeling, and the utilization of pharmaceuticals. Boundary conditions, such as forces and constraints are then applied to the structure and a computer is used to predict the mechanical response of the tissue. If a remodeling algorithm is applied to the model, the model could be used to predict the effects of the loading condition or drug treatment algorithm on the remodeling state of the bone, in addition to the mechanical response of the tissue.

Although FEA modeling can be used to predict the responses of complex systems, it is not always entirely accurate. Since many assumptions are made during the modeling process and during the computation of the results, one can expect that the results may not be an exact representation of what might happen in actuality. It is therefore important that the FEA model be consistent with actual data, before it can be used to provide significant results.

FEA models can be validated by a number of methods. The most commonly used methods of validating FEA bone models involve comparing real specimens to the models. For example, if the researcher created a model of a femur and subjected the model to three-point bending, he could validate his model by subjecting a cadaver femur to a three-point bend on a material tester, and compare the results to those predicted by the FEA model. Another 
approach would be to compare the histology of the real bone specimen to the structure and histology predicted by the FEA model.

Carter, et al, used an FEA model, to successfully simulate the relationship between bone tissue density and structure to the loading history of a femur [23]. The model calculated bone density structures that were similar to previously documented samples. Similarly, Huiskes, et al, used FEM to model the effects of stress shielding by a medullary stem, such as used in a Total Hip Arthroplasty, on the bone tissue density distribution in a femur [24]. He showed that the rigidity and bonding characteristics of the implant affect the resorption of the surrounding bone.

The methods used by Huiskes and Carter required the use of a specific bone remodeling algorithm. Figures 10 illustrates, in general, the algorithm loops used by each to simulate bone remodeling under particular loading conditions. In each case, loads, boundary conditions, and material properties were input into a finite element model. The stress and strain fields output by the model were used to predict a remodeling response by the tissue. The changes in the tissue structure resulted in changes in material properties, which would be used as inputs in the next iteration.

Huiskes used the FEM to determine strain energy density (SED), which is essentially the product of the local stress and strain tensors [24]. The difference between the calculated SED and the homeostatic SED, which was determined at homogeneous conditions, was used to predict the remodeling response. The change in material properties was determined from the 
remodeling rate, and the apparent density was determined from the change in the material properties.

Carter's method was slightly different in that he utilized a stress stimulus as opposed to strain energy density, to determine the remodeling response [23]. The stress stimulus was derived from the effective stress applied at a particular number of cycles, based on the activity (walking, standing, etc.). Additionally, Carter derived the changing material properties from the apparent density, as opposed to Huiskes, who derived the apparent density from the changing material properties. 


\section{Huiskes, et al.}

Apparent Density

Material Properties

Boundary Conditions

Loads

Stress/Strain Fields/Tensors

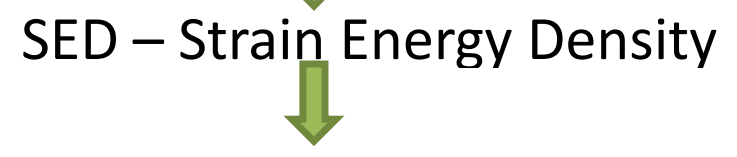

Difference Between Actual SED and Homogeneous SED

Remodeling Response

\section{Carter, et al.}

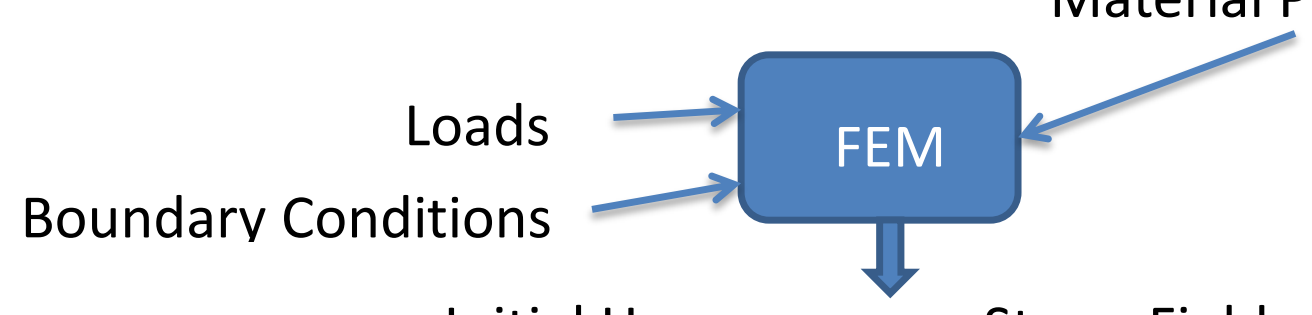

Initial Homogeneous Stress Fields

Effective Stress

Actual Stress Stimulus

Difference Between Actual and Attractor Stress Stimulus

Remodeling Response

Apparent Density 


\section{Goal}

Experimental studies have been conducted to determine the short term effects of various antiremodeling agents on the mechanical properties and remodeling behavior of bone tissue. One study showed that the treatments affect osteoblasts and bone formation differently, depending on the predominant mechanism of formation, either modeling or remodeling [25]. The second study showed that higher dosages of bisphosphonate treatments reduce bone toughness [9]. Each study was performed on skeletally mature beagles, which were treated daily with various antiremodeling agents. The results of each study were determined from rib tissues that were extracted once the treatment periods were concluded.

The goal of this thesis is to develop a finite element model of the $10^{\text {th }}$ beagle rib, under normal and untreated loading conditions. Ultimately, the model will be utilized to further the experimental studies by predicting the long term effects of various bisphosphonate treatments on the mechanical properties, microdamage accumulation, and bone turnover rate of the rib. As a first step in that process, the model developed and validated in this project will be the initial baseline model of the rib prior to bisphosphonate treatment. 
In order to validate the model, a bone remodeling algorithm will be applied and the resulting structure/histology of the model will be compared to that of an actual beagle specimen. Creating and validating the FEA model will involve the following objectives:

1) Researching the proper natural loading conditions of the $10^{\text {th }}$ beagle rib.

2) Generating an FEA model of the rib.

3) Applying the remodeling algorithm to the model.

4) Validating the model by comparing structure/histology to actual rib. 


\section{Methods}

\section{Overall Model Generation/Execution Procedure}

As noted before, the goal of this thesis was to develop and validate an initial, baseline FEA model that could accurately simulate the bone tissue properties of a dog rib. The method used was similar to the method used by Huiskes [24], described in the previous section. The FEA model was used to calculate the strains and stresses throughout the bone tissue. The stress and strain values generated by the model was inputted into a user created material subroutine (UMAT subroutine), to predict the structure of the resulting bone tissue. UMAT subroutines are essentially lines of code that ABAQUS can use to simulate complex tissues and materials. The following steps were taken to develop the FEA model.

- Determination of Loading/Boundary Conditions.

- Application of Loading/Boundary Conditions to FEA Model.

- Generation/Modification of Input file to be utilized in concert with UMAT subroutine.

- Modification of UMAT Subroutine parameters to simulate structure/histology.

- Validation of model by comparing to CT scan results.

\section{Determination of Loading Conditions}

Muscle insertion locations, forces, functions, and action angles all affect the stresses and strains exerted on the rib, thereby having a great deal of influence over the structure of the bone tissue. In order to create an accurate model, the natural loading conditions of the dog rib were researched utilizing various canine anatomy books. It was decided that the activities of inspiration and expiration would be the most dominating activities under normal conditions 
that influenced the rib; therefore, the muscle groups that participate in each activity were investigated.

The muscle force was determined based on the assumption that the maximal force produced by a muscle is proportional to its cross sectional area. The area of contact of each muscle group was estimated based on anatomy and the structure of the rib. Maximal stresses in muscle tissue have been measured to be between 20 and $100 \mathrm{~N} / \mathrm{cm}^{2}$ [4], and it was assumed that the muscle tissue in this study produced $20 \mathrm{~N} / \mathrm{cm}^{2}$, because the dog which is the primary focus of this study was small compared to humans.

A visual inspection of the cranial, (See Figure 11 for definition of anatomical directions for canines), portion of the rib reveals two separate areas on the bone which contain 2 to 3 and 7 to 9 peaks. These peaks indicate the insertion points of the levatores costarum and the cranial serratus dorsalis muscle groups [12], respectively. The area enclosing the entirety of the peaks was estimated as the area of muscle insertion for each group.

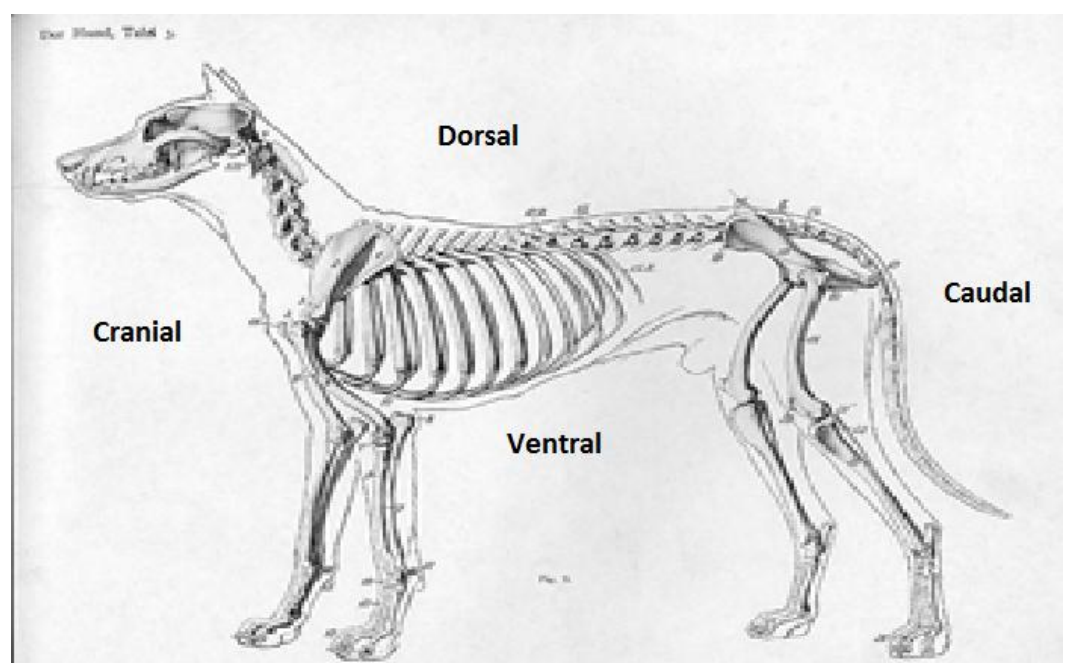

Figure 11 - Canine Anatomic Directions/Terms [2] 
The external intercostals span the spaces between ribs, from the insertion of the levatores costarum, to the costrachondral junctions, and are 4-5mm thick on large dogs [1]. The area of the external intercostals' muscle insertion was estimated by using a thickness of $4 \mathrm{~mm}$, covering the extent of the rib. The internal intercostals span the length of the rib as well, but lie medial to the external intercostals. The muscle insertion area for the internal intercostals was estimated in a similar fashion, using a thickness of $2 \mathrm{~mm}$ (the thickness of the internal intercostals is $2-3 \mathrm{~mm}$ in large dogs [1]).

The magnitude of the force values were distributed over the nodes on the FEA model in the areas that the muscle group acts on, and then broken up into horizontal and vertical components. To simplify the model, the forces were assumed to be acting in two dimensions, as opposed to three dimensions.

\section{Respiration}

During inspiration, the diaphragm contracts and is displaced caudally into the abdomen, and the ribs are pulled forward, resulting in the expansion of the thoracic cavity and the filling of the lungs. The ribs are pulled forward by the external intercostals, levatores costarum, rectus thoracis, cranial serratus dorsalis, and the scalenus muscles (Figure 12) [11]. Expiration involves the opposite action, the pulling of the ribs caudally, towards the tail, and the relaxation of the diaphragm, thus reducing the volume of the thoracic cavity, resulting in the expulsion of air from the lungs. The muscles involved in the movement of the ribs caudally are the internal intercostals and the caudal serratus dorsalis. In addition to experiencing the muscle forces that draw the ribs cranially and caudally, the ribs endure a continuous pleural pressure that resists 
the motions of respiration. Pleural pressure is defined as the pressure of the cavity surrounding the lungs.

\section{Pleural Pressure}

During inspiration, the pressure of the pleural cavity increases from $-2 \mathrm{cmH}_{2} \mathrm{O}$ to approximately $-4 \mathrm{cmH}_{2} \mathrm{O}$ [9]. This pressure resists the motion of inspiration and increases in magnitude as the thoracic cavity expands and for this model, it is assumed that the pressure is applied to the entire medial surface of the rib.

\section{Inspiration}

As stated before, the ribs are drawn forward by the external intercostals, levatores costarum, rectus thoracis, cranial serratus dorsalis, and the scalenus muscles, in order to facilitate the expansion of the thoracic cavity (See Figure 12). The rectus thoracis and scalenus muscles only act on the first few ribs, and since the goal of this thesis was to model the $10^{\text {th }}$ rib, these muscle groups were ignored. In addition, the actions of the abdominal muscles were assumed to be negligible. The remaining muscle groups act on most of the ribs and therefore were included in the analysis. For a detailed list of the muscle forces see Table 1, page 30. 


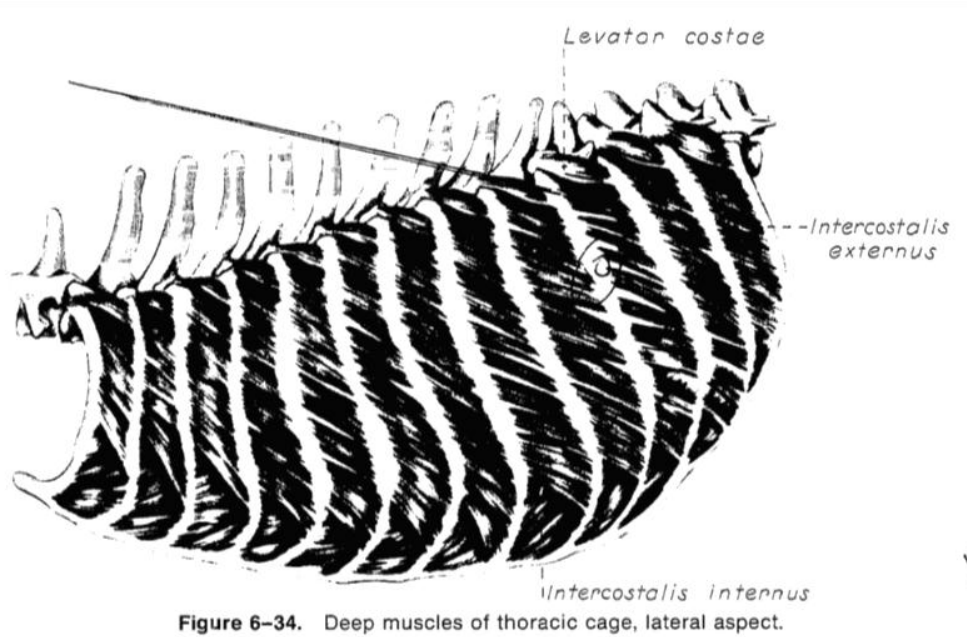

Figure 12 - Thoracic Cavity, levatores costarum, rectus thoracis, cranial serratus dorsalis, and scalenus muscles. [2]

\section{External Intercostals}

The external intercostals and internal intercostals fill the spaces between the ribs (intercostals spaces). The external intercostals form the thicker outer layer of the intercostal spaces, ranging from 4 to $5 \mathrm{~mm}$ thick in large dogs [1]. They cover the extent of the ribs, from the insertion of the levatores costarum, to the costochondral junctions. Their fibers originate from the caudal border of each rib, and run caudoventrally to the cranial border of the next rib. In addition, their fibers run perpendicular to the fibers of the internal intercostals, which run cranioventrally [13]. Since they run perpendicular to the internal intercostals, it was assumed that they act at $a 5^{\circ}$ to the surface of the rib where they attach. In addition, the muscles were assumed to act laterally at an angle of $35^{\circ}$ (See Figures 13,14 ). 


\section{Levatores Costarum}

The levatores costarum insert into the cranial portion of the rib near the vertebrae and extend cranially to attach to the transverse process of the adjacent rib. Their insertion points can typically be easily identified by $2-3$ peaks near the dorsal portion of the rib (see Figures 13,14). The angle of action of the levatores costarum was measured from a drawing in Millers Anatomy [1] using a protractor.

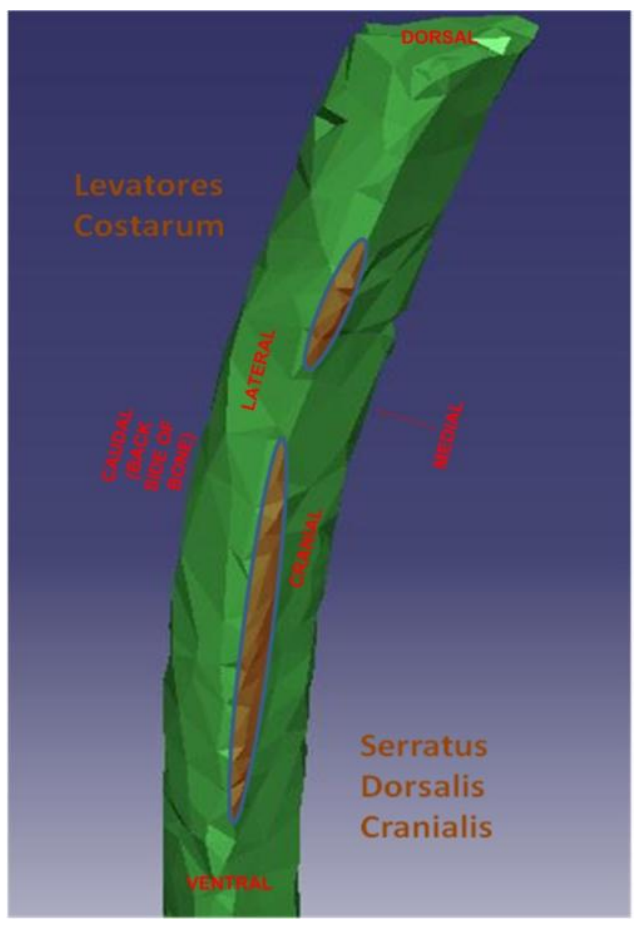

Figure 13 - Insertion Points for Serratus Dorsalis Cranialis and Levatores Costarum [2] 


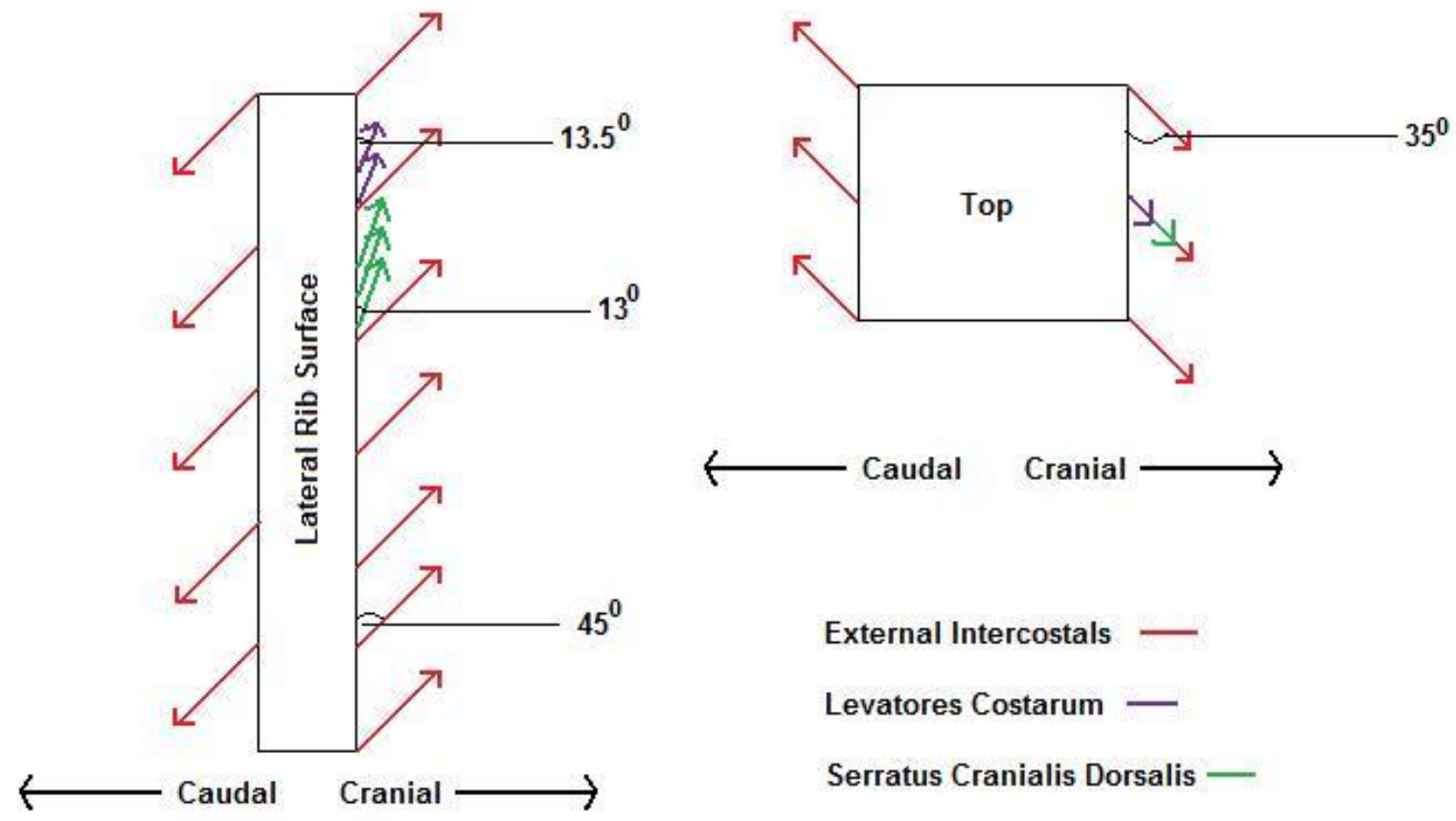

Figure 14 - Summary of Inspiration Forces

\section{Cranial Serratus Dorsalis}

The cranial serratus dorsalis muscle group emerges from the supraspinous ligament and inserts into seven to nine peaks in the cranial borders of ribs three to ten [12]. (See Figures 13, 14) The angle of action was estimated by using a protractor to measure a drawing from Millers Anatomy [1].

\section{Expiration}

Expiration requires the use of less muscle groups to be performed due to the inherent elasticity of the thorax and the magnitude of pleural pressure. As more and more air is drawn in, this resistance and pressure increases. During expiration, these act to help reduce the 
volume of the thoracic cavity, and expel air. Due to the lessened need for muscle interaction, only a couple muscle groups are utilized during respiration; the internal intercostals and caudal serratus dorsalis. The caudal serratus dorsalis exists only on the last ribs; ribs eleven through thirteen [12], so they were ignored in the development of this model.

\section{Internal Intercostals}

The internal intercostals lie medial to the external intercostals and originate from the cranial border of one rib to the caudal border of the rib next to it. The fibers run cranioventrally and run perpendicular to the fibers of the external intercostals [13]. This muscle group has a thickness of 2 to $3 \mathrm{~mm}$ in large dogs, about half as thick as the external intercostals. Following the assumptions made for the external intercostals, the fibers of the internal intercostals run at $45^{\circ}$ from the surface of the rib, and instead of acting laterally at an angle of $35^{\circ}$, they act medially, at $35^{\circ}$. See figure 15 for a summary of the expiratory muscle forces.

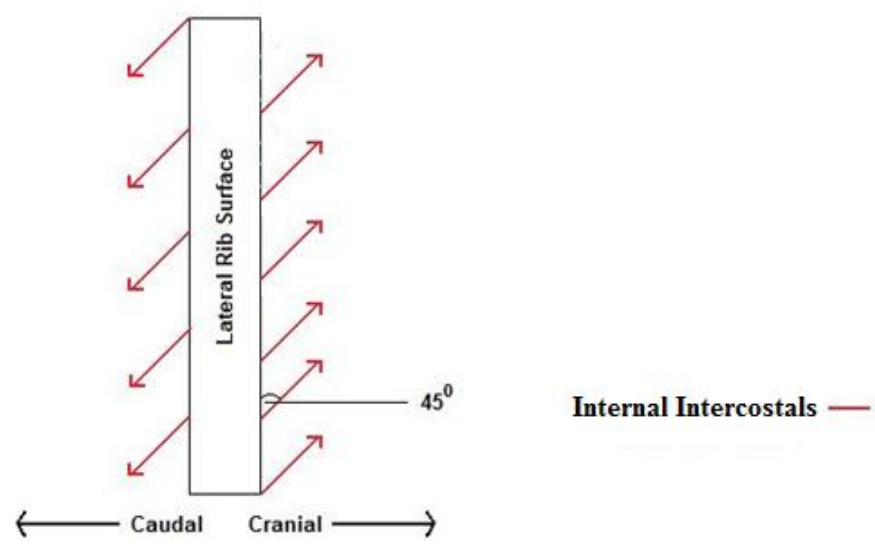

Figure 15 - Summary of Expiratory Forces 


\section{Summary of Loading Conditions}

The following table summarizes the loading conditions of the rib discussed in the prior

sections. Notice that most of the loading from the muscles occurs during inspiration.

Table 1 - Loading Conditions of 10th Rib During Inspiration and Expiration

\begin{tabular}{|c|c|c|c|c|c|c|c|}
\hline $\begin{array}{l}\text { Rib Loading } \\
\text { Condition }\end{array}$ & Insertion & $\begin{array}{l}\text { Muscle } \\
\text { Fiber } \\
\text { Direction }\end{array}$ & $\begin{array}{c}\text { Area } \\
\left(\mathrm{mm}^{2}\right)\end{array}$ & $\begin{array}{c}\# \\
\text { Nodes }\end{array}$ & $\begin{array}{l}\text { Magnitude } \\
\text { of Force } \\
\text { per Node } \\
\text { (N/node) }\end{array}$ & $\begin{array}{c}\text { Vertical } \\
\text { Component } \\
\text { (N/node) }\end{array}$ & $\begin{array}{c}\text { Horizontal } \\
\text { Componen } \\
\text { (N/node) }\end{array}$ \\
\hline $\begin{array}{l}\text { External } \\
\text { Intercostals } \\
\text { Inspiration }\end{array}$ & $\begin{array}{l}\text { On cranial } \\
\text { and caudal } \\
\text { rib surfaces. } \\
\text { Superficial } \\
\text { to internal } \\
\text { intercostals. }\end{array}$ & $\begin{array}{l}45^{\circ} \text { from face - } \\
\text { fibers run } \\
\text { caudoventrally }\end{array}$ & 119.3 & 179 & 0.133 & 0.092 & 0.092 \\
\hline $\begin{array}{l}\text { Levatores } \\
\text { Costarum } \\
\text { Inspiration }\end{array}$ & $\begin{array}{c}2 \text { to } 3 \text { peaks } \\
\text { on cranio- } \\
\text { dorsal } \\
\text { portion of } \\
\text { rib surface. }\end{array}$ & $\begin{array}{c}13.5^{\circ} \text { from } \\
\text { face - fibers } \\
\text { run } \\
\text { caudoventrally }\end{array}$ & 0.87 & 10 & 0.017 & 0.004 & 0.017 \\
\hline $\begin{array}{c}\text { Cranial } \\
\text { Serratus } \\
\text { Dorsalis } \\
\text { Inspiration }\end{array}$ & $\begin{array}{l}7 \text { to } 9 \text { peaks } \\
\text { on cranial } \\
\text { portion of } \\
\text { rib surface. }\end{array}$ & $\begin{array}{l}13^{\circ} \text { from face - } \\
\text { fibers run } \\
\text { caudoventrally }\end{array}$ & 5.7 & 37 & 0.031 & 0.007 & 0.03 \\
\hline $\begin{array}{l}\text { Internal } \\
\text { Intercostals } \\
\text { Expiration }\end{array}$ & $\begin{array}{c}\text { On cranial } \\
\text { and caudal } \\
\text { rib surfaces. } \\
\text { Internal to } \\
\text { external } \\
\text { intercostals. }\end{array}$ & $\begin{array}{l}45^{\circ} \text { from face - } \\
\text { fibers run } \\
\text { cranioventrally }\end{array}$ & 44.6 & 129 & 0.069 & 0.052 & 0.052 \\
\hline $\begin{array}{l}\text { Pleural } \\
\text { Pressure } \\
\text { Both }\end{array}$ & \multicolumn{7}{|c|}{$\begin{array}{l}\text { Pleural pressure varies from }-2 \mathrm{cmH}_{2} \mathrm{O} \text { to }-4 \mathrm{cmH}_{2} \mathrm{O} \text { from beginning of inspiration to beginning of } \\
\text { expiration, respectively. }\end{array}$} \\
\hline
\end{tabular}




\section{Determination of Boundary Conditions}

\section{The Motion of the Ribs}

The head of each rib articulates with costal articular surfaces on the bodies of vertebrae, and the heads of each rib are held in place against the surfaces by ligaments [10], (Figure 16). This mechanism allows the ribs to rotate cranially and caudally during inspiration and expiration, respectively. To simulate this, the boundary conditions of the dorsal portion of the rib model were modeled fixed (no rotation, or displacement allowed). In canines, only the costal cartilages of the first nine ribs are fixed to the sternum, the costal cartilages of ribs ten through twelve are not attached to the sternum, but unite to form the costal arch. The thirteenth ribs end freely in musculature and are referred to as floating ribs. Since the tenth rib is attached to the costal arch, the ventral portion of the rib was modeled similarly to the dorsal portion, fixed. In addition, boundary conditions that constrain lateral translation of the outer surface of the rib were added to simulate the effects of the abdominal muscles that encase the thorax (Figure 17).

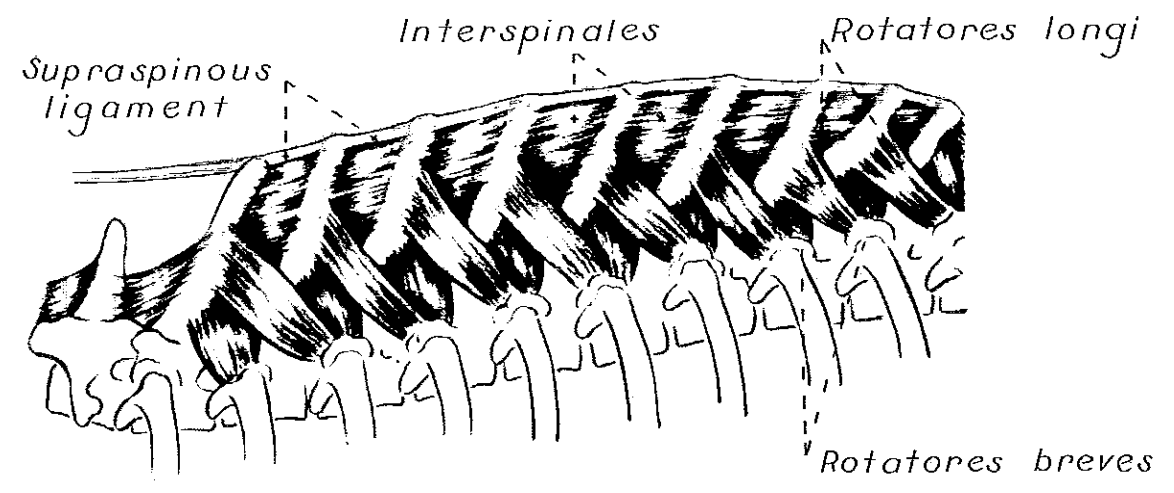

Figure 16 - Diagram Depicting Head of Ribs [2] 


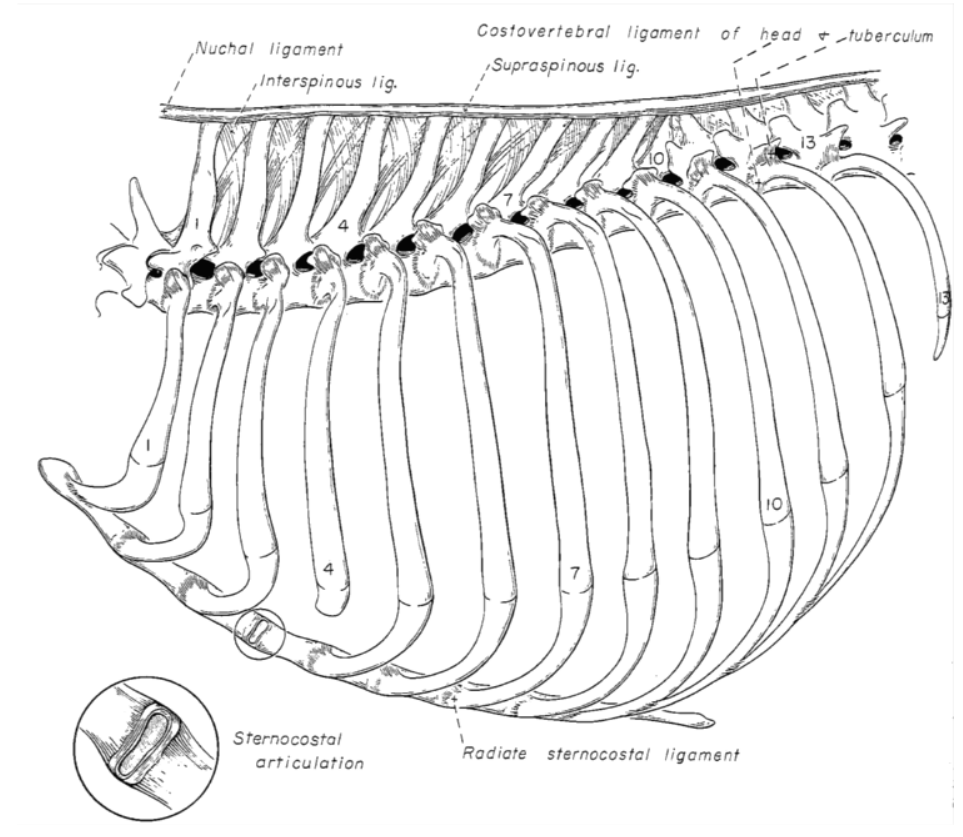

Figure 17 - Thorax [2]

\section{Application of Loading/Boundary Conditions to FEA Model}

\section{Generation of FEA Mesh}

The mesh utilized in this research was provided by Dr. Hazelwood. The mesh was generated by the following procedure:

- A beagle rib was excised and run through a CT scan.

- Mimics was used to generate a 3d model and surface mesh from the CT scan.

- The surface mesh was imported into Abaqus. 
- The surface mesh was then converted to a 3d solid mesh in Abaqus, using 4 node tetrahedrons, generating a model consisting of 4,252 elements and 1,160 nodes.

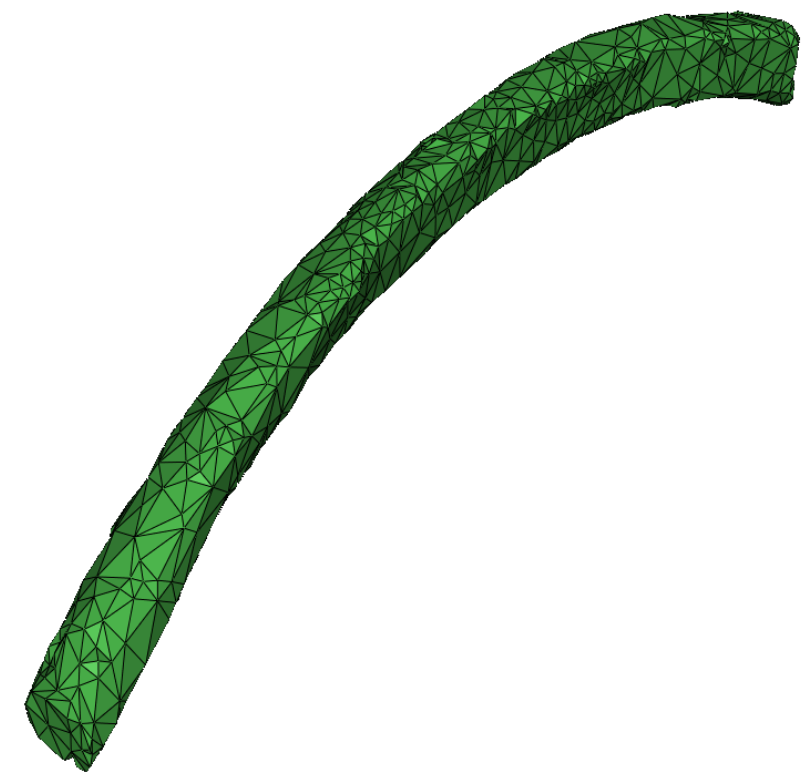

Figure 18 - Mesh of Rib

\section{Application of Loading/Boundary Conditions to FEA Mode}

Abaqus was used to add the boundary and loading conditions specified in Table 1 to the provided mesh. The first step was to define the node and surface sets that would ultimately represent the insertions and action points of the various muscle groups and boundary conditions. Surfaces were picked to define the areas that would be affected by the pleural pressure, and node sets were picked to define the locations of muscle forces and boundary conditions. 
Once the sets were defined, the specific loads and boundary conditions were applied to the appropriate set The following figures (Figures 19-28) illustrate the loading and boundary conditions applied to the rib.

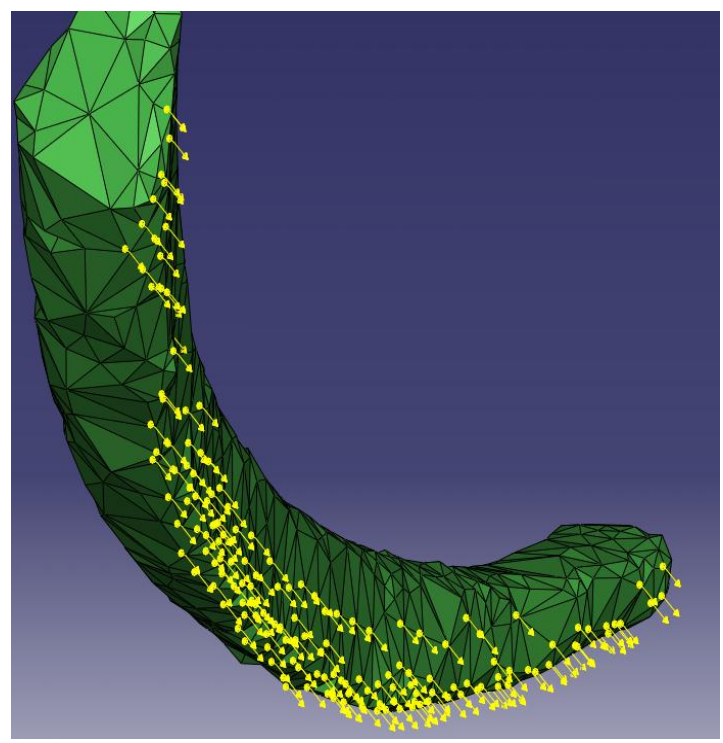

Figure 19 - Cranial External Intercostals

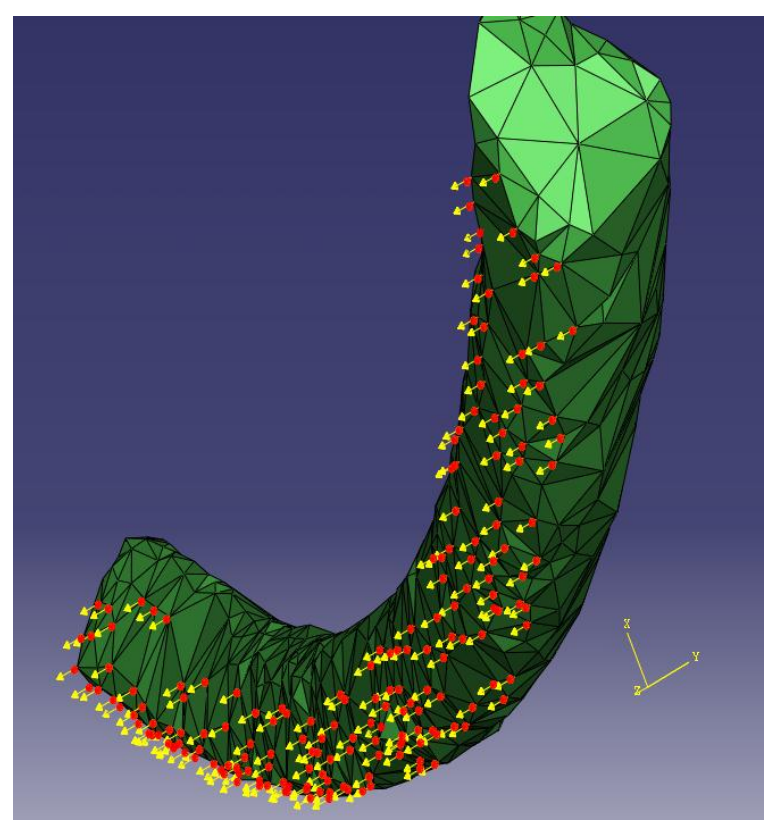

Figure 20 - Caudal External Intercostals 


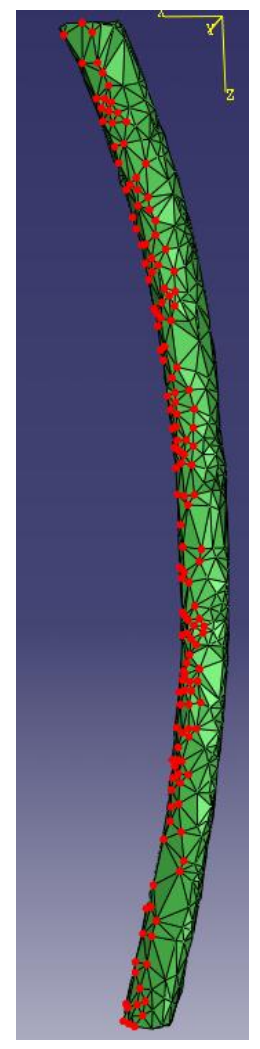

Figure 21 - Caudal Internal Intercostals (Loading Not Shown)

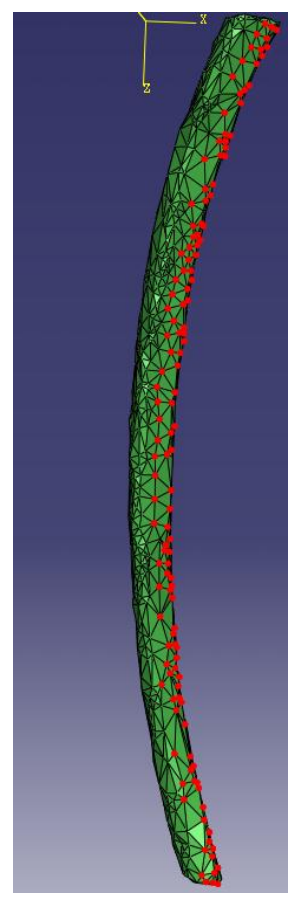

Figure 22 - Cranial Internal Intercostals (Loading Not Shown) 


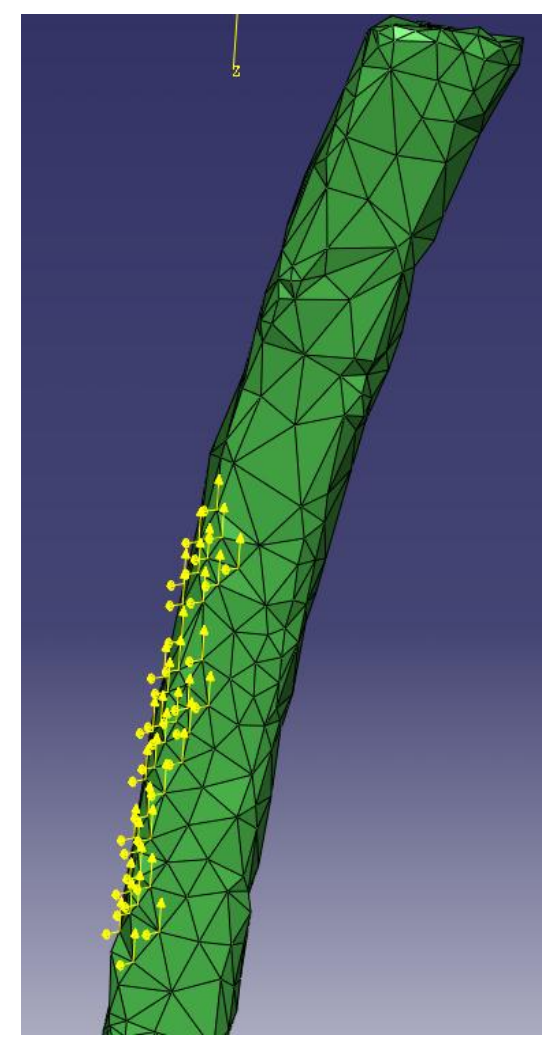

Figure 23 - Cranial Serratus Dorsalis

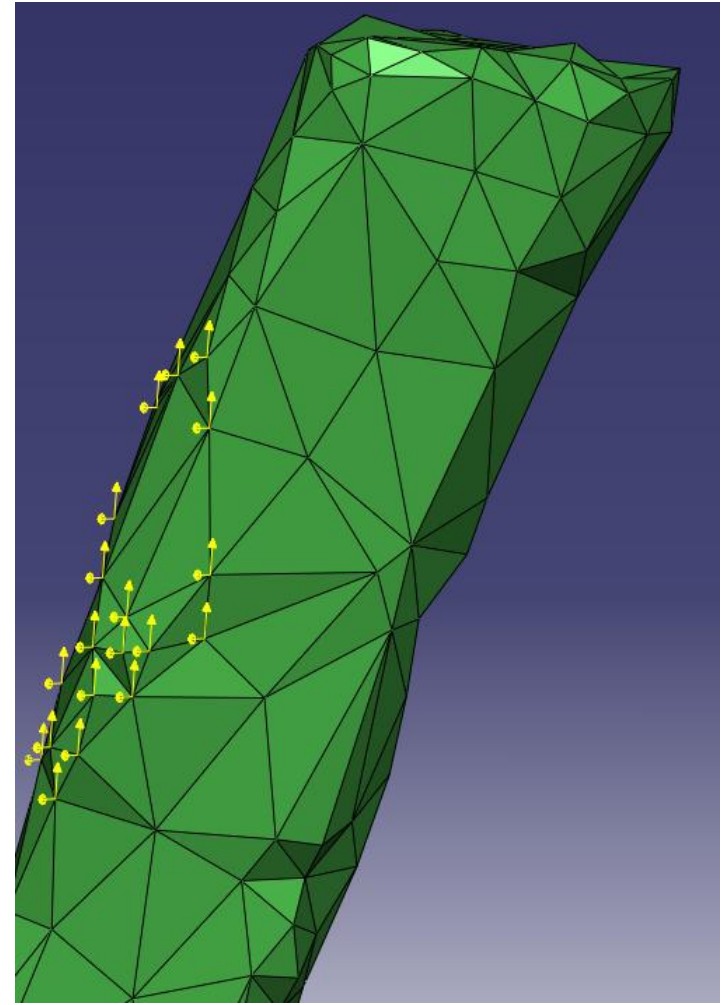

Figure 24 - Levatores Costarum 


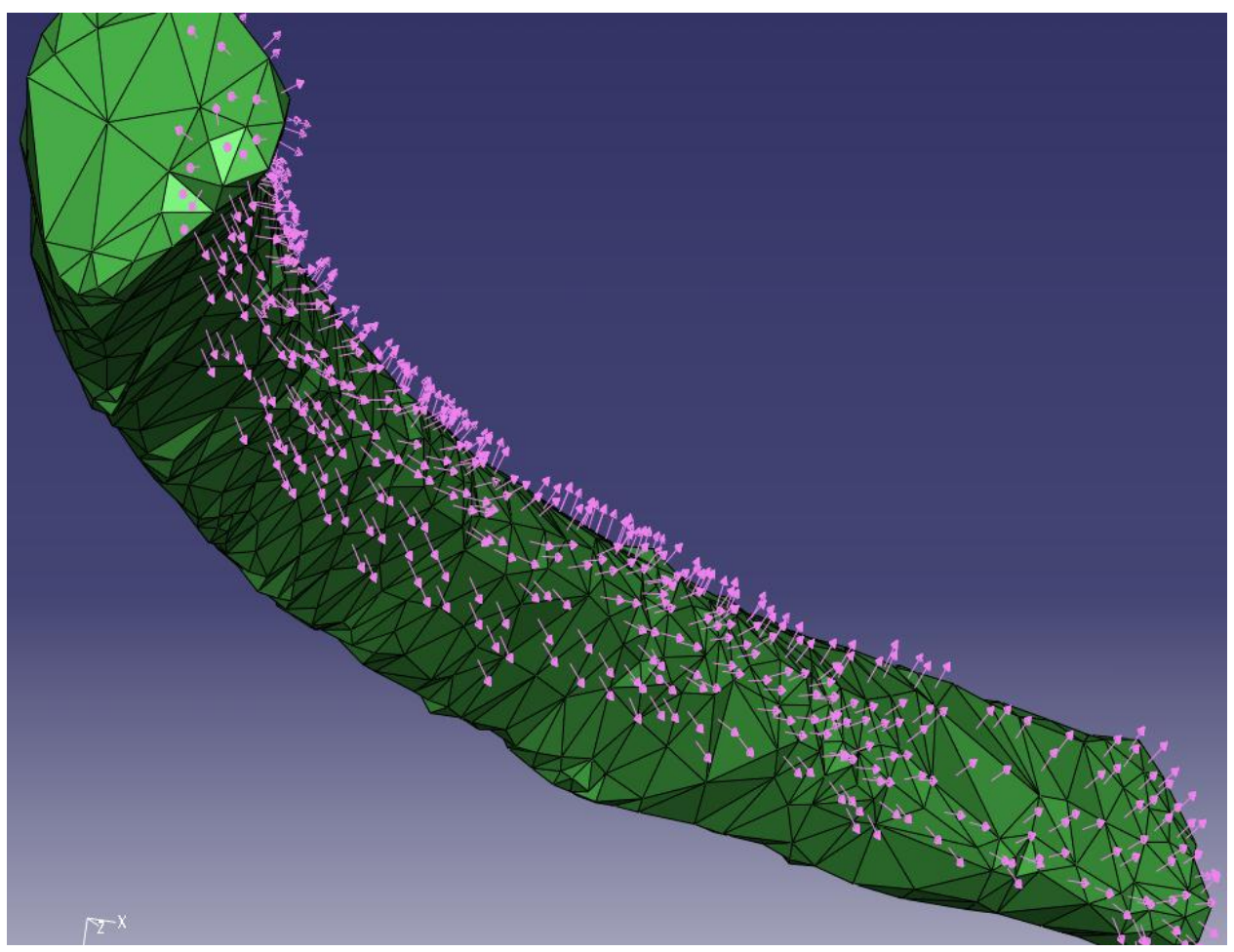

Figure 25 - Pleural Pressure (Applied to Medial Surfaces of Rib, Varies Based on Inspiration or Expiration, Pressure Applied Normal to Surface)

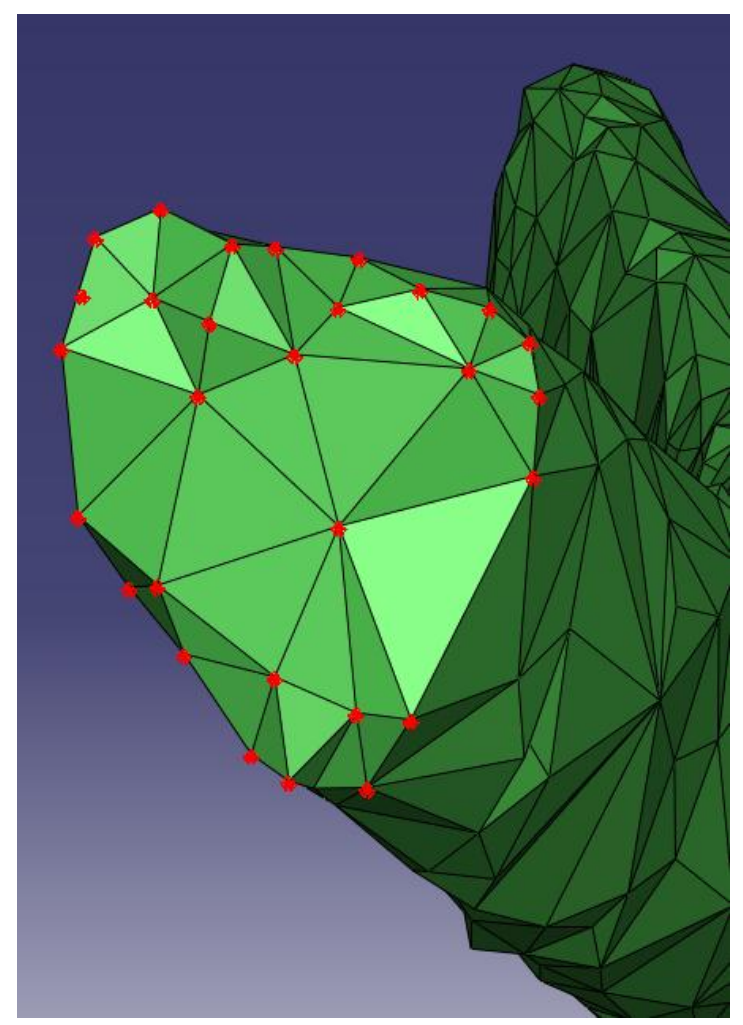

Figure 26 - Dorsal Boundary Conditions (FIXED) 


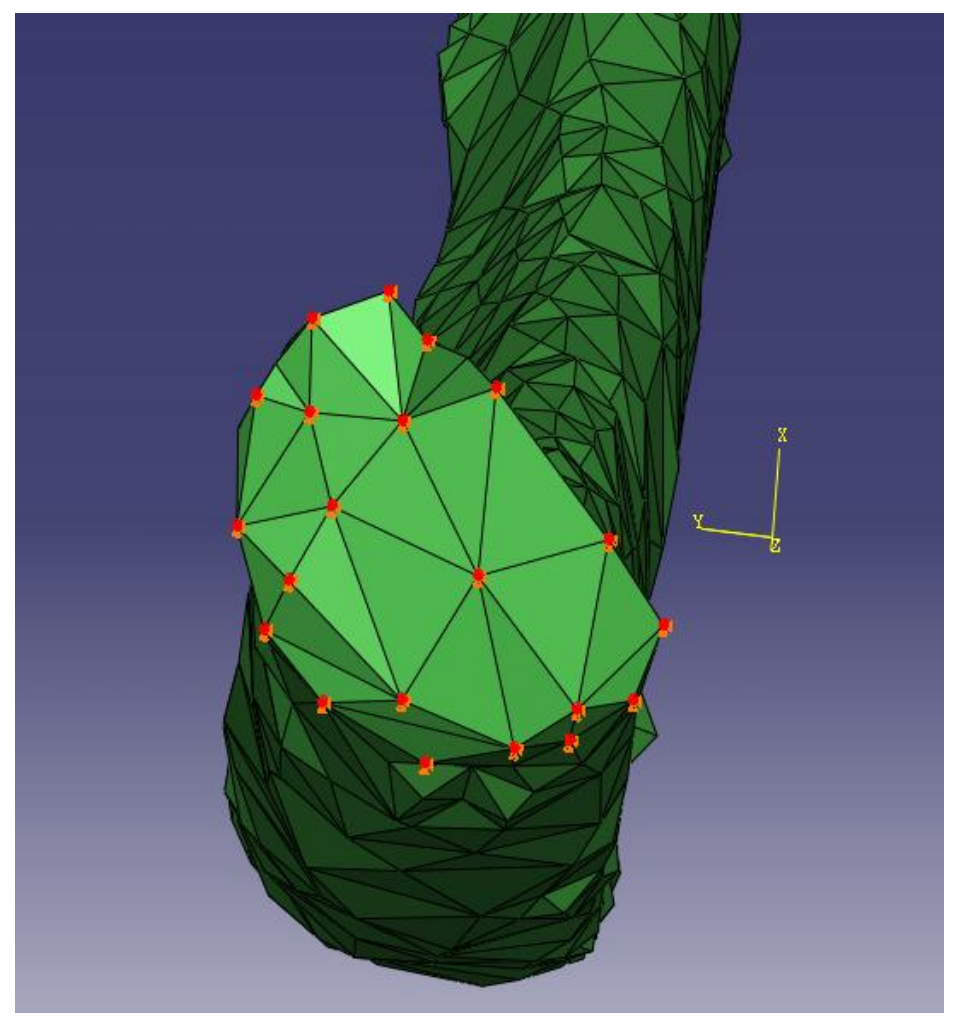

Figure 27 - Ventral Boundary Conditions (FIXED)

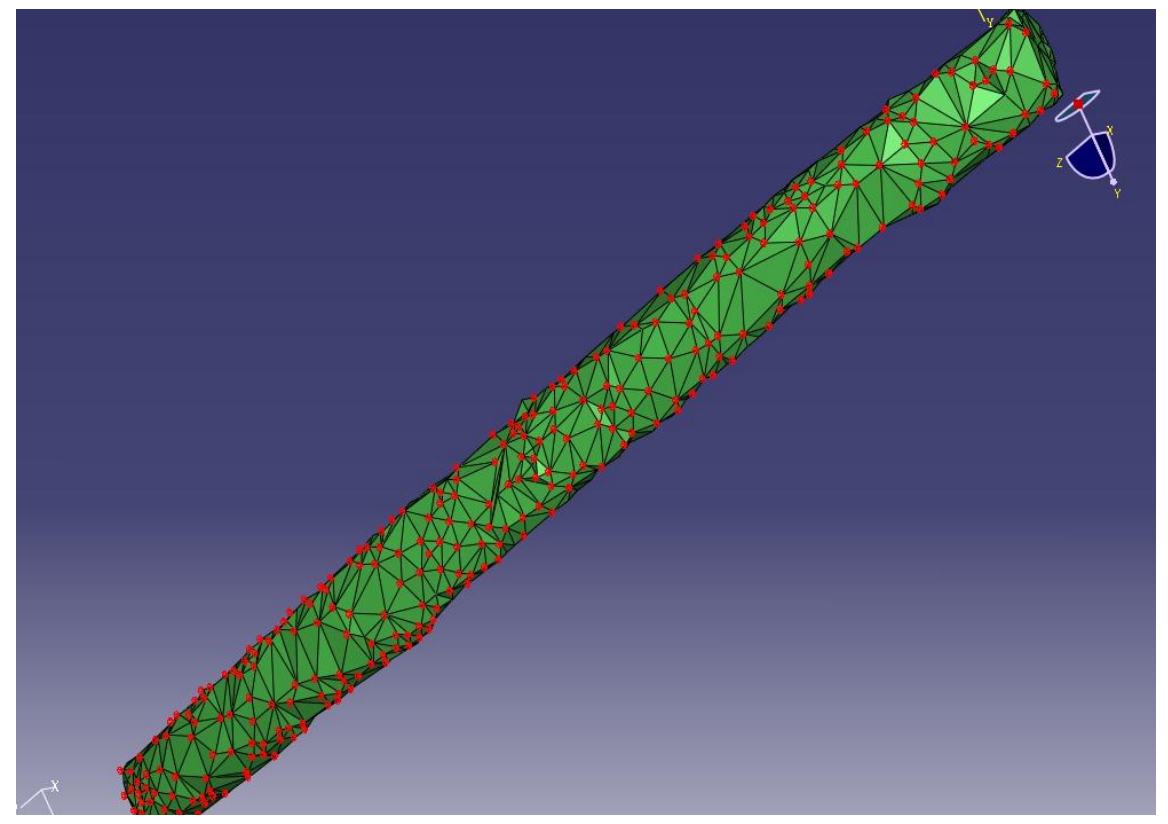

Figure 28 - Lateral Boundary Conditions (No Rotation or Displacement Allowed) 


\section{FEA Model Parameters}

Three separate load steps were created and utilized with a UMAT subroutine. The UMAT subroutine is a Fortran program developed by Dr. Hazelwood which utilizes the strains, generated by the loads and boundary conditions on the model, to predict the adaptation of the bone tissue to its mechanical environment after a specified number of days [15], (See Figure 29). The subroutine is called by an input file in Abaqus to generate these results. In the model, each loading condition represents a different phase in the respiration cycle.

Essentially, the model simulates changes in the mechanical properties and porosity of the bone tissue resulting from damage and disuse stimuli, which are determined from the strain state and loading conditions of the bone. Damage is estimated from strain and the number of loading cycles. Disuse exists when the stress stimulus is below a predefined equilibrium stimulus. The BMU activation frequency, a function of disuse and damage, is used to estimate the populations of refilling and resorbing bmu's, based on the resorption, reversal, and refilling time intervals of the BMU activation frequency history. Porosity values are calculated from the resorbing and refilling rates, and are used to calculate the resulting elastic modulus of the material.

An equilibrium mechanical stimulus is set based on the natural loading conditions and strain state of the bone tissue. Any stimulus above the equilibrium stimulus generates damage, and therefore, activates BMU's for repair. Any stimulus below the equilibrium generates a state of disuse, and BMU's are activated to remove tissue. The FEA model calculates the strain energy density, which is used to calculate the mechanical stimulus. The remodeling algorithm 
uses the resulting mechanical stimulus, to predict the remodeling response of the tissue. The remodeling response of the tissue changes the resulting porosity of the bone.

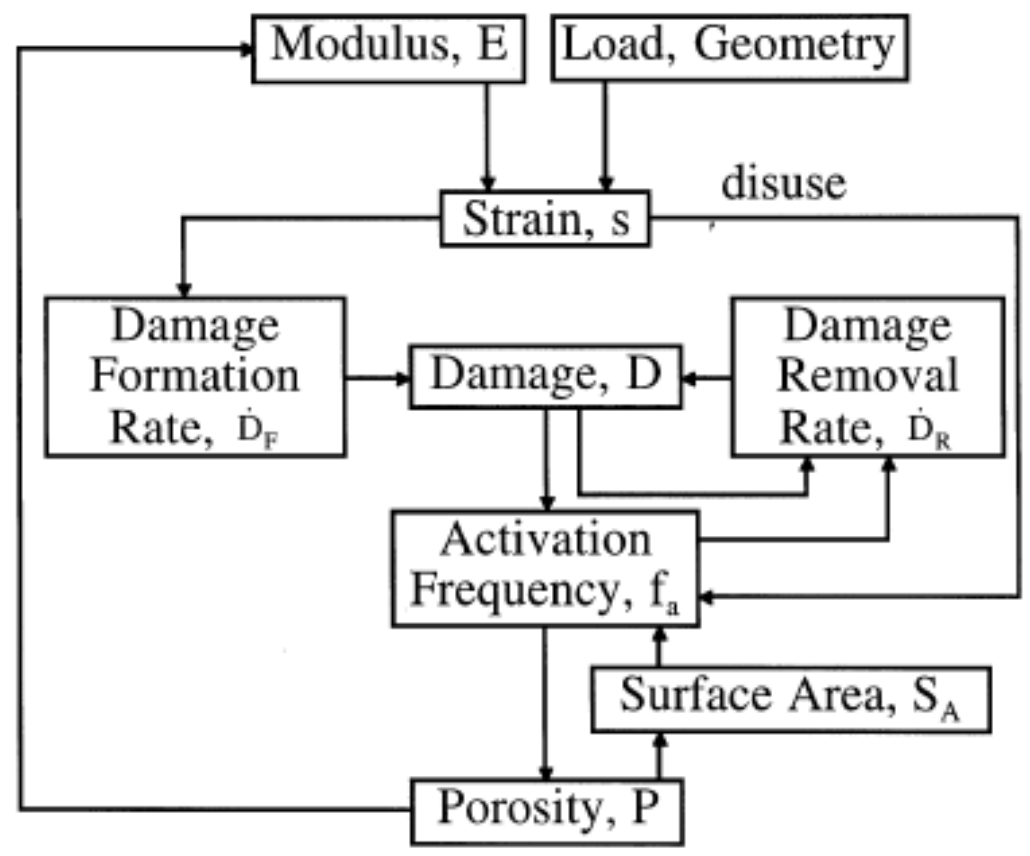

Figure 29 - UMAT Subroutine Flow Chart [10]

It was assumed that canines breathe at a rate of 15 breaths/minute [14], so the model assumed the load steps were applied for a total of 21600 breaths/day. The UMAT subroutine was run to simulate 400 days of breathing until a steady state condition was reached by the remodeling parameters. 


\section{Boundary Conditions}

Dorsal and Ventral Ends of Rib - FIXED (No Rotation, No Displacement)

Lateral Surface of Rib - (No Rotation, No Displacement)

Load Steps

1. Onset of Inspiration - Beginning of Inspiration Cycle

- External Intercostals - Cranial Surface

- External Intercostals - Caudal Surface

- Levatores Costarum

- Cranialis Serratus Dorsalis

- Pleural Pressure $(-2 \mathrm{cmH} 20)$

2. End of Inspiration - After Full Breath Has Been Taken

- External Intercostals - Cranial Surface

- External Intercostals - Caudal Surface

- Levatores Costarum

- Cranialis Serratus Dorsalis

- Pleural Pressure $(-4 \mathrm{cmH} 20)$

3. Onset of Expiration - Canine Begins to Exhale

- Internal Intercostals - Cranial Surface

- Internal Intercostals - Caudal Surface

- Pleural Pressure $(-4 \mathrm{cmH} 20)$

\section{Modification of UMAT Subroutine Parameters to Simulate Bone Adaptation for the Dog Rib}

The next step was to modify the UMAT subroutine to simulate adaptation of bone tissue for dog ribs, because the original subroutine provided was developed to simulate human bone 
tissue adaptation. Four parameters would have to be changed to more closely simulate dog rib bone tissue adaptation. They are as follows:

- Number of loading cycles - The original UMAT subroutine was written to model a human femur. Since the goal of the current model was of a dog rib and was used to simulate respiration, this value had to be changed to the number of breaths a dog takes per day.

- Remodeling Periods - The remodeling periods of dogs and humans are not the same. The remodeling periods for humans were determined from several histomorphometric studies [10]. The human remodeling periods were scaled down, to shorter periods for canines.

- For humans, the remodeling periods are:

- $\operatorname{Tr}($ resorption) $=24$ Days

- $\quad \mathrm{Ti}($ reversal) $=8$ Days

- $\operatorname{Tf}$ (filling) = 64 Days

O In this study, these periods were defined as:

- $\operatorname{Tr}($ resorption) $=10$ Days*

- $\mathrm{Ti}($ reversal) $=5$ Days*

- $\operatorname{Tf}($ filling $)=44$ Days $*$

*Various numbers for remodeling periods were picked and evaluated in separate models. The periods which created the model that most closely matched the natural bone porosity were utilized and are noted above. 
- Equilibrium Stimulus $\left(\phi_{0}\right)$ - The equilibrium stimulus is the set point for bone remodeling. Stresses/strains and loading cycles that produce a stimulus above or below this value activate remodeling to adapt bone to its mechanical environment. It was assumed that the values of equilibrium stimulus for humans and dogs are not the same. See the following section for the procedure of determining the equilibrium stimulus for the dog rib.

- Damage Coefficient $(\mathbf{K d})-A$ constant utilized in the subroutine which is calculated from the value of the equilibrium stimulus and other remodeling parameters from the dog rib.

\section{Determining the Equilibrium Stimulus}

The equilibrium stimulus and the damage coefficient for the dog rib are unknown and had to be estimated for this analysis. They were calculated by the following formulas:

(1) $\phi_{0}=\varepsilon^{4} * \mathrm{RL}[10]$

(2) $K_{d}=D_{0} * f_{a 0} * A * F_{s} / \phi_{0}[10]$

Where:

- $\mathbf{D}_{0}=.03660 \mathrm{~mm} / \mathrm{mm}^{2}$ (Initial Damage Rate Coefficient) [10]

- $\mathbf{f}_{\mathrm{a} 0}=.00670 \mathrm{BMUs} / \mathrm{mm}^{2} /$ day (Initial Activation Frequency) [10]

- $\mathbf{A}=.02840 \mathrm{~mm}^{2}[10]$

- $\mathbf{F}_{\mathrm{s}}=5$ (Damage Removal Specificity Factor) [10]

- $\varepsilon=$ Strain 
- $\quad \mathbf{R L}=$ Number of Loading Cycles

The strain values used in the determination of the equilibrium stimulus for the dog rib were predicted using a standard analysis in Abaqus with an assumed modulus of 17.4 Gpa [4]. The results predicted strain values between 72 and -72 microstrains.

Values with magnitudes between 0 and 72 microstrains were used to estimate the equilibrium stimulus and corresponding Kd value. These values were then used in the UMAT subroutine to generate models simulating the structure/porosity of the resulting rib bone tissue. The ideal result would be a structure that closely matches the natural bone tissue, which would indicate that the loading and boundary conditions, and model parameters are accurate. As stated in the introduction, bone generally has a higher porosity near the center (trabecular bone), surrounded by bone of lower porosity (lamellar bone). Over 30 simulations were run in Abaqus, each utilizing different equilibrium stimulus, corresponding Kd values, and remodeling periods, in an attempt to find a resulting model that closely match the predicted structure. Table 2 on the following page lists the ranges of values investigated, and figure 30, on the following page illustrates the some of the structures that were predicted utilizing this method. The model in the far left of the figure generated an inconsistent and sporadic porosity structure. The model in the center of the figure predicted a very high porosity throughout the entire bone. The final model (Appendix A) that most closely matched the actual structure of untreated bone, pictured in Figure 30 on the far right, utilized the following values:

- Strain Value - $27 \mu$ Strain

- Equilibrium Stimulus $-1.15 \times 10^{-14} \mathrm{cpd}$

- $\mathrm{Kd}-3.03 \times 10^{9} \mathrm{~mm} / \mathrm{mm}^{2}$ 
Table 2- Range of Remodeling Parameters Investigated

\begin{tabular}{ccc}
\hline Parameter & Min & Max \\
\hline Strain $(\boldsymbol{\mu \varepsilon})$ & 0 & 72 \\
\hline Equilibrium Stimulus (cpd) & 0 & $5.80 \mathrm{E}-13$ \\
\hline $\mathbf{k d}\left(\mathbf{m m} / \mathbf{m m}^{2}\right)$ & 0 & $6.00 \mathrm{E}+07$ \\
\hline
\end{tabular}
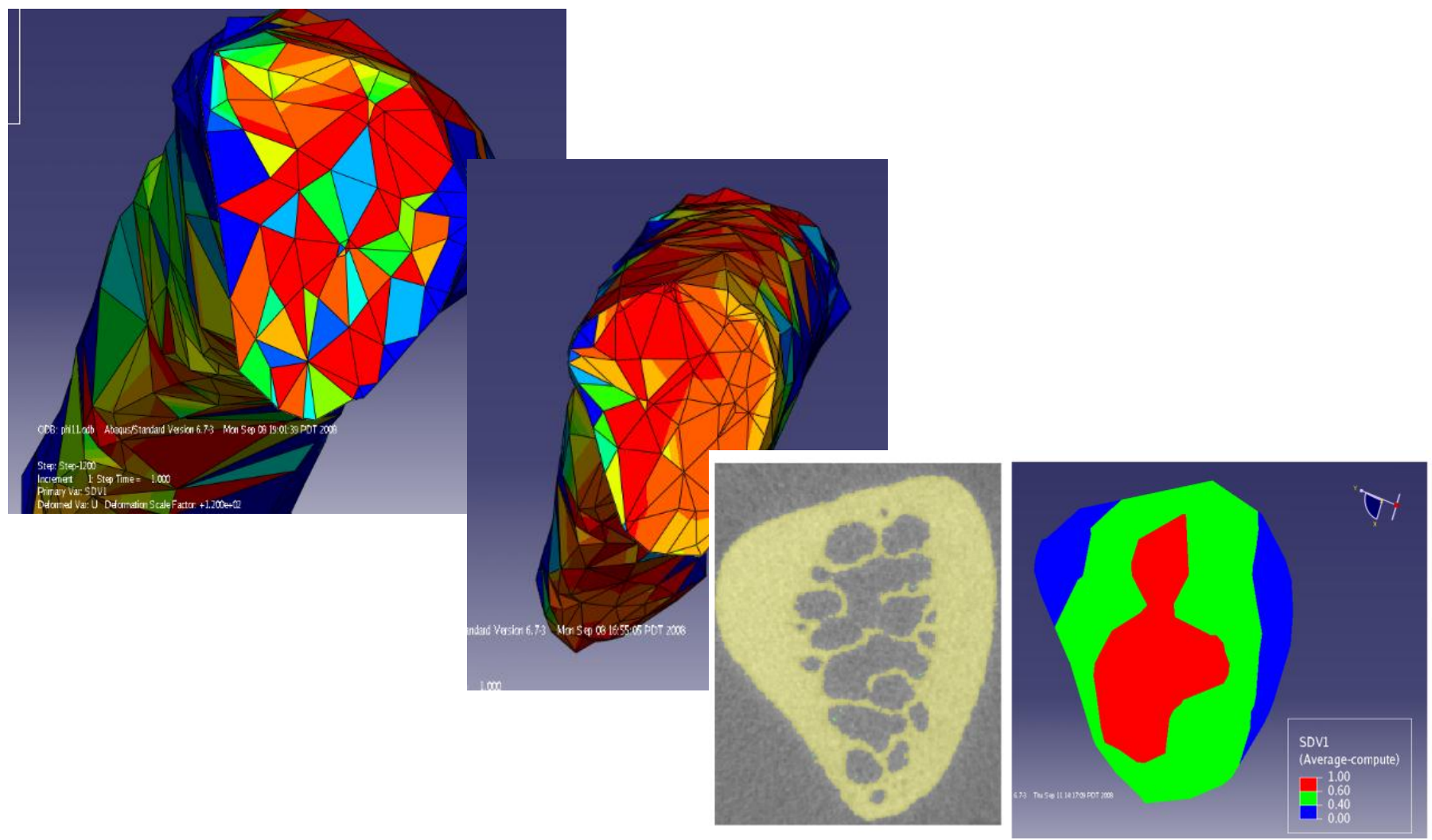

Figure 30 - Remodeling Parameters Effects on Predicted Bone Structure 


\section{Validation of model by comparing to CT scan results}

In order to validate the model, the porosity values predicted by the simulation were compared to the density/porosity values computed from the CT scan. This involved calculating porosity values from grayscale values in Mimics for cross sections of bone at seven different locations (Figure 31), and comparing those values to porosities predicted by Abaqus at the same locations. Each cross section was divided into four equal quadrants, and each section was compared on a quadrant by quadrant basis. It was decided to compare porosity values of the cortical regions of bone tissue in each quadrant to simplify the validation. The quadrants were divided about the centerline of each cross section in the manner illustrated in Figure 32.

Quadrants 1 and 4 lay on the lateral portion of the bone, and quadrants 1 and 2 lie cranial to the rib.

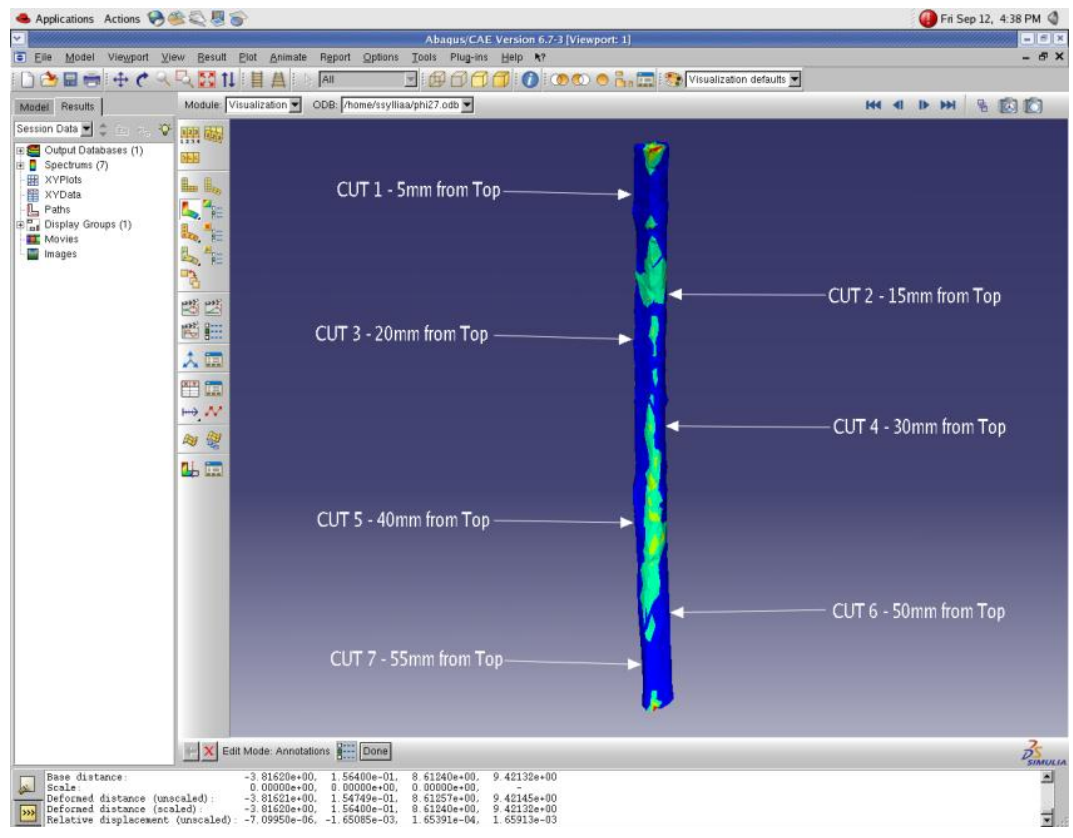

Figure 31 - Locations of Cross Sections for Comparison of Predicted Porosities to Actual 


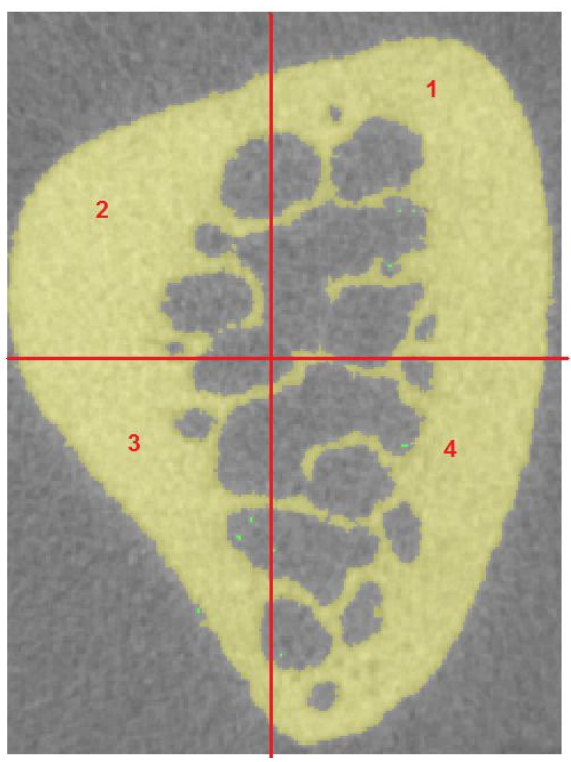

Figure 32 - Identification of Quadrants

\section{Obtaining Density/Porosity from Mimics}

The grayscale values reported from Mimics were converted to apparent density by the following relationship:

\section{(3) $\rho_{\text {app }}=.001 * H U[15]$}

Where the grayscale value is measured in Hounsfield Units and $\boldsymbol{\rho}_{\text {app }}$ is measured in $\mathrm{g} / \mathrm{cm}^{3}$. The grayscale values are reported as the "mean" in Figure 29 on the following page.

These values were then converted into porosity using the relationship:

(4) $\left(\rho_{\text {app }}-\rho_{m}\right) /\left(\rho_{v}-\rho_{m}-\right)=P_{v}[4]$ 
where $\boldsymbol{\rho}_{\mathrm{m}}$ is the density of the bone tissue, $\boldsymbol{\rho}_{\mathrm{v}}$ is the density of the voids or soft tissue, and $\mathbf{P}_{\mathrm{v}}$ is the porosity.

During the validation procedure, values of $\rho_{v}=0 \mathrm{~g} / \mathrm{cm}^{3}$ and $\rho_{m}=2 \mathrm{~g} / \mathrm{cm}^{3}$ were used to calculate the porosity of the bone tissue. The use of each of these values is discussed in the results and discussion sections of this report. Three porosity values per quadrant were averaged to produce the average porosity per quadrant for each cross section (See Figure 33). 


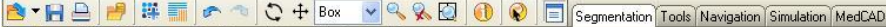

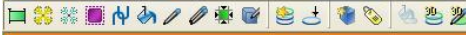

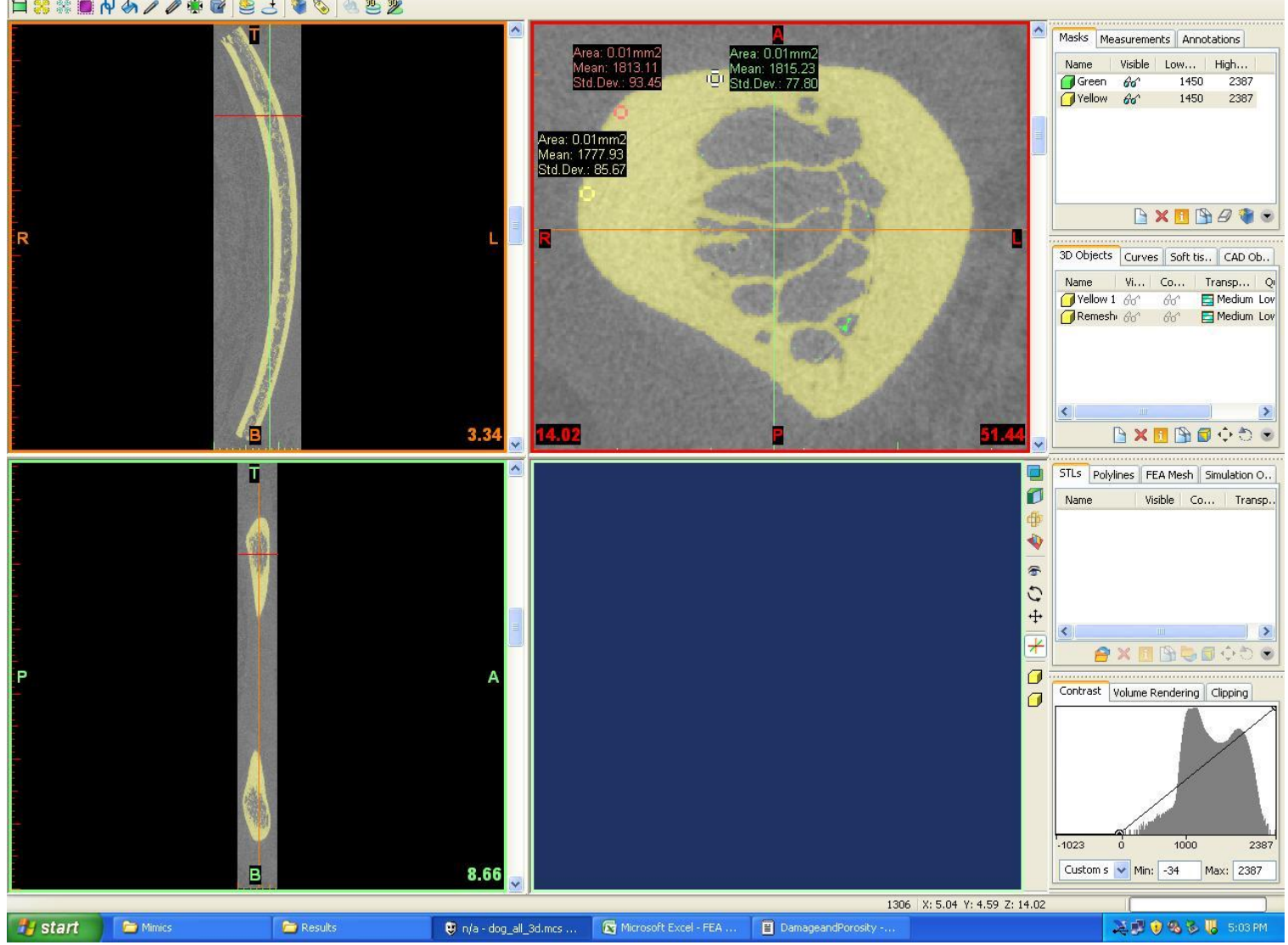

Figure 33 - Mimics Interface, Grayscale Values Listed as "Mean". Three locations where grayscale measured highlighted in Yellow, Red and Purple. 


\section{Obtaining Porosity Values from Abaqus}

Porosity values at three nodes per quadrant were identified in Abaqus using the view cut manager to view each cross section (See Figure 34). The locations/heights of the quadrants were identical to the locations in the Mimics model, and the nodes were taken from the same general area as the points measured in Mimics. An average value for each quadrant for each cross section was determined.

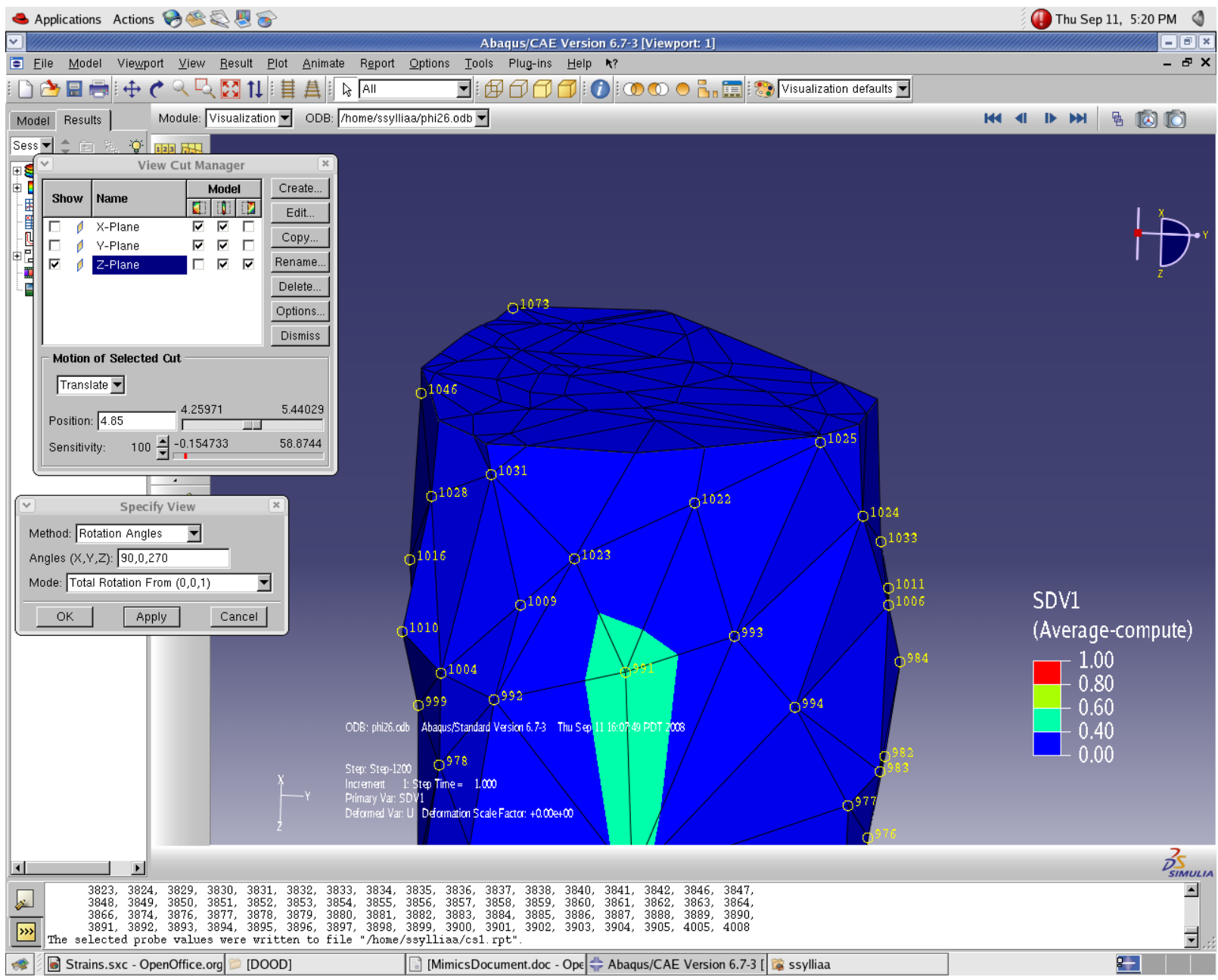

Figure 34 - Cross Sectional Porosity Analysis of FEA Model 


\section{Statistical Analysis}

The predicted tissue structure determined by the model was compared qualitatively (visual inspection) and quantitatively (comparison of porosity values). Cross-sections of the model were examined visually and compared to cross-sections taken from identical locations of the actual rib CT data. The goal was for the model to have higher porosities towards the interior of the rib, matching what is observed in dog ribs. To compare the model quantitatively, the porosities obtained from specific quadrants of the model were compared to the porosities obtained from the actual rib in the same locations, using a T-test, assuming $95 \%$ confidence, to indicate if a statistically significant difference existed. 


\section{Results}

\section{Visual Comparison of Model and Tissue Sample}

Figure 35 depicts a longitudinal view of the rib model generated by performing the analysis using the methods in the previous section. On a cross-section by cross-section basis, the model predicted fairly well the structure of the bone. Figures 33 and 34 illustrate the structure of bone tissue obtained from the rib sample side by side with the structures predicted by the FEA model.

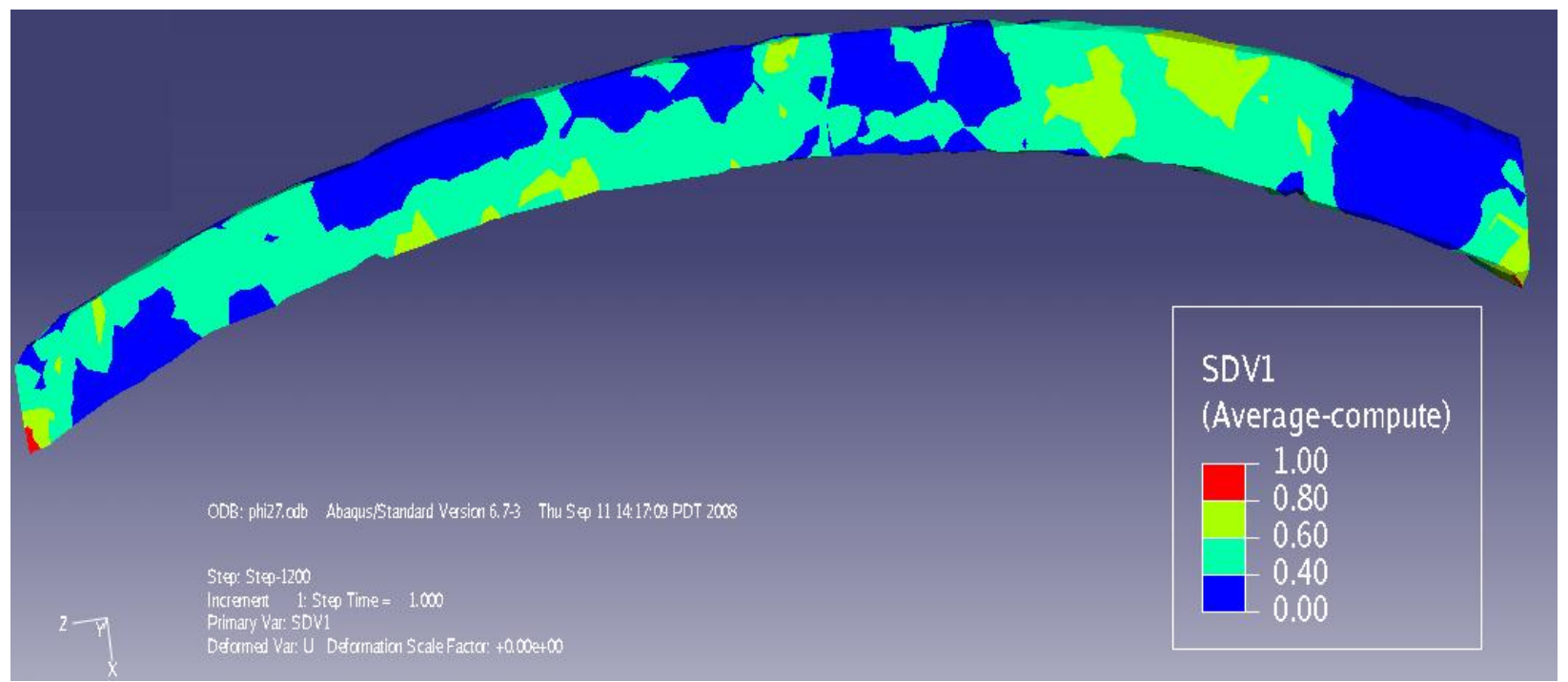

Figure 35 - Longitudinal Cross Section of Abaqus Model (SDV1 = Porosity \%) 
Figures 36 and 37 are images of horizontal cross sections taken from the FEM side by side with CT data taken from the same location. The FEM predicts a high porosity around the center of the rib, which can be seen in the cross section of the actual tissue and is consistent with the structure of a typical medullary cavity. The thickness of the cortical bone surrounding the center of the rib appears to be fairly consistent with that of the actual tissue as well.
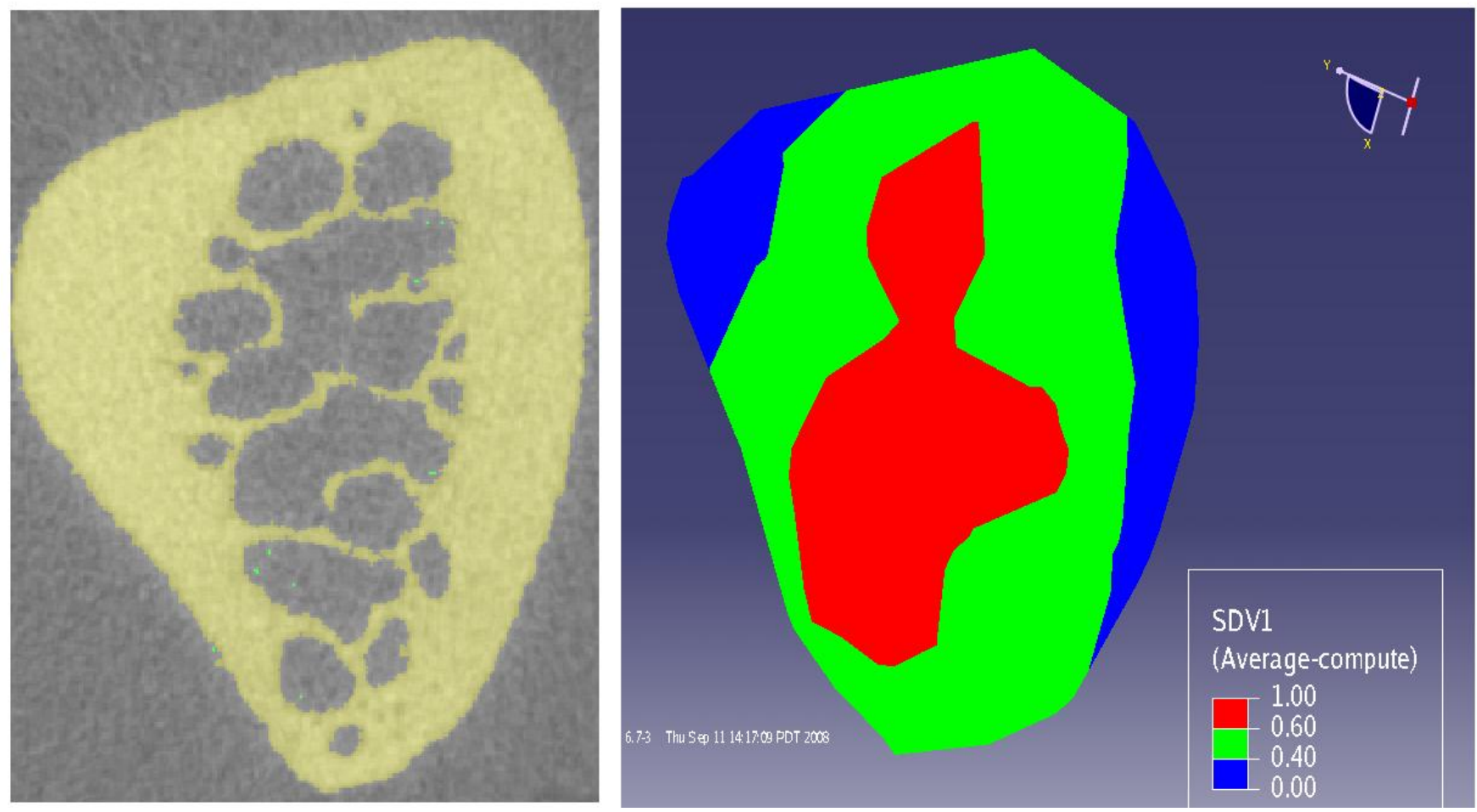

Figure 36 - Horizontal Cross Section (Mimics Left, Abaqus Right, SDV1 = Porosity \%) 


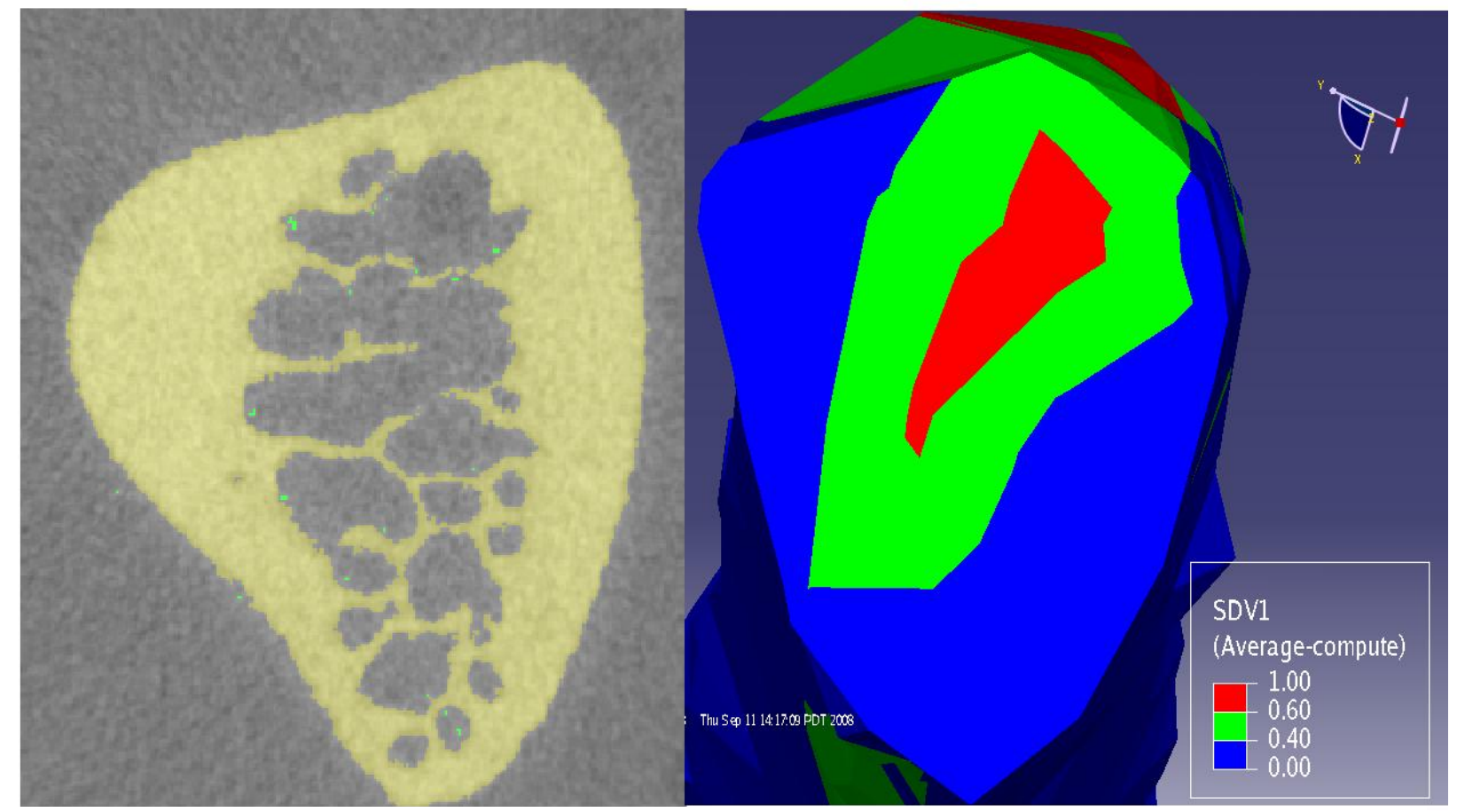

Figure 37 - Horizontal Cross Section (Mimics Left, Abaqus Right, SDV1 = Porosity \%)

\section{Quantitative Comparison of Model and Tissue Sample}

As stated in the methods section, the porosity values predicted by the FEA model were compared to the porosities computed from the grayscale values obtained from Mimics. Seven cross section locations of each set were compared on a quadrant by quadrant basis. Statistical analysis suggests that the model predicted the porosity of the resulting bone tissue relatively well. There were no statistically significant differences between the majority of quadrants, 25 of 28 , and cross-sections, 5 of 7. 
The model predicted the tissue densities exceptionally well, \% Differences $<20 \%$, in the following regions:

Table 3 - Regions where Model Predicted Tissue Densities Exceptionally Well (\% Diff < 20\%)

\begin{tabular}{ccc}
\hline Cross Section & Distance From Dorsal End $(\mathbf{m m})$ & Quadrant(s) \\
\hline $\mathbf{1}$ & 5 & $1,3,4$ \\
$\mathbf{2}$ & 15 & 2 \\
$\mathbf{3}$ & 20 & 1,4 \\
$\mathbf{4}$ & 30 & $1,2,4$ \\
$\mathbf{5}$ & 40 & 1,2 \\
$\mathbf{6}$ & 50 & 4 \\
$\mathbf{7}$ & 55 & $1,2,4$ \\
\hline
\end{tabular}

Statistically significant differences between the model results and the CT scan results existed in a few sections. In cross-section 5, quadrant 4, the predicted porosity from the model was $0.515 \pm 0.099$ and the value obtained from Mimics was $0.184 \pm 0.045$. Similarly in cross section 6 , quadrant 2 , the FEA model predicted a porosity of $0.463 \pm 0.104$ and the value obtained from Mimics was $0.153 \pm 0.037$; these values create a percent difference of about $200 \%$, but these values are still within reasonable limits given that porosity values in other cross-section quadrants were statistically similar. Tables 4 and 5 on the following pages summarize the results of these comparisons. 
Figure 38 was generated by averaging the predicted and actual porosities for each cross section, and plotting the difference vs. the location of the cross section. It illustrates that the model consistently predicted porosities that were higher than existed in the actual tissue in the same location. The model did very well in predicting the porosity of the tissue between 20 and $30 \mathrm{~mm}$ away from the dorsal end of the rib, and had differences exceeding $50 \%$ throughout the rest of the tissue. The model had the most error at a location $15 \mathrm{~mm}$ from the dorsal end, with an average $\%$ difference of $115 \%$.

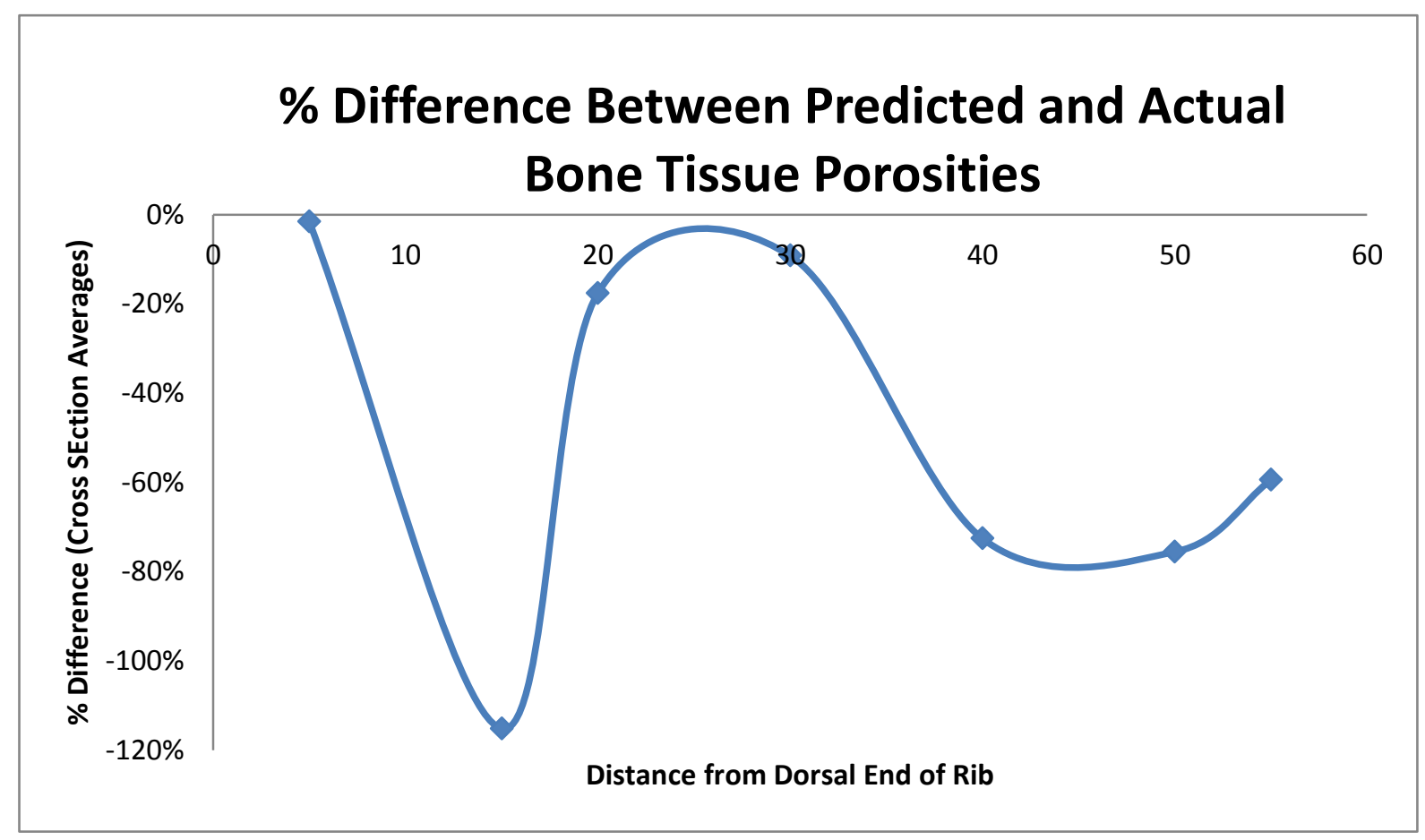

Figure 38 - Comparison of Predicted and Actual Porosities Based on Location on Rib 
Figure 39 below illustrates how well the model predicted porosities for each quadrant. The percentages represented in the figure were generated by taking the average $\%$ difference for each quadrant, across all of the cross sections. It is apparent that the model struggled predicting accurate porosities in the third quadrant, caudal-medially, and performed better in all other quadrants.

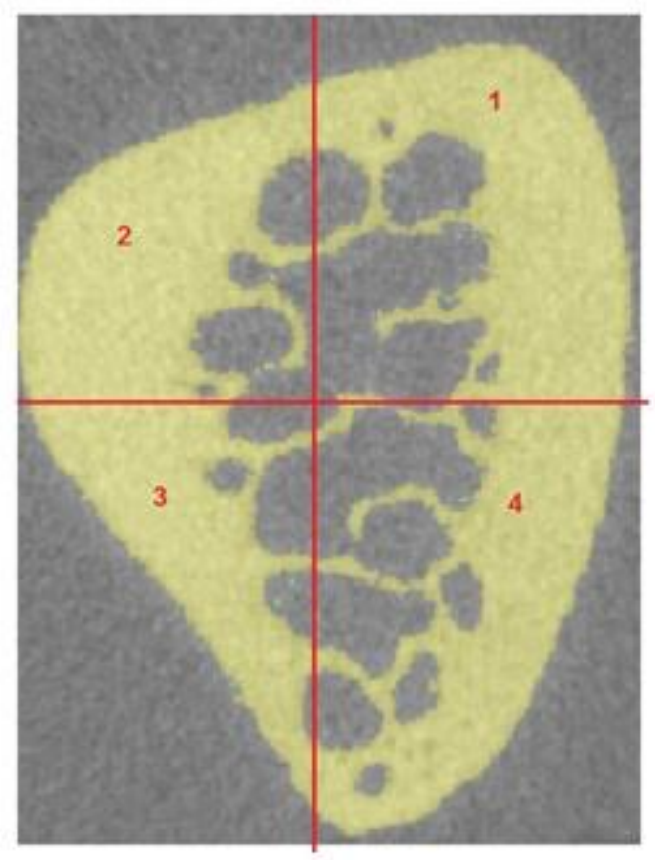

$-37.82 \%$

$-79.66 \%$

$-42.37 \%$

Figure 39 - \% Differences for Porosity Values by Quadrant 
Table 4 - Summary of Quadrant Based Porosity Comparisons of Bone Tissue Porosities (Cortical Only)

\begin{tabular}{|c|c|c|c|c|c|c|c|c|}
\hline \multicolumn{3}{|c|}{ Location } & \multicolumn{2}{|c|}{ FEA Porosities } & \multicolumn{2}{|c|}{$\begin{array}{c}\text { Mimics } \\
\text { Porosities }\end{array}$} & \multirow[t]{2}{*}{$\begin{array}{l}\text { T-Test Results } \\
\text { (95\% Confidence) }\end{array}$} & \multirow{2}{*}{$\begin{array}{c}\% \\
\text { Difference }\end{array}$} \\
\hline $\begin{array}{c}\text { Cross } \\
\text { Section } \\
\#\end{array}$ & $\begin{array}{l}\text { Distance } \\
\text { from } \\
\text { Dorsal } \\
\text { End } \\
\text { (mm) }\end{array}$ & Quadrant & $\begin{array}{l}\text { Avg. } \\
\text { Porosity }\end{array}$ & $\begin{array}{c}\text { Std } \\
\text { Deviation }\end{array}$ & $\begin{array}{l}\text { Avg. } \\
\text { Porosity }\end{array}$ & $\begin{array}{c}\text { Std } \\
\text { Deviation }\end{array}$ & & \\
\hline \multirow{4}{*}{1} & \multirow{4}{*}{$5 \mathrm{~mm}$} & 1 & 0.141 & 0.026 & 0.153 & 0.012 & 0.526 & $8.07 \%$ \\
\hline & & 2 & 0.161 & 0.057 & 0.13 & 0.027 & 0.487 & $-23.50 \%$ \\
\hline & & 3 & 0.137 & 0.037 & 0.128 & 0.007 & 0.723 & $-6.96 \%$ \\
\hline & & 4 & 0.16 & 0.043 & 0.178 & 0.06 & 0.705 & $10.01 \%$ \\
\hline \multirow{4}{*}{2} & \multirow{4}{*}{$15 \mathrm{~mm}$} & 1 & 0.488 & 0.209 & 0.154 & 0.01 & 0.109 & $-216.62 \%$ \\
\hline & & 2 & 0.182 & 0.114 & 0.157 & 0.051 & 0.763 & $-15.80 \%$ \\
\hline & & 3 & 0.322 & 0.122 & 0.143 & 0.04 & 0.138 & $-124.71 \%$ \\
\hline & & 4 & 0.323 & 0.115 & 0.157 & 0.041 & 0.142 & $-106.43 \%$ \\
\hline \multirow{4}{*}{3} & \multirow{4}{*}{$20 \mathrm{~mm}$} & 1 & 0.183 & 0.055 & 0.175 & 0.017 & 0.833 & $-4.54 \%$ \\
\hline & & 2 & 0.215 & 0.127 & 0.132 & 0.05 & 0.404 & $-62.68 \%$ \\
\hline & & 3 & 0.23 & 0.155 & 0.172 & 0.058 & 0.605 & $-33.74 \%$ \\
\hline & & 4 & 0.138 & 0.069 & 0.172 & 0.042 & 0.515 & $19.84 \%$ \\
\hline \multirow{4}{*}{4} & \multirow{4}{*}{$30 \mathrm{~mm}$} & 1 & 0.193 & 0.06 & 0.18 & 0.003 & 0.738 & $-7.40 \%$ \\
\hline & & 2 & 0.189 & 0.08 & 0.173 & 0.057 & 0.798 & $-9.18 \%$ \\
\hline & & 3 & 0.213 & 0.031 & 0.171 & 0.014 & 0.165 & $-24.32 \%$ \\
\hline & & 4 & 0.184 & 0.109 & 0.189 & 0.034 & 0.945 & $2.74 \%$ \\
\hline
\end{tabular}


Table 4 Cont. - Summary of Quadrant Based Porosity Comparisons of Bone Tissue Porosities (Cortical Only)

\begin{tabular}{|c|c|c|c|c|c|c|c|c|}
\hline \multicolumn{3}{|c|}{ Location } & \multicolumn{2}{|c|}{ FEA Porosities } & \multicolumn{2}{|c|}{ Mimics Porosities } & $\begin{array}{l}\text { T-Test Results } \\
\text { (95\% Confidence) }\end{array}$ & \multirow{2}{*}{$\begin{array}{c}\% \\
\text { Difference }\end{array}$} \\
\hline $\begin{array}{c}\text { Cross } \\
\text { Section } \\
\#\end{array}$ & $\begin{array}{l}\text { Distance } \\
\text { from } \\
\text { Dorsal } \\
\text { End (mm) }\end{array}$ & Quadrant & $\begin{array}{l}\text { Avg. } \\
\text { Porosity }\end{array}$ & $\begin{array}{c}\text { Std } \\
\text { Deviation }\end{array}$ & $\begin{array}{l}\text { Avg. } \\
\text { Porosity }\end{array}$ & $\begin{array}{c}\text { Std } \\
\text { Deviation }\end{array}$ & P Value & \\
\hline \multirow{4}{*}{5} & \multirow{4}{*}{$40 \mathrm{~mm}$} & 1 & 0.131 & 0.135 & 0.134 & 0.004 & 0.974 & $2.13 \%$ \\
\hline & & 2 & 0.077 & 0.045 & 0.089 & 0.007 & 0.695 & $13.43 \%$ \\
\hline & & 3 & 0.266 & 0.12 & 0.167 & 0.03 & 0.297 & $-59.79 \%$ \\
\hline & & $4^{*}$ & 0.516 & 0.099 & 0.184 & 0.045 & 0.034 & $-179.98 \%$ \\
\hline \multirow{4}{*}{6} & \multirow{4}{*}{$50 \mathrm{~mm}$} & 1 & 0.292 & 0.039 & 0.194 & 0.012 & 0.052 & $-50.41 \%$ \\
\hline & & $2^{*}$ & 0.463 & 0.104 & 0.153 & 0.037 & 0.039 & $-203.02 \%$ \\
\hline & & $3 *$ & 0.217 & 0.144 & 0.144 & 0.021 & 0.0476 & $-50.68 \%$ \\
\hline & & 4 & 0.148 & 0.076 & 0.147 & 0.005 & 0.983 & $-0.74 \%$ \\
\hline \multirow{4}{*}{7} & \multirow{4}{*}{$55 \mathrm{~mm}$} & 1 & 0.147 & 0.101 & 0.153 & 0.009 & 0.925 & $4.05 \%$ \\
\hline & & 2 & 0.142 & 0.044 & 0.15 & 0.009 & 0.783 & $5.42 \%$ \\
\hline & & 3 & 0.516 & 0.257 & 0.144 & 0.027 & 0.131 & $-257.40 \%$ \\
\hline & & 4 & 0.117 & 0.034 & 0.131 & 0.003 & 0.568 & $10.36 \%$ \\
\hline
\end{tabular}

*Statistically significant difference exists. 
Table 5 - Summary of Cross-Section Based Porosity Comparisons of Bone Tissue Porosities

\begin{tabular}{|c|c|c|c|c|c|c|c|}
\hline \multicolumn{2}{|c|}{ Location } & \multicolumn{2}{|c|}{ FEA Porosities } & \multicolumn{2}{|c|}{$\begin{array}{c}\text { Mimics } \\
\text { Porosities }\end{array}$} & \multirow{2}{*}{$\begin{array}{c}\begin{array}{c}\text { T-Test } \\
\text { Results }\end{array} \\
\text { P Value }\end{array}$} & \multirow{2}{*}{$\begin{array}{c}\% \\
\text { Difference }\end{array}$} \\
\hline $\begin{array}{c}\text { Cross } \\
\text { Section } \\
\#\end{array}$ & $\begin{array}{c}\text { Position } \\
\text { (from } \\
\text { Top) }\end{array}$ & $\begin{array}{c}\text { Avg } \\
\text { Porosity }\end{array}$ & $\begin{array}{c}\text { Std } \\
\text { Deviation }\end{array}$ & $\begin{array}{c}\text { Avg } \\
\text { Porosity }\end{array}$ & $\begin{array}{c}\text { Std } \\
\text { Deviation }\end{array}$ & & \\
\hline 1 & $5 \mathrm{~mm}$ & 0.150 & 0.013 & 0.147 & 0.036 & 0.878 & $-1.58 \%$ \\
\hline $2^{*}$ & $15 \mathrm{~mm}$ & 0.329 & 0.046 & 0.153 & 0.034 & 0.004 & $-115.15 \%$ \\
\hline 3 & $20 \mathrm{~mm}$ & 0.191 & 0.047 & 0.163 & 0.042 & 0.377 & $-17.60 \%$ \\
\hline 4 & $30 \mathrm{~mm}$ & 0.194 & 0.033 & 0.178 & 0.030 & 0.442 & $-9.20 \%$ \\
\hline 5 & $40 \mathrm{~mm}$ & 0.248 & 0.039 & 0.144 & 0.044 & 0.102 & $-72.57 \%$ \\
\hline $6^{*}$ & $50 \mathrm{~mm}$ & 0.280 & 0.044 & 0.160 & 0.028 & 0.018 & $-75.53 \%$ \\
\hline 7 & $55 \mathrm{~mm}$ & 0.230 & 0.103 & 0.145 & 0.016 & 0.186 & $-59.42 \%$ \\
\hline
\end{tabular}




\section{Discussion}

The goal of this study was to create and validate a finite element model of the $10^{\text {th }}$ beagle rib, under normal and untreated loading conditions. Anatomy textbooks and related literature were reviewed to determine the loads and boundary conditions applied to the rib during respiration. These loads and boundary conditions were applied to a finite element model, with an integrated bone remodeling algorithm, to estimate the structure of the bone. The structure/histology that was estimated by the model developed in this research was comparable to that of an actual canine rib specimen, which indicates that the goal of this thesis was completed.

Visually, the model predicted the structure of the bone tissue fairly well as illustrated by Figure 33. The model predicts a porous interior, representative of trabecular bone with a much less porous exterior, representing lamellar bone. Comparing a cross section of the model, to a cross section taken from a CT scan of the exact same area reveals that the model also matched the actual tissue sample quite well.

Comparing the porosity values generated by the model with the actual porosity determined from the CT scans revealed that the model also predicted the porosity values fairly well. In most cases, the model predicted porosities that were not statistically significantly different from the actual tissue sample porosities. In two regions, approximately 10-15 mm from the dorsal and ventral end of the rib, the model predicted porosities that were statistically 
significantly different from the actual tissue data, indicating that the model was not accurate at these locations.

The model seemed to consistently overestimate the porosities of the tissue throughout the length of the bone, with \% differences ranging from $-2 \%$ to $-115 \%$ (negative implies the model overestimated the porosity values). These errors are likely due to the limitations and assumptions made to generate this model.

\section{Model Limitations}

\section{Loading/Boundary Conditions}

The locations where the model struggled in accuracy are the areas approximately 10$15 \mathrm{~mm}$ away from the points where the rib was fixed. At these locations, the model predicted porosities that were significantly higher than the porosities obtained from the Mimics analyses. These higher porosity values indicate that the interactions between the loads and boundary conditions did not create enough stress in those areas to prevent the bone tissue from being remodeled away (increasing porosity). Although there were high differences between the predicted and actual porosity values in these areas, statistically significant differences were only observed close to the ventral portion of the rib model. This indicates that there is a higher level of error in the ventral portion of the model than the dorsal. A likely cause of the error in the ventral portion of the model is that in creating this model, the actions of the abdominal muscles, the external and internal obliques, and rectus abdominis, were ignored. These muscles aid in an action called abdominal press, which aids in such vital functions as expiration, 
urination, and defecation. It was assumed that the actions of these muscles during respiration were negligible, but the results of these analyses indicate that they may play a bigger part in respiration than originally thought. The model could be improved by investigating and incorporating the stresses that are generated by the abdominal muscles during expiration.

Additionally, respiration was the primary activity of interest in this research. Certainly the muscles that line the thorax are utilized in many different activities, in addition to respiration. This research did not take into account the action of those muscle groups during walking, running, eating, etc. A more detailed and accurate model would include more than just one activity, and therefore many more loading conditions.

Another factor that inhibits the accuracy of the model is that the boundary conditions applied to the model were generalizations of the complex boundary interactions that exist in the dog rib cage. The movement of the dorsal portion of the rib is limited by complex geometries and interactions between the rib and the vertebrae, along with many tendons and muscles which hold the rib in place. On the other end, the rib attaches to cartilage, which extends towards the sternum through the abdominal muscles, creating another complex set of boundary interactions.

The simplifications of these conditions lead to an inaccurate strain environment for the portions of the rib closest to the ends where the boundary conditions were applied. This explains the high error and level of statistically significant differences between the model and the actual data. Further research might be done to determine the more specific interactions between the bone, muscle, tendon, and other tissue, to create more accurate and complex 
boundary conditions to be applied to the model. This would result in a more accurate strain environment for the extreme portions of the bone, leading to better models.

\section{Remodeling Algorithm}

As stated previously, the UMAT subroutine used to simulate the adaptation of the rib bone tissue was originally developed to simulate human bone tissue adaptation. More specifically, the original program was developed for a human femur. Four parameters from this subroutine were modified to transform the program into something suitable for dog bone. The four parameters which were changed were:

- Number of Loading Cycles

- Remodeling Periods/Rates

- Equilibrium Stimulus

- $\mathrm{Kd}-\mathrm{A}$ constant

As stated previously, the equilibrium stimulus was calculated from the product of the principle strain and the number of loading cycles per day. Since this research was focused on respiration as the primary contributor to stresses on the $10^{\text {th }}$ rib, the equilibrium stimulus was calculated from the number of breaths a dog may take a day. Certainly other activities would change both the principle strain and number of loading cycles. This estimation of the equilibrium stimulus based on respiration alone may generate a model which is stressed much less than in actual life, and therefore result in the model predicting a higher porosity. 
For this study, the principle strain was estimated by loading the dog rib with each of the three respiratory loading conditions, and boundary conditions, and performing a standard analysis in Abaqus; this analysis provided a range of strain values. An equilibrium stimulus and Kd were generated for a broad spectrum of principle strains within that range. Each of those instances -representing a particular principle strain value- was put into the bone tissue model, and the resulting porosity structure was examined. The final model described in this research is a result of this iterative process. It is therefore important to understand that this procedure was not optimized, that the model that was chosen as the final model was a product of this "fine tuning". Each model generated was visually inspected for a bone density structure that most closely represented what theory suggests, low porosity tissue surrounding the bone, with a higher porosity interior. The tuning process was fairly time consuming, although it was fairly straightforward to determine which principle strain within the range produced the most ideal bone density structure.

Another possible limitation of this model is that the elastic modulus used to determine the equilibrium stimulus was 17.4 GPa, which was determined for human compact or cortical bone. This number may not be representative of dog rib tissue, and therefore the principle strain range may be inaccurate, resulting in inaccurate equilibrium stimulus and $\mathrm{Kd}$ variables. A model that more closely represents an actual dog rib would rely on an elastic modulus of canine rib tissue, as opposed to human cortical bone.

The remodeling rates and periods used in this model were determined by comparing the various model predictions to the $\mathrm{CT}$ data using a range of remodeling period values. The rates 
that produced the model that most closely represented the natural tissue were used. This method produced decent results for this study, but it cannot be said whether or not the rates are exactly correct.

\section{Future Studies}

\section{Loading Conditions}

Generally speaking, the model predicted higher proportions of lower density tissue than existed in the actual sample. This was likely due to fact that this study included only one activity as a source for bone strains; respiration, split into three actions (inhalation, exhalation, and rest). The reality is that the ribs likely experience a greater variety of stresses, due to a greater variety of activities beyond respiration, such as walking, running, etc. Additionally, the abdominal muscles were assumed to have minimal interaction with the particular rib this model was based on.

An improvement on this model would include the inclusion of multiple activities and load states, as well as the addition of the abdominal muscles. An increased variability and magnitude of stresses on the bone would certainly decrease the porosities in many areas, and likely produce a model that more closely mimics the structure of the rib tissue.

\section{Material Properties}


The elastic modulus-porosity relationship used in this model was determined from human bone tissue samples. Perhaps another model could be made, utilizing the same tissue the CT data was obtained from, to determine the material properties to utilize in the model. This would closely pair the model's material properties to those of the natural tissue under examination, and improve the accuracy of the model, in terms of how closely it mimics natural conditions.

\section{Remodeling Parameters}

The remodeling parameters used in this study were developed from studies relating to human bone tissue. Certainly, future studies would include parameters which are more relevant to dog bone. One specific example is that the remodeling periods used in this study were scaled down from the human remodeling periods, using an interpolation method, in which the periods were changed, and the resulting model was studied. The final periods picked, were chosen because they produced the model that most closely predicted the natural tissue. Other parameters, such as the initial damage rate coefficient, the initial activation frequency, and the damage removal specificity factor could be optimized for canine bone, in a similar fashion as the one used to pick the remodeling periods. Additional studies could be done to determine these parameters, independent from this model, to more closely represent canine bone tissue. 
The activation frequency calculations may not be accurate for canines, because they were developed from estimates from data found in literature and were developed to model human bone. The relationships between activation frequency and mechanical stimulus and damage were assumed to be sigmoidal [10]. Coefficients representing the slopes and inflection points of the curves were assumed to be of a particular value, but it is possible that these values are not appropriate for modeling canine bones. The value for the maximum activation frequency, which is used to calculate the activation frequency for damage and disuse, was based on data collected from studies on human bone. Updating this value with a more appropriate value, more representative of canine bones, would improve the accuracy of the model.

\section{Addition of Bisphosphonates to Model}

The model and UMAT sub-routine in this study ultimately will be modified to model the effects of bisphosphonate treatments on the structure of the bone tissue. Bisphosphonates work by inhibiting the remodeling process, so the UMAT could be modified to include factors that reduce the remodeling rate. Different doses/levels of bisphosphonate treatments could be compared to estimate the effects of different treatment strategies on bone strength. The results of these studies could be compared to the results from the two studies by Allen, et al., $[25,9]$, to gain more insight on the effects of anti-remodeling agents on the structure and mechanical properties of bone. 


\section{Conclusion}

The ultimate goal of this study was to develop a finite element model of a canine bone rib in order to facilitate a better understanding of the effects of bisphosphonate treatments on the mechanical properties, microdamage, and turnover rate of bone tissue. These studies aim to improve the treatment of osteoporosis; a medical condition which limits the activity and comfort of many individuals.

The natural loading conditions of the rib were estimated from literature, and applied to an FEA model. In conjunction with the model, a UMAT subroutine was modified to simulate the bone tissue remodeling behavior. The simulation predicted a particular bone density structure which was compared to densities estimated from a CT scan of an actual canine rib.

In most regions the outer layer of the rib had lower porosities, and the inner layer had typically higher porosities, which agrees well with what the rib exhibits. The model consistently predicted porosity values that were higher than the actual tissue sample, with percent differences ranging from $-1 \%$ to $-115 \%$. The model predicted the tissue densities exceptionally well, \% Differences $<20 \%$, in 15 of the 28 regions ( 7 cross sections $\times 4$ quadrants each). The 
model did struggle with predicting accurate porosities approximately $10-15 \mathrm{~mm}$ from each end (ventral and dorsal), with $\%$ differences of $-75 \%$ and $-115 \%$, respectively.

\section{Works Cited}

1. Ellenberger, W. H. (1911-1925). Handbuch der Anatomie der Tiere fur Kunstler. Leipzig: Dieterichsche Verlagsbuchhandlung.

2. Miller, Malcolm E., Howard E. Evans, and George C. Christensen. Miller's Anatomy of the Dog.Philadelphia: Saunders, 1979.

3. Ethier, Christopher Ross, and Craig A. Simmons. Introductory Biomechanics from Cells to Organisms. Cambridge: Cambridge UP, 2007.

4. Martin, R. Bruce, David B. Burr, and Neil A. Sharkey. Skeletal Tissue Mechanics. New York: Springer, 2004.

5. Bartel, Donald L., Dwight T. Davy, and Tony M. Keaveny. Orthopaedic Biomechanics: Mechanics and Design in Musculoskeletal Systems. Upper Saddle River, NJ:

Pearson/Prentice Hall, 2006.

6. Chapurlat, R. D., et al. "Microcrack Frequency and Bone Remodeling in Postmenopausal Osteoporotic Women on Long-Term Bisphosphonates: A Bone Biopsy Study." Journal of Bone and Mineral Research 22.10 (2007): 1502-09.

7. Mashiba T., Hirano T., Turner CH., Forwood MR., Johnston CC., Burr DB. "Suppressed bone turnover by bisphosphonates increases microdamage accumulation and reduces some biomechanical properties in dog rib." Journal of Bone and Mineral Research 15 (2000): 613-620.

8. Komatsubara S., Mori S., Mashiba T., Li J., Nonaka K., Kaji Y., Akiyama T., Miyamoto K., Cao Y., Kawanishi J., Norimatsu H. "Suppressed bone turnover by long-term bisphosphonate treatment accumulates microdamage but maintains intrinsic material properties in cortical bone of dog rib." Journal of Bone and Mineral Research 19 (2004): 999-1005. 
9. Allen, M., S. Reinwald, and D. B. Burr, "Alendronate Reduces Bone Toughness of Ribs without Significantly Increasing Microdamage Accumulation in Dogs Following 3 Years of Daily Treatment." Calcified Tissue International (2008)

10. Hazelwood, Scott J., R. Bruce Martin, Mark M. Rashid, and Juan J. Rodrigo. "A Mechanistic Model for Internal Bone Remodeling Exhibits Different Dynamic Responses in Disuse and Overload." Journal of Biomechanics 34 (2001): 299-308.

11. Adams, Donald R. Canine Anatomy, A Systemic Study. lowa City: lowa State UP, 1986.

12. Budras, Klaus-Dieter. Anatomy of the Dog: an Illustrated Text. 4th ed. Hannover: Schlüter, 2002.

13. Gropper, Michael A., and Stephen J. Lai-Fook. "Pleural Liquid Pressure in Dogs Measured Using a Rib Capsule." Cardiovascular Research Institute and Deprtments of Physiology and Medicine, University of California, San Francisco (1985).

14. Evans, Howard E., Alexander DeLahunta, and Malcolm E. Miller. Guide to the Dissection of the Dog. St. Louis: Saunders, 2004.

15. Dyce, K. M., W. O. Sack, and C. J. G. Wensing. Textbook of Veterinary Anatomy. Philadelphia: Saunders, 2002.

16. Troyer, Anrdre De, and Theodore A. Wilson. "Sternum Dependence of Rib Displacement During Breathing." Journal of Applied Physiology 75 (1993): 334-40.

17. Farkas, Gaspar A., and Andre De Troyer. "The Ventral Rib Cage Muscles in the Dog: Contractile Properties and Operating Lengths." Respiration Physiology 68 (1987): 30109.

18. Margulies, S. S., J. R. Rodarte, and E. A. Hoffman. "Geometry and Kinematics of Dog Ribs." Journal of Applied Physiology 67 (1989): 707-12.

19. Liu, Shaobo, Susan S. Margulies, and Theodore A. Wilson. "Deformation of the Dog Lung in the Chest Wall." Journal of Applied Physiology 68 (1990): 1979-987.

20. Kikuchi, Yoshihiro, Dimitrije Stamenovic, and Stephen H. Loring. "Dynamic Behavior of Excised Dog Rib Cage." Journal of Applied Physiology 70 (1991): 1059-067.

21. Farkas, G. A., and D. F. Rochester. "Contractile Characteristics and Operating Lengths of Canine Neck Inspiratory Muscles." Journal of Applied Physiology 61 (1986): 220-26. 
22. Beaupre, G. S., T. E. Orr, and D. R. Carter. "An Approach for Time-Dependent Bone Modeling and Remodeling - Application: A Preliminary Remodeling Simulation." Journal of Orthopaedic Research8 (1990): 662-70.

23. Carter, D. R., D. P. Fyhrie, and R. T. Whalen. "Trabecular Bone Density and Loading History: Regulation of Connective Tissue Biology by Mechanical Energy." Journal of Biomechanics 8 (1987): 785-94.

24. Huiskes, r., Weinans, H, Grootenboer, H. J., Dalstra, M., Fudala, B., and Sloof, T.J. "Adaptive Bone-Remodeling Theory Applied to Prosthetic-Design Analysis." Journal of Biomechanics 20 (1987): 1135-1150.

25. Allen, MR. Follet, H., Khurana, M., Sato, M., Burr, DB. “Antiremodeling Agents Influence Osteoblast Activity Differently in Modeling and Remodeling Sites of Canine Rib." Calcified Tissue International 79 (2006): 255-261 


\section{APPENDIX A - UMAT SUBROUTINE}

subroutine sdvini(statev,coords,nstatv, ncrds, noel,npt,

* layer,kspt)

c

include '/usr/apps/abaqus/6.7-3/site/aba_param_dp.inc'

c

dimension statev(nstatv), coords(ncrds)

C

c initialize porosity

C

statev(1) $=0.04432132964$

C

c initialize minimum principal strain for first,

C

second, and third steps

c

statev $(2)=0.0$

$\operatorname{statev}(3)=0.0$ 


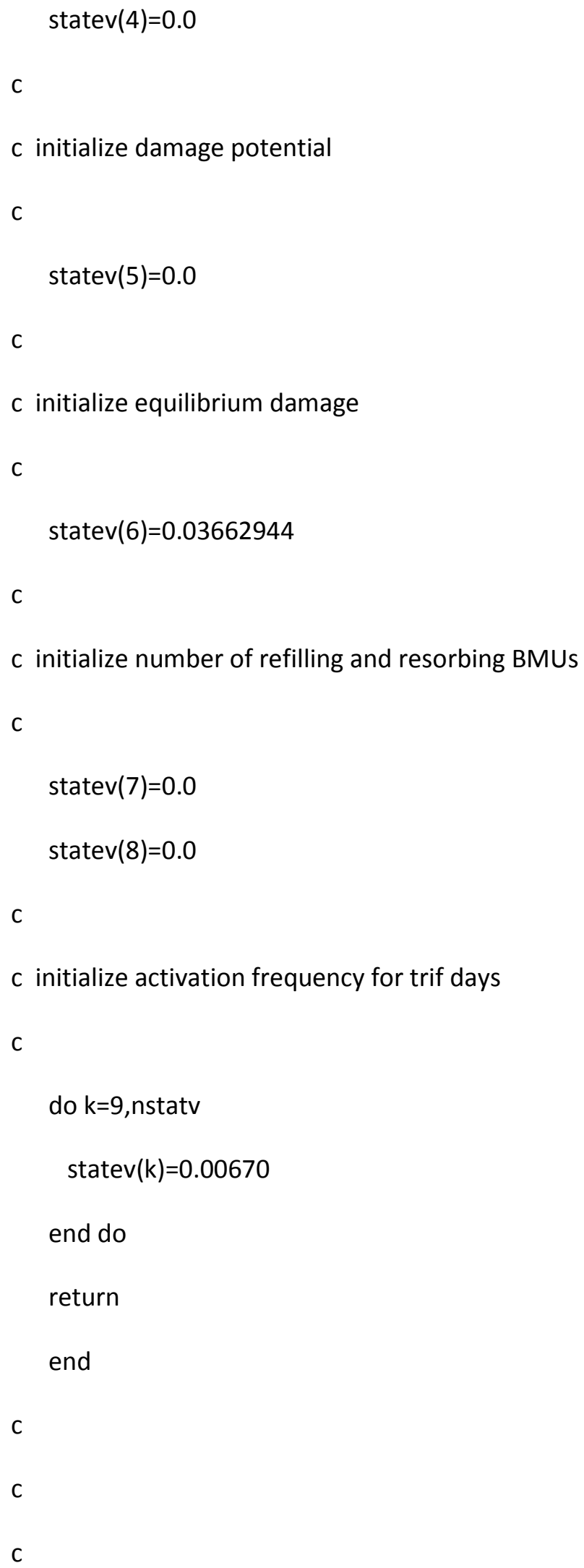


subroutine umat(stress,statev,ddsdde,sse,spd,scd,

* rpl,ddsddt,drplde,drpldt,

* stran,dstran,time,dtime,temp,dtemp,predef,dpred,bone,

* ndi,nshr,ntens,nstatv,props,nprops,coords,drot,pnewdt,

* celent,dfgrd0,dfgrd1,noel,npt,layer,kspt,kstep,kinc)

C

include '/usr/apps/abaqus/6.7-3/site/aba_param_dp.inc'

C

character* 8 bone

dimension stress(ntens), statev(nstatv),ddsdde(ntens, ntens),

* stran(ntens),dstran(ntens),props(nprops),s(3),ps(3)

integer trif,tr,ti,tf,Istr

real kb,kc,kd,kr,nf,nr,nfexist,nrexist,do,sa,modulus,nu,

* tstep,minprin,rl1,rl2,rl3,phi,shearmod,bulkmod,lambda,samax,

* q,pi,fs,dt,facur,famax1,famax2,fao,rc,rh, dexist,area,ddotform,

* ddotrep,dcurrent,fadivsa,fa,ab,ac,qb,qc,phc,qnet,dp,maxprin,

* maxmag

C

c elastic properties

C

if (statev(1).It.0.097267787) then

modulus $=23440 *(1-\operatorname{statev}(1)) * * 5.74$

else 


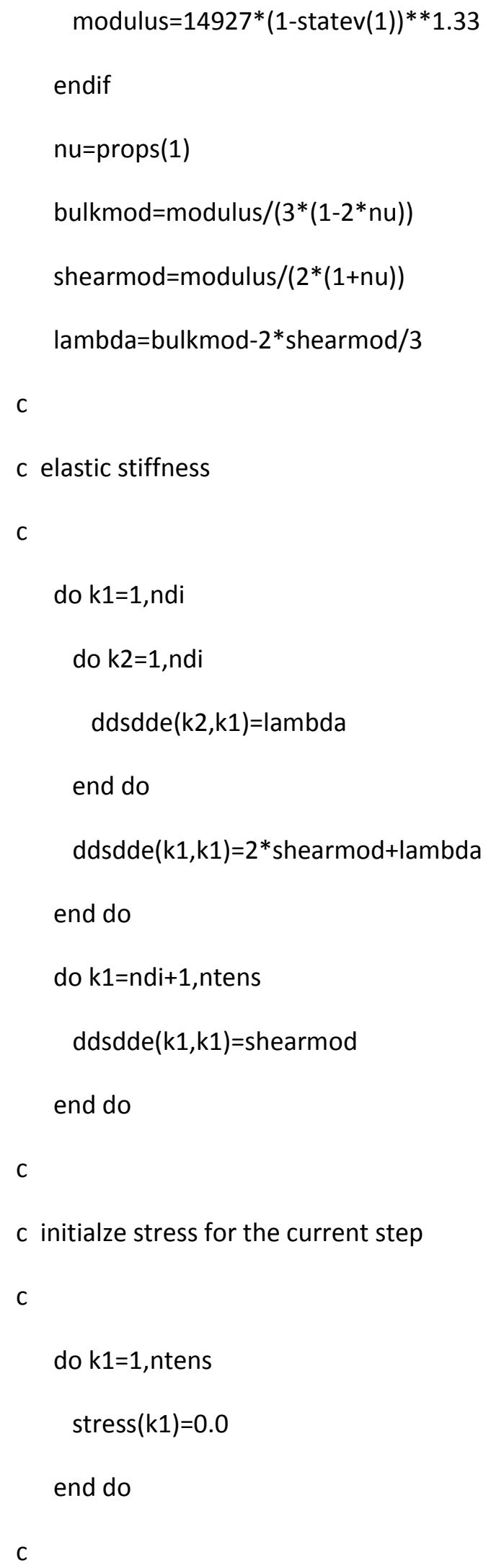


c calculate stress

C

do $\mathrm{k} 1=1$, ntens

do $k 2=1$, ntens

$\operatorname{stress}(k 2)=\operatorname{stress}(k 2)+d d s d d e(k 2, k 1) *(\operatorname{stran}(k 1)+d \operatorname{tran}(k 1))$

end do

end do

c

c proceed through remodeling algorithm for elements defining bone

C

if (noel.It.5500) then

C

c calculate minimum and maximimum principle strains

c transform current steps to tstep to define first, second, and

C

third steps of input file

c store maximum magnitude principle strain as state variable for each step

C

c

do $\mathrm{k} 1=1$, ntens

$s(k 1)=\operatorname{stran}(k 1)+d s t r a n(k 1)$

end do

Istr=2

call sprinc(s,ps,Istr,ndi,nshr)

if $(\operatorname{abs}(p s(1)) \cdot g e \cdot a b s(p s(2)))$ then

$\operatorname{maxmag}=\mathrm{ps}(1)$ 


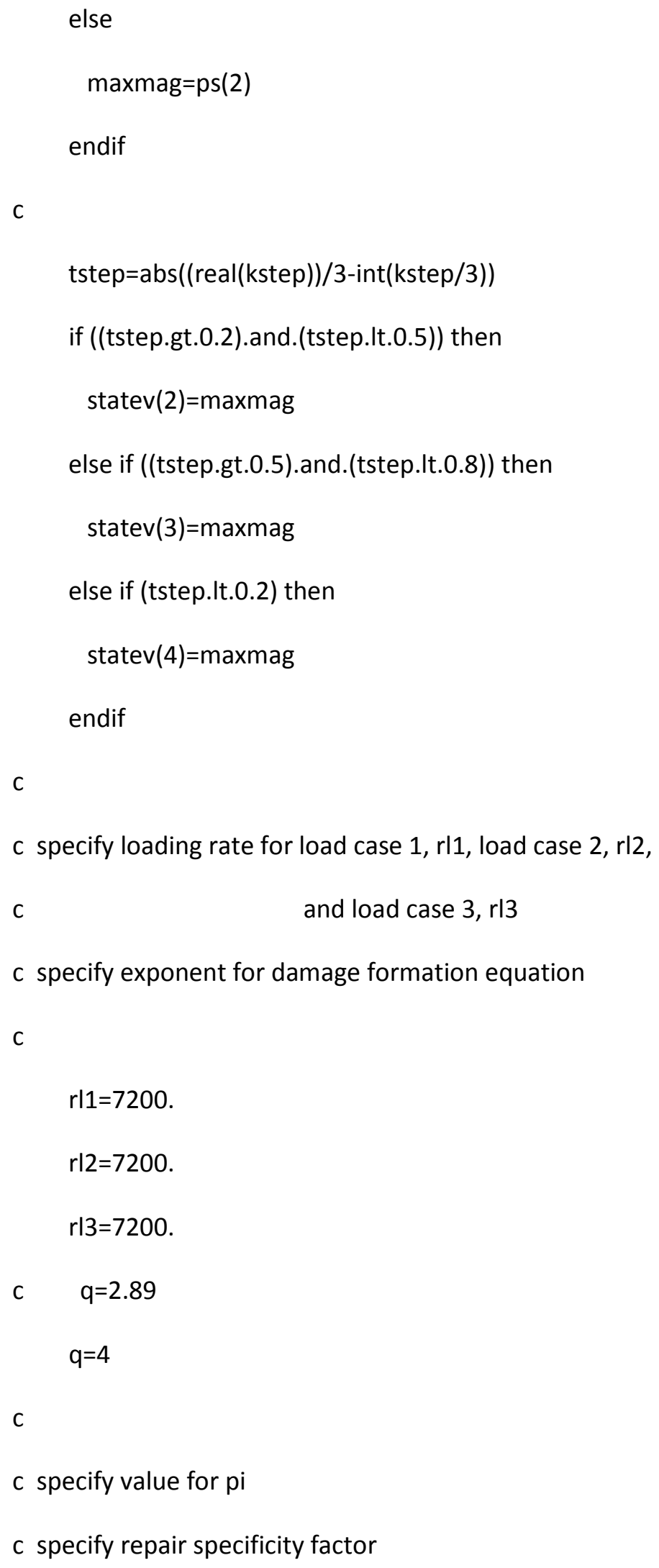


c specify time step

C

$$
\begin{aligned}
& p i=3.1415926535897932385 \\
& f s=5.0 \\
& d t=1.0
\end{aligned}
$$

c

c specify current day activation frequency

c specify max activation frequency/max specific surface area

c specify activation frequency at equilibrium

C

$$
\begin{aligned}
& \text { facur=statev(9) } \\
& \text { famax } 1=0.50 \\
& \text { famax } 2=1.15 \\
& \text { samax }=4.1905 \\
& \text { fao }=0.00670 \\
& r c=0.095 \\
& r h=0.020
\end{aligned}
$$

C

c specifiy equilibrium damage

c initialize existing damage

c specify existing damage

C

$d o=0.03662944$

dexist=statev(6)

C 
c specify coefficients for damage formation equation and

C activation frequency equations

$k d=3033440108$.

$k r=-1.6$

$k b=65000000000$.

$k c=0.0000000000938$

c

c calculate time for resorptive phase of remodeling cycle, $\mathrm{tr}$

c calculate time for reversal phase of remodeling cycle, ti

c calculate time for refilling phase of remodeling cycle, tf

c calculate total time of remodeling cycle, trif

C

$\operatorname{tr}=10$

$\mathrm{ti}=5$

$\mathrm{tf}=44$

trif $=\mathrm{tr}+\mathrm{ti}+\mathrm{tf}$

c

c initialize the existing number of refilling and resorbing BMUs

c specify existing number of refilling and resorbing BMUs

C

if (kstep.eq.1) then

$\operatorname{statev}(7)=f a{ }^{*}$ tf

statev $(8)=f a o * \operatorname{tr}$

endif

nfexist=statev $(7)$ 
nrexist $=\operatorname{statev}(8)$

C

c proceed through porosity update after the third step

c

if ((kstep.ne.1).and.(tstep.It.0.2)) then

C

c calculate damage potential

c store damage potential as state variable

c calculate rate of damage formation

c calculate rate of damage repair

c calculate current day damage

c store current day damage as state variable

C

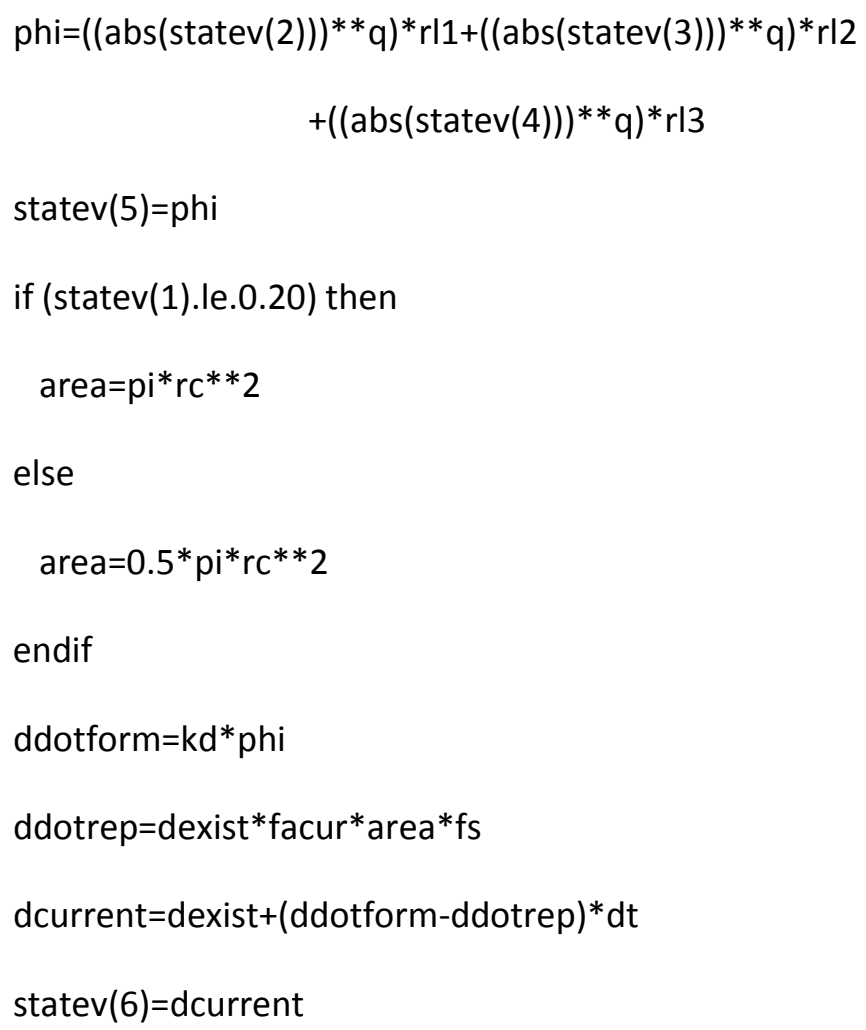


c update current activation frequency

c calculate specific surface area

C

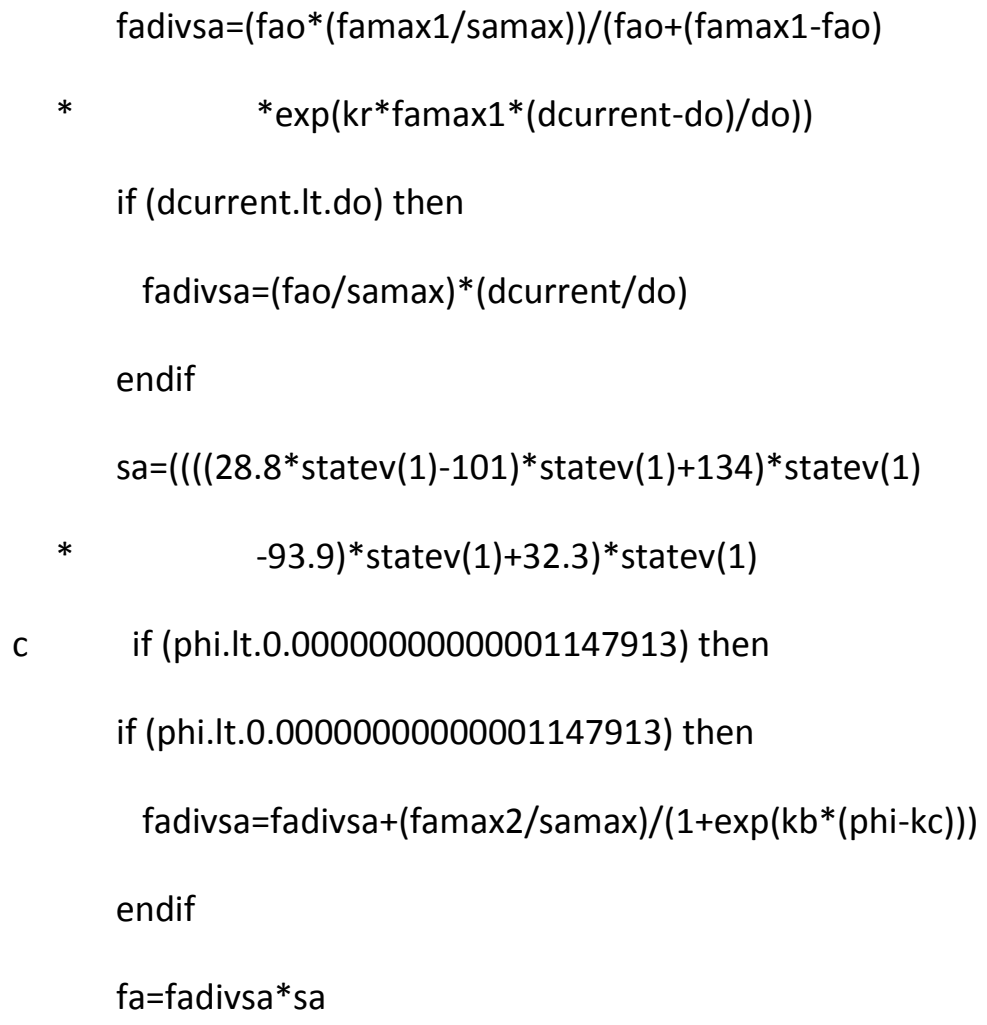




$$
\operatorname{statev}(9)=f a
$$

c

c calculate daily amount of bone added per refilling BMU

c calculate daily amount of bone removed per resorbing BMU

c include less refilling on trabecular surfaces in disuse

c

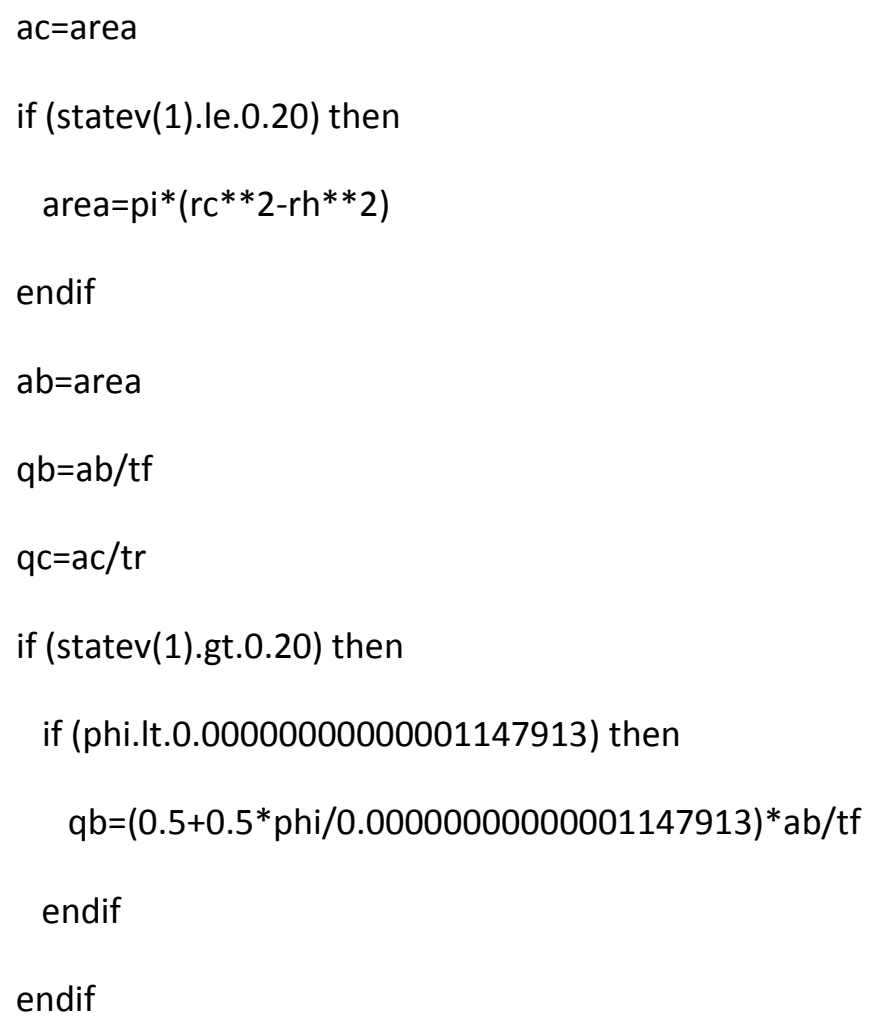




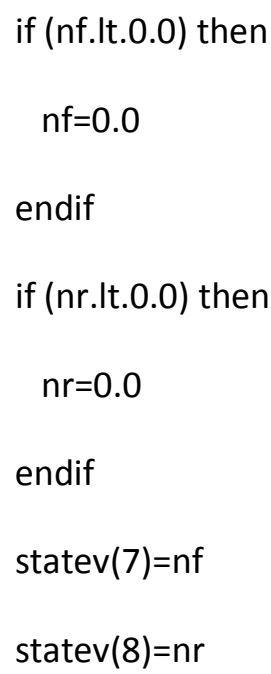

c

c calculate net amount of bone added per day

C

phc $=0.04432132964$

qnet=(qb*nf)-(qc*nr)

if (statev(1).le.0.20) then

qnet $=\left(q b^{*} n f\right)-(1-p h c) *\left(q c^{*} n r\right)$

endif

c

c calculate change in porosity

c update porosity

c

$$
d p=-q n e t * d t
$$$$
\operatorname{statev}(1)=\operatorname{statev}(1)+d p
$$

c

endif

endif 
return

end 